\title{
Ambulatory feedback at daily physical activity patterns
}

\begin{abstract}
A treatment for the chronic fatigue syndrome in the home environment?
\end{abstract}

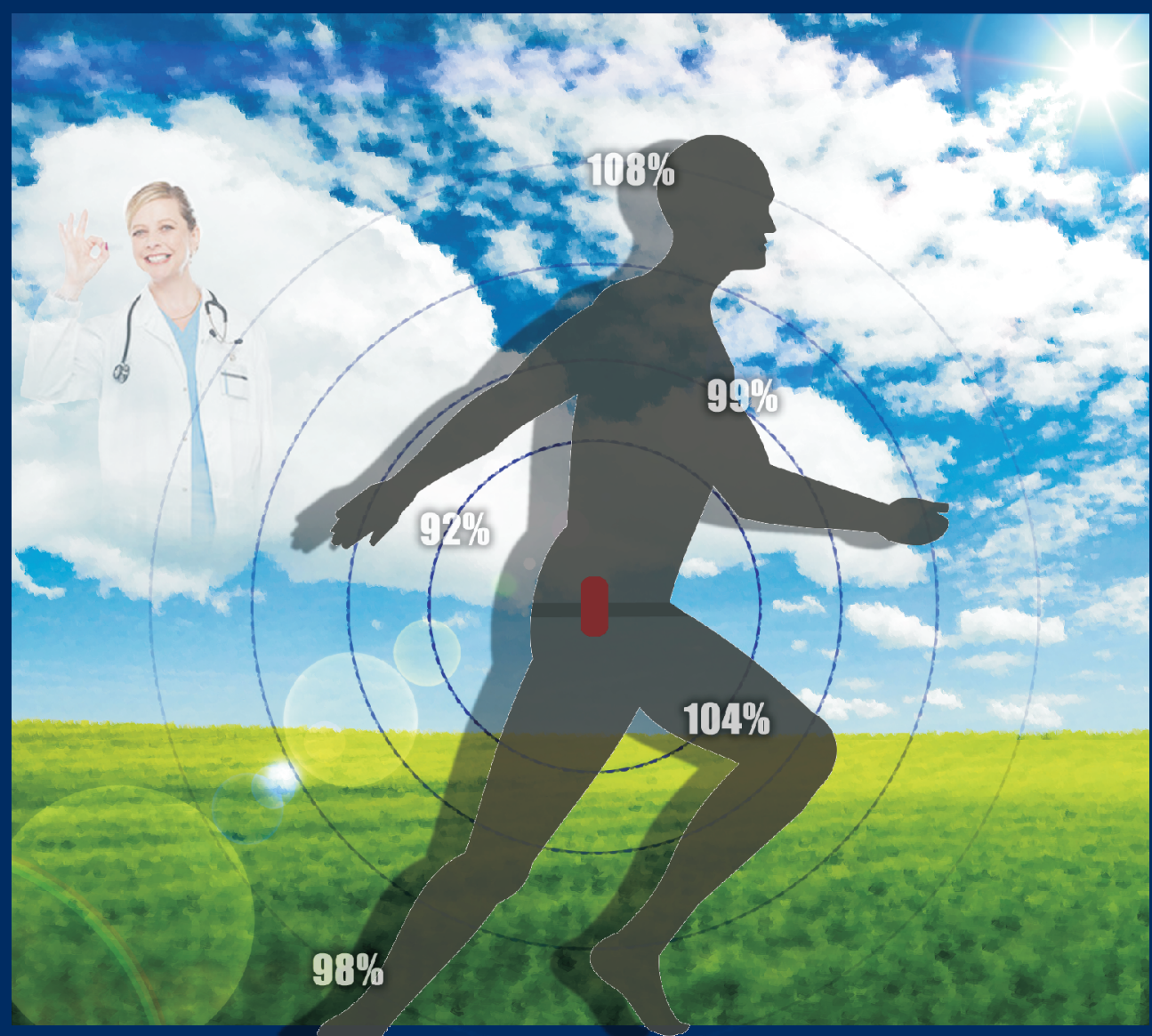

Richard Evering 


\section{AMBULATORY FEEDBACK AT DAILY PHYSICAL}

\section{ACTIVITY PATTERNS}

A TREATMENT FOR THE CHRONIC FATIGUE SYNDROME

IN THE HOME ENVIRONMENT?

Richard M.H. Evering 


\section{Address of correspondence}

Richard Evering

Roessingh Research and Development

PO Box 310

$7500 \mathrm{AH}$ Enschede

The Netherlands

r.evering@rrd.nl

\section{Colophon}

ISBN: $\quad 978-90-365-3512-0$

DOI number: $\quad 10.3990 / 1.9789036535120$

Printing: $\quad$ Gildeprint Drukkerijen Enschede, the Netherlands

Cover design: Jos Spoelstra, Roessingh Research and Development, Enschede

The publication of this thesis was generously sponsored by:

Roessingh Research and Development, Enschede

Roessingh Centrum voor Revalidatie, Enschede

Chair Biomedical Signals and Systems of the University of Twente, Enschede Kenniscentrum Gezondheid Welzijn en Technologie van Saxion, Enschede Academie Gezondheidszorg van Saxion, Enschede

Copyright (C) Richard Evering, Enschede, the Netherlands, 2013 All rights reserved. No part of this book may be reproduced, stored in a retrieval system, or transmitted, in any form or by any means, electronic, mechanical, photocopying, recording or otherwise, without the written permission of the holder of the copyright. 


\section{AMBULATORY FEEDBACK AT DAILY PHYSICAL}

\section{ACTIVITY PATTERNS}

\section{A TREATMENT FOR THE CHRONIC FATIGUE SYNDROME \\ IN THE HOME ENVIRONMENT?}

\section{PROEFSCHRIFT}

ter verkrijging van,

de graad van doctor aan de Universiteit Twente,

op gezag van de rector magnificus,

prof. dr. H. Brinksma,

volgens besluit van het College voor Promoties

in het openbaar te verdedigen

op vrijdag 12 april 2013 om 12.45 uur

door

Richard Maria Hermanus Evering

geboren op 2 september 1983

te Losser 
Dit proefschrift is goedgekeurd door:

Prof. dr. M.M.R. Vollenbroek-Hutten (promotor) 
De promotiecommissie is als volgt samengesteld:

Voorzitter/secretaris (chairman/secretary):

Prof. dr. ir. A.J. Mouthaan

Universiteit Twente

\section{Promotor:}

Prof. dr. M.M.R. Vollenbroek - Hutten Universiteit Twente

Overige commissieleden en referenten (committee members and referees):

Prof. dr. ir. H.J. Hermens

Prof. dr. J.A.M. van der Palen

Prof. dr. G. Bleijenberg

Dr. J.B.J. Bussmann

Prof. dr. L.P. de Witte

Dr. M.G.H. Dekker - van Weering
Universiteit Twente

Universiteit Twente

Emiraat / Radboud Universiteit Nijmegen

Erasmus MC

Universiteit Maastricht

Universiteit Twente

Paranimfen:

Thijs M. Tönis

Birgit I. Molier 



\section{Table of contents}

$\begin{array}{lll}\text { Chapter } 1 \quad \text { General introduction } & 9\end{array}$

Chapter 2 Daily physical activity of patients with the chronic fatigue syndrome: A 21 systematic review

Chapter 3 Deviations in daily physical activity patterns in patients with the 69 chronic fatigue syndrome: A case control study

Chapter $4 \quad$ Ambulatory feedback at daily physical activities in treatment of the 95 chronic fatigue syndrome

Chapter 5 Ambulatory feedback at daily physical activities in treatment of chronic fatigue syndrome: A randomized controlled trial

Chapter 6 Is there a difference in response to ambulatory activity feedback when different goal settings are used? A randomized controlled trial

Chapter $7 \quad$ General discussion

Chapter $8 \quad$ Summary

Chapter $9 \quad$ Samenvatting

Chapter 10 Dankwoord

Chapter 11 Over de Auteur 



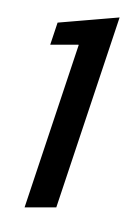

General introduction 


\section{The chronic fatigue syndrome}

Patients with chronic fatigue syndrome (CFS) are characterized with persistent fatigue which disturbs activities of daily life. Fatigue is in most people an accepted state of health, temporarily and often the consequence of a reasonable cause. However, some people are fatigued for a prolonged period of time without an explicit cause and which interferes activities of daily life. One can be diagnosed as having CFS if the fatigue is lasting for at least six months. CFS is a symptom-based or clinical diagnosis that is made without findings of distinguished physical examination or laboratory tests (1). The Centre for Disease Control and prevention (CDC) 1994 definition of CFS is, out of several other definitions, still considered the international accepted standard definition which is used in scientific CFS research (2-5). The CDC defines CFS as a severe, disabling chronic fatigue lasting for at least six months, and patients must report four out of eight symptoms i.e. unrefreshing sleep, post-exertional malaise, headache, muscle pain, multi-joint pain, sore throat, tender lymph nodes, and concentration and memory impairment (2). The prevalence of CFS in the Netherlands is estimated to be between 30,000 to 40,000 patients (6). The prognosis of CFS without treatment is not favourable, a review showed that only $5 \%$ of the patients recover spontaneously (7).

\section{Role of physical activity in CFS}

The aetiology of CFS is unknown, however the recognition of predisposing, precipitating and perpetuating factors has given more insight into CFS (8). The recognition of predisposing and precipitating factors can help patients to find an explanation for the development of CFS. The perpetuating factors do give an explanation for the persistence of chronic fatigue after the initial trigger has disappeared, and give reasons how to treat CFS $(9,10)$. Vercoulen et al. (1998) have described in a model the role of perpetuating factors in the persistence of CFS (11). In this model the perpetuating factors are subdivided in cognitive factors (low level of sense of control, somatic attributions and somatic focus) and behavioural factors (low level of physical activity and physical impairment) (11). Physical inactivity is a key risk factor in the development and perpetuation of chronic diseases like CFS 
(12). CFS patients show low levels of physical activity and Wessely et al. (1989) have outlined a model which gives an explanation for these low levels in CFS (13). In this model, CFS starts with an acute illness accompanied by a period of inactivity, which is a necessary and an adaptive behaviour in acute illness situations (13). However, this is followed by experiencing fatigue after exertion resulting in further avoidance of activity. At the same time there is a loss of tolerance to everyday activity owing to a decreased fitness level. In the end, symptoms develop at increasingly lower levels of exercise and activities previously undertaken become more difficult. As such, the model reflects a negative vicious circle explaining the avoidance of physical activities (13). However, some patients do not accept their illness state and attempt to perform at pre-morbid levels resulting in bursts of activities (14). These bursts of activity do often not improve, but exacerbate, the fatigue and other symptoms and are followed by a return to inactivity (14).

\section{Treatment of CFS}

The most promising treatment results are found for cognitive behavioural therapy (CBT) and graded exercise therapy (GET) $(13,15-18)$. CBT for CFS is based on the model of perpetuating factors $(10,11)$. CBT is directed at decreasing somatic attributions and the patient's focus on bodily symptoms, increasing the patient's sense of control over his or her symptoms, and restoring balance in activity patterns (9). GET involves a structured activity management program that aims for a gradual increase in the exercise pattern of the patient (18). The results found for CBT and GET in the treatment of CFS are promising $(13,15,16,18)$. However, despite the promising results, still a significant number of CFS patients do not encounter a reduction of CFS complaints after CBT and GET (19-22). Treatment programs based on the principles of CBT and GET include prescriptions about improving daily physical activity patterns $(9,22)$.

\section{Ambulant feedback at physical activities in daily life}

Treatment prescriptions from healthcare professionals about physical activity are usually based on measurements of physical activity levels in CFS patients at baseline and comparisons of these levels with that of healthy controls (23). The 
healthcare professional can motivate patients to follow the prescriptions at home by making them aware about the importance of a balanced daily physical activity pattern. However, when CFS patients are at home they have to follow these prescriptions by themselves without getting any additional insight and feedback about the progress in their daily physical activity behaviour. The progress at home is evaluated in recurrent consultations in which the healthcare professional provides advices how to move on based on subjective interpretations. It is unknown if CFS patients adhere to the treatment prescriptions and improve their daily physical activity pattern when they are at home because of:

1. The inability or negligently to have accurate insight in the daily physical activity pattern of CFS patients

2. The inability of providing a goal pattern to which the individual CFS patient should strive for in daily life

3. The inability of providing ambulant feedback at physical activity levels instantaneously during the day

It could be of great additional value to objectify the progress of the CFS patient in the physical activity program by measuring physical activities at home. In the past, an ambulant feedback system is developed for chronic patients which enables the possibility to provide ambulant feedback at daily physical activity levels in the home environment of the patient (24). The feedback is provided instantaneously by comparing the physical activity level of the chronic patient with that of a predefined goal (24). The feedback system consists of an accelerometer and a personal digital assistant (PDA). The accelerometer is worn at the waist and measures accelerations in tri-axial dimensions i.e. anteroposterior, mediolateral and longitudinal $(25,26)$. The PDA visualises the daily physical activity pattern of the patient and the predefined goal by presenting these in a figure on the screen of the PDA. Moreover, the feedback system can provide automatically generated text messages to the patient at fixed time moments containing feedback and advices based on the actual activity measurements of the patient in relation to the predefined goal. The feedback system has been tested in patients with chronic low back pain (CLBP) and has shown to have potential benefits in the treatment of patients with CLBP (24). 
It is expected that such an ambulant monitoring and feedback provided automatically with a feedback system will also give the CFS patient and healthcare professional more insight in the daily physical activity pattern of the CFS patient at home. Moreover, the use of the feedback system enables the possibility to tailor feedback and advices to individual needs and is in line with the current trend of enhancing self-management. It is expected that more individual tailoring of treatment programs to the individual needs may enhance treatment outcome (2729). Several studies have already shown the potential value of telecommunication technology in improving physical activity levels in chronic patients (30-35). It is hypothesised that the use of the feedback system for providing ambulant feedback can be of supplemental value in the treatment of CFS.

\section{Goal and outline thesis}

The goal of this thesis is to study whether ambulant monitoring of and providing direct feedback on daily physical activity patterns during day life activities can improve the balance in the daily physical activity pattern and result in improved treatment outcome in patients with CFS.

Chapter 2 starts with exploring the problem in CFS patients of having low daily physical activity levels. Several studies have investigated the physical activity level in chronic patients, however till now no systematic overview is performed in patients with CFS as compared to healthy controls. Therefore, a systematic review of the existing literature is performed about the daily physical activity level in CFS patients as compared to healthy controls. Differences in outcome between subjective and objective outcome measurements are studied. Also the methodological quality and use of valid and reliable measurement devices are evaluated.

In chapter 3 more insight is obtained in the daily physical activity pattern of CFS patients as compared to healthy controls. Other studies have found low levels of daily physical activity and deviations in specified aspects of daily physical activity in patients with CFS $(23,36)$. However, till now no insight has been given in the 
distribution of daily physical activity in patients with CFS. Moreover, it is unknown if patients with CFS are aware about their performance of daily physical activity. Our research group have already found increased physical activity levels in the morning and decreased levels in the evening in patients with CLBP as compared to healthy controls (37). Patients with CLBP have found also to be unaware in the performance of daily physical activity (38). Therefore, in chapter 3 more insight is obtained in the distribution of daily physical activity and in the awareness of performing daily physical activity in patients with CFS.

A state of the art feedback system has been introduced in chapter 4, 5 and 6 for providing ambulant feedback at daily physical activities to patients with CFS. The feedback system creates the possibility to support CFS patients at home in restructuring their daily physical activity pattern in an adequate way. The feedback system measures objectively physical activities performed in the home situation, and actual values of physical activity levels are presented to the patient continuously. The feedback system also supports the patient to keep up a balanced daily physical activity pattern by providing feedback. The feedback consists of a figure and text messages displayed at the screen of the PDA. The figure presents the current daily physical activity pattern of the CFS patient and the pattern of a predefined goal. The text messages are based on the difference between the individual pattern of the CFS patient and the predefined goal. A feedback program has been supplemented to a current multi-component rehabilitation program in “Het Roessingh' (Enschede, the Netherlands) based on the principles of CBT and GET.

In chapter 4 the compliance with the feedback system and changes made in the daily physical activity pattern towards the predefined goal based on healthy controls is studied in patients with CFS. In chapter 5 the additional value of the ambulant feedback as supplement to the current rehabilitation program is studied. A randomized controlled trial has been performed in which the intervention group has received the standard rehabilitation program plus the ambulant feedback intervention and the control group has received only the standard rehabilitation program. The additional value of the feedback program in the rehabilitation of CFS 
is evaluated with fatigue severity and physical functioning and other secondary outcome parameters of the rehabilitation treatment.

The predefined goal in the feedback program as used in chapter 4 and 5 is based on the pattern of healthy controls. The working mechanism of such a goal corresponds with the mechanisms outlined in the 'Social Comparison Theory' (39) meaning that the goal has been based on the mean daily physical activity pattern of a healthy control group. The ambulant feedback program will possibly support individual CFS patients more adequately if the goal is adapted to the individual activity pattern at baseline. A goal adapted to individual abilities corresponds with the working mechanisms outlined in the 'Temporal Comparison Theory' (40). In chapter 6 is explored if the ambulant feedback program will support individual CFS patients more adequately if the goal is adapted to the individual activity pattern at baseline. Fort this, a second randomized controlled trial is performed in which CFS patients received the feedback program for two weeks consecutively. One group has received feedback with a goal based on the pattern of healthy controls, and one group has received feedback with a goal adapted to the individual physical activity pattern at baseline. The two groups are compared by evaluating the effectiveness of the feedback in changing daily physical activity patterns, and by evaluating compliance and satisfaction with the feedback system.

In chapter 7 , the main findings of the previous five chapters are integrated and evaluated in the context of existing literature and the aim of this thesis. 


\section{References}

1. Afari N, Buchwald D. Chronic fatigue syndrome: a review. Am J Psychiatry. 2003 Feb;160(2):221-36.

2. Fukuda K, Straus SE, Hickie I, Sharpe MC, Dobbins JG, Komaroff A. The chronic fatigue syndrome: a comprehensive approach to its definition and study. International Chronic Fatigue Syndrome Study Group. Ann Intern Med. 1994 Dec 15;121(12):953-9.

3. Holmes GP, Kaplan JE, Gantz NM, Komaroff AL, Schonberger LB, Straus SE, et al. Chronic fatigue syndrome: a working case definition. Ann Intern Med. 1988 Mar;108(3):387-9.

4. Lloyd AR, Hickie I, Boughton CR, Spencer O, Wakefield D. Prevalence of chronic fatigue syndrome in an Australian population. Med J Aust. 1990 Nov 5;153(9):522-8.

5. Sharpe MC, Archard LC, Banatvala JE, Borysiewicz LK, Clare AW, David A, et al. A report--chronic fatigue syndrome: guidelines for research. J R Soc Med. 1991 Feb;84(2): $118-21$.

6. Gezondheidsraad. Het chronische-vermoeidheidssyndroom. Den Haag: Gezondheidsraad, 2005;publicatie nr. 2005/02.

7. Cairns R, Hotopf M. A systematic review describing the prognosis of chronic fatigue syndrome. Occup Med (Lond). 2005 Jan;55(1):20-31.

8. Prins JB, van der Meer JW, Bleijenberg G. Chronic fatigue syndrome. Lancet. 2006 Jan 28;367(9507):346-55.

9. Bazelmans E, Prins J, Bleijenberg G. Cognitive Behavior Therapy for Relatively Active and for Passive Chronic Fatigue Syndrome Patients. Cognitive and Behavioral Practice. 2006;13(2):157-66.

10. Vercoulen JH, Swanink CM, Fennis JF, Galama JM, van der Meer JW, Bleijenberg G. Prognosis in chronic fatigue syndrome: a prospective study on the natural course. J Neurol Neurosurg Psychiatry. 1996 May;60(5):489-94.

11. Vercoulen JH, Swanink CM, Galama JM, Fennis JF, Jongen PJ, Hommes OR, et al. The persistence of fatigue in chronic fatigue syndrome and multiple sclerosis: development of a model. J Psychosom Res. 1998 Dec;45(6):507-17. 
12. Armstrong T, Bauman A, Bull F, Candeias V, Lewicka M, Magnussen C, et al. A guide for population-based approaches to increasing levels of physical activity. Implementation of the WHO global strategy on diet, physical activity and health. 2007.

13. Wessely S, David A, Butler S, Chalder T. Management of chronic (post-viral) fatigue syndrome. J R Coll Gen Pract. 1989;39(318):26-9.

14. Surawy C, Hackmann A, Hawton K, Sharpe M. Chronic fatigue syndrome: a cognitive approach. Behav Res Ther. 1995 Jun;33(5):535-44.

15. Reid SF, Chalder T, Cleare A, Hotopf M, Wessely S. Chronic fatigue syndrome. Clin Evid (Online). 2008;2008.

16. Price JR, Mitchell E, Tidy E, Hunot V. Cognitive behaviour therapy for chronic fatigue syndrome in adults. Cochrane Database Syst Rev. 2008(3):CD001027.

17. Malouff JM, Thorsteinsson EB, Rooke SE, Bhullar N, Schutte NS. Efficacy of cognitive behavioral therapy for chronic fatigue syndrome: a meta-analysis. Clin Psychol Rev. 2008 Jun;28(5):736-45.

18. Rimes KA, Chalder T. Treatments for chronic fatigue syndrome. Occup Med (Lond). 2005 Jan;55(1):32-9.

19. Bazelmans E, Prins JB, Lulofs R, van der Meer JW, Bleijenberg G. Cognitive behaviour group therapy for chronic fatigue syndrome: a non-randomised waiting list controlled study. Psychother Psychosom. 2005;74(4):218-24.

20. Prins JB, Bleijenberg G, Bazelmans E, Elving LD, de Boo TM, Severens JL, et al. Cognitive behaviour therapy for chronic fatigue syndrome: a multicentre randomised controlled trial. Lancet. 2001 Mar 17;357(9259):841-7.

21. Stulemeijer M, de Jong LW, Fiselier TJ, Hoogveld SW, Bleijenberg G. Cognitive behaviour therapy for adolescents with chronic fatigue syndrome: randomised controlled trial. BMJ. 2005 Jan 1;330(7481):14.

22. Torenbeek M, Mes CA, van Liere MJ, Schreurs KM, ter Meer R, Kortleven GC, et al. [Favourable results of a rehabilitation programme with cognitive behavioural therapy and graded physical activity in patients with the chronic-fatigue syndrome]. Ned Tijdschr Geneeskd. 2006 Sep 23;150(38):2088-94. 
23. Van der Werf SP, Prins JB, Vercoulen JH, van der Meer JW, Bleijenberg G. Identifying physical activity patterns in chronic fatigue syndrome using actigraphic assessment. J Psychosom Res. 2000 Nov;49(5):373-9.

24. Van Weering M, Vollenbroek-Hutten MM, Hermens HJ. Chapter 6: Potential value of an activity-based feedback system for treatment of patients with chronic low back pain. In: Van Weering M, editor. Towards a new treatment for chronic low back pain patients, using activity monitoring and personalized feedback. Enschede, The Netherlands: Gildeprint Drukkerijen; 2011 . p. 115-42.

25. Bouten CV, Westerterp KR, Verduin M, Janssen JD. Assessment of EnergyExpenditure for Physical-Activity Using a Triaxial Accelerometer. Medicine and Science in Sports and Exercise. 1994 Dec 1994;26(12):1516-23.

26. Bouten CVC, Verboeket-van de Venne WPHG, Westerterp KR, Verduin M, Janssen JD. Daily Physical Activity Assessment: Comparison Between Movement Registration and Doubly Labeled Water. Journal of Applied Physiology. 1996 Aug 1996;81(2):1019-26.

27. Van Houdenhove $B$, Luyten P. Customizing treatment of chronic fatigue syndrome and fibromyalgia: the role of perpetuating factors. Psychosomatics. 2008 Nov-Dec;49(6):470-7.

28. Jason L, Benton M, Torres-Harding S, Muldowney K. The impact of energy modulation on physical functioning and fatigue severity among patients with ME/CFS. Patient Educ Couns. 2009 Nov;77(2):237-41.

29. Larun L, Malterud K. Finding the right balance of physical activity: a focus group study about experiences among patients with chronic fatigue syndrome. Patient Educ Couns. 2011 May;83(2):222-6.

30. Weinstock RS, Brooks G, Palmas W, Morin PC, Teresi JA, Eimicke JP, et al. Lessened decline in physical activity and impairment of older adults with diabetes with telemedicine and pedometer use: results from the IDEATel study. Age Ageing. $2011 \mathrm{Jan}$;0(1):98-105.

31. Christian JG, Bessesen DH, Byers TE, Christian KK, Goldstein MG, Bock BC. Clinic-based support to help overweight patients with type 2 diabetes increase physical activity and lose weight. Arch Intern Med. 2008 Jan 28;168(2):141-6. 
32. King DK, Estabrooks PA, Strycker LA, Toobert DJ, Bull SS, Glasgow RE. Outcomes of a multifaceted physical activity regimen as part of a diabetes selfmanagement intervention. Ann Behav Med. 2006 Apr;31(2):128-37.

33. Rosser BA, Vowles KE, Keogh E, Eccleston C, Mountain GA. Technologicallyassisted behaviour change: a systematic review of studies of novel technologies for the management of chronic illness. J Telemed Telecare. 2009;15(7):327-38.

34. Hermens HJ, Vollenbroek-Hutten MM. Towards remote monitoring and remotely supervised training. J Electromyogr Kinesiol. 2008 Dec;18(6):908-19.

35. Kairy D, Lehoux P, Vincent C, Visintin M. A systematic review of clinical outcomes, clinical process, healthcare utilization and costs associated with telerehabilitation. Disabil Rehabil. 2009;31(6):427-47.

36. Kop WJ, Lyden A, Berlin AA, Ambrose K, Olsen C, Gracely RH, et al. Ambulatory monitoring of physical activity and symptoms in fibromyalgia and chronic fatigue syndrome. Arthritis Rheum. 2005;52(1):296-303.

37. van Weering MG, Vollenbroek-Hutten MM, Tonis TM, Hermens HJ. Daily physical activities in chronic lower back pain patients assessed with accelerometry. Eur J Pain. 20092009 Jul;13(6):649-54.

38. van Weering MG, Vollenbroek-Hutten MM, Hermens HJ. The relationship between objectively and subjectively measured activity levels in people with chronic low back pain. Clin Rehabil. 2011 Mar;25(3):256-63.

39. Festinger L. a theory of social comparison processes. Human relations : studies towards the integration of the social sciences. 1954;2.

40. Albert S. Temporal Comparison Theory. Psychological Review. 1977;84(6):485503. 
20 Chapter 1 


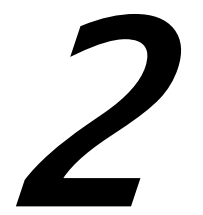

Daily physical activity of patients with the chronic fatigue syndrome: A systematic review

Evering RMH, van Weering MGH, Groothuis-Oudshoorn KCGM, Vollenbroek-Hutten MMR. Daily physical activity of patients with the chronic fatigue syndrome: a systematic review. Clin Rehabil. 2011 Feb; 25 (2): 112-33. 


\begin{abstract}
Objective: To give an overview of the physical activity level of patients with chronic fatigue syndrome in comparison with asymptomatic controls.

Data sources: MEDLINE, Web of Science, EMBASE, PsycINFO, Picarta, the Cochrane Controlled Trial Register that is included in the Cochrane Library and reference tracking.
\end{abstract}

Review methods: A systematic literature search was conducted focusing on studies concerning physical activity levels of chronic fatigue syndrome patients compared to controls. A meta-analysis was performed to pool data of the studies.

Results: Seventeen studies were included with 22 different comparisons between chronic fatigue syndrome patients and controls. Fourteen studies, including 18 comparisons, showed lower physical activity levels in chronic fatigue syndrome patients as compared to controls. Four studies, including four comparisons, showed no differences between both groups. The meta-analysis included seven studies and showed a daily physical activity level in chronic fatigue syndrome patients of only $68 \%$ of the physical activity level observed in control subjects. The pooled mean coefficient of variation in chronic fatigue syndrome patients was higher as compared to control subjects ( $34.3 \%$ vs. $31.5 \%$ ), but this difference did not reach significance.

Conclusion: Chronic fatigue syndrome patients appear to be less physically active compared to asymptomatic controls. There is no difference in variation of physical activity levels between chronic fatigue syndrome patients and healthy control subjects, however the validity and reliability of some methods of measuring physical activity is questionable or unknown. 


\section{Introduction}

Chronic fatigue syndrome is characterized by severe, disabling chronic fatigue lasting for at least six months. Other symptoms can include musculoskeletal pain, sleep disturbance, impaired concentration, and headaches. ${ }^{1}$ Chronic fatigue syndrome is a symptom-based or clinical diagnosis that is made without findings of distinguished physical examination or laboratory tests. ${ }^{2}$ This makes it difficult for clinicians to diagnose chronic fatigue syndrome. The 'Centre for Disease Control and prevention (CDC) 1994 definition of chronic fatigue syndrome ${ }^{3}$, is still considered the international accepted standard definition which is used in scientific chronic fatigue syndrome research.3-6 However, many interpret these mentioned criteria as vague and over inclusive and like to use other definitions for clinical use. ${ }^{7}$ Consequently, the prevalence estimates of chronic fatigue syndrome vary considerably depending on definition, population and study method used.8 For example, the prevalence numbers found in different studies varied between $0.23 \%$ and $0.42 \%$ in US populations and up to $0.6 \%$ and $2.6 \%$ in Korean and British primary care populations, respectively. ${ }^{9-12}$ The highest levels of chronic fatigue syndrome have consistently been found among women. 1012

Physical activity is widely believed to have important health benefits, and physical inactivity is a key risk factor for chronic diseases. ${ }^{13}$ Initial acute illnesses are often accompanied by avoidance of most forms of activity, which is a necessary and an adaptive behaviour in acute illness situations. However, when the acute illness continues to develop into a chronic disease, further avoidance of physical activity becomes deleterious for the individual's health and are considered maladaptive for chronic pain. 14-16 Wessely et al.16 also hypothesised such a 'cognitive-behavioural model' as seen in chronic pain for chronic fatigue syndrome reflecting avoidance of physical activities. In his model, chronic fatigue syndrome starts with an acute illness accompanied by a period of inactivity. 16 This is followed by experiencing fatigue after exertion resulting in further avoidance of activity. At the same time there is a loss of tolerance to everyday activity owing to a decreased fitness level. In the end, symptoms develop at increasingly lower levels of exercise and activities previously undertaken become more difficult. As such, the model reflects a negative 
vicious circle. Consistent with this model, Surawy et al. ${ }^{15}$ also formulated a model of the aetiology of chronic fatigue syndrome that underlines the development of avoidance behaviour in the perpetuation of chronic fatigue syndrome. However, the model of Surawy et al. 15 is expanded with predisposing and precipitating factors, which should play a role in the development of chronic fatigue syndrome.

Several treatment procedures for chronic fatigue syndrome patients exist to break through the vicious circle of avoidance behaviour in physical activity. The most promising treatment results have been found with cognitive behavioural therapy and graded exercise therapy. 117 Cognitive behavioural therapy involves planned activity and rest, graded exercise, a sleep routine and a cognitive restructuring of unhelpful beliefs and assumptions. 17 Graded exercise therapy involves a structured activity management program that aims for a gradual increase in the exercise pattern of the patient. 17 Both treatment strategies underline the importance of a regular and balanced daily activity pattern. As such, it is important to have a good understanding of the physical activity level of chronic fatigue syndrome patients for designing adequate treatment procedures. 18

However, no attempt has been made to present a good overview of the existing literature about the physical activity level of chronic fatigue syndrome patients as compared to asymptomatic controls. The physical activity level for a heterogeneous group of patients with chronic pain and/or fatigue in comparison to asymptomatic controls was reviewed. 18 Twelve studies were included and five studies about chronic fatigue syndrome did show significantly lower physical activity levels in chronic fatigue syndrome patients as compared to controls. 18 However, the overall results were not conclusive with large heterogeneity between different syndromes and subjective outcome measures did result more often in significantly lower physical activity levels in patients than objective outcome measures. 18 Besides, more studies about the physical activity level of chronic fatigue syndrome patients are needed to be able to draw conclusions on whether chronic fatigue syndrome patients have different physical activity levels as compared to control subjects. The objective of this study is to give an overview of the physical activity level of chronic fatigue syndrome patients as compared to asymptomatic controls by performing a systematic review. 


\section{Methods}

An extensive literature search was conducted consulting the following electronic databases: MEDLINE (www.pubmed.com), Web of Science, (www.isiwebofknowledge.com), EMBASE (www.embase.com), PsycINFO (www.ebsco.com), Picarta (picarta.pica.nl) and the Cochrane Controlled Trial Register that is included in the Cochrane Library. This search strategy encompassed a systematic search within electronic databases (appendix 1), and a non-systematic search within all accessible literature sources. The non-systematic search strategy was performed for an additional check of relevant articles and included reference tracking on all included articles, and the options 'related articles' in PubMed and 'times cited' in Web of Science. The computerized search strategy was based on the following keywords: chronic fatigue syndrome, myalgic encephalomyelitis, myalgic encephalopathy, daily activity, activities of daily living, accelerometer, actometer, actigraphy, monitoring, physical activity and combinations thereof. Articles published from 1988 till August 2009 were included in this review. Full text versions were retrieved if title and abstract did not give full explanation about the inclusion criteria. Final inclusion was based on full text versions.

The criteria for inclusion of a study were as follows: report on subjects with chronic fatigue syndrome, inclusion of an asymptomatic control group, physical activity level as one of the outcome parameters, and be written in English, German or Dutch. Study selection was based on titles and abstracts of articles obtained with the systematic and non-systematic search strategies. Articles were included if title and abstract gave sufficient information to include the article. Full text versions were retrieved and read if title and abstract were insufficient to conclude if the article met the inclusion criteria. Final inclusion was based on full text versions of the studies. 


\section{Study characteristics}

Study characteristics were extracted from each included study on the following parameters: gender, age, sample size, work status, duration of complaints, methodological quality, measurement device, measurement period, outcome measure, reported results and conclusions. The parameter 'outcome measure' indicates how the daily physical activity level was measured in each study. 'Measurement device' indicates in which way the physical activity level was measured and is subdivided into objective and subjective outcome assessments. Objective outcome assessments are performed using various apparatus measuring the actual daily physical activity level. Subjective outcome assessments are based on personal interpretations obtained from questionnaires or rating diaries.

\section{Methodological quality}

The methodological quality of the studies included was scored on a methodological criteria list. Until now, there is no consensus about critical assessment tools for assessing methodological quality. The criteria list as described in table I (operationalisation in appendix 2 ) is established using criteria recommended by the Cochrane Back Group. ${ }^{19}$ Criteria 3 and 4 were extracted from a study by Ross et al. 20 and have specific emphasis on the assessment of populations with chronic fatigue syndrome. The final list of criteria assessed descriptive characteristics (D; $n$ $=5)$, internal validity $(\mathrm{l} ; \mathrm{n}=4)$ and statistics $(S ; n=2)$.

Every criterion was scored as 'yes', 'no', 'do not know' or 'not applicable', with the final score being the sum of 'yes' scores. The overall quality, and the quality of the subscales separately were rated as 'high' 'medium' or 'low' following the number of 'yes' scores as stated in table I. The decisions made concerning methodological quality were subjective and no study was excluded in this review from analysis, presentation of results, or discussion. The methodological quality was assessed independently by two authors (RE, MvW). These authors were not blinded with respect to the origin of the article such as authors, institution and journal of publication because they were familiar with the literature. Consensus was used to resolve disagreements and an independent third author was consulted to resolve persistent disagreements (MV). 
Table I Criteria list for methodological quality assessment

\section{Descriptive characteristics (D)}

1. Were the eligibility criteria specified?

2. Were the groups similar at baseline regarding the most important prognostic indicators?

3. Chronic fatigue syndrome was defined according to at least one of the acceptable criteria. All patients meet these criteria.

4. Work activity or work/disability status was reported.

5. Was the procedure explicitly described?
Low score: 0 - 1
Medium score: 2 - 3
High score: 4 - 5

\section{Internal validity (I)}

6. Was the compliance acceptable in both groups?

7. Were the outcome measures reliable and valid?

8. Was the withdrawal/drop-out rate described and acceptable?

9. Was the timing of the outcome assessment in both groups comparable?
Low score: $0-1$
Medium score: 2
High score: $3-4$

\section{Statistics (S)}

10. Was the sample size for each group described?

11. Were point estimates and measures of variability presented for the primary outcome measures?

Low score: $0 \quad$ Medium score: $1 \quad$ High score: 2

Total score methodological quality
Low score: 0 - 5
Medium score: 6 - 9
High score: $10-11$ 


\section{Reliability and validity}

The reliability and validity of each measurement device used for measuring the physical activity level was evaluated. Judgement about reliability relied on internal consistency and/or test-retest reliability. Judgement about validity relied on congruent validity with energy expenditure and workload. Correlation coefficient scores on internal consistency, test-retest reliability and congruent validity were stated as good $(+; \geq 0.80)$, moderate $(+/-;<0.80$ and $\geq 0.50)$, bad $(-;<0.50)$, or unknown (?). These boundaries were based on other reports about reliability and validity. 2122

\section{Descriptive analysis}

The conclusions drawn in the included studies, means (SD) and statistical analysis ( $p$-value) were used to get an overview of results found about the physical activity level of chronic fatigue syndrome patients as compared to control subjects. In addition, for each study the outcome was outlined against the methodological quality and the reliability and validity of the measurement device used.

\section{Meta-analysis}

A meta-analysis was performed by pooling data from those studies that used objective assessment methods to analyse the daily physical activity level. The QUOROM statement was taken into account in achieving the standards stated for performing a meta-analysis. ${ }^{23}$ Subjective assessment methods yielded different outcome measures of daily physical activity levels which could not be pooled together. Therefore, subjective outcome assessments were excluded from the meta-analysis. The meta-analysis required that sample size (n), mean physical activity level and SD were available for each group (control- and chronic fatigue syndrome group). The primary outcome measure in the meta-analysis for quantification of the daily physical activity level was the mean ratio of the daily physical activity level (physical activity level of the chronic fatigue syndrome group divided by the control group). The mean ratio was taken instead of a standardized mean difference because objective assessment methods differed considerably and 
resulted in different outcome values between studies which were not directly comparable. 24

Using a data pooling model appropriate to the characteristics and data of the selected studies, we estimated the pooled mean ratio. The standard error of the ratio is based on the standard errors of the chronic fatigue syndrome and control group and estimated by applying the delta method. ${ }^{25} \mathrm{~A}$ random effect model was chosen for combining study estimates because tests of heterogeneity between studies was significant $(\mathrm{Q}=85.1, \mathrm{P}<0.05) .{ }^{26}$ This model assumes the presence of different underlying effect sizes between studies and corrects for between and within study variance. Furthermore, the weighted least squares method was used to analyse the random effect model in which the weight of each study in the metaanalysis depends on the SD of the mean ratio. In this way, the sample size of each study implicitly determines the weight of each study in the meta-analysis.

\section{Coefficient of variation}

The coefficient of variation is a useful statistic quantity to gain insight in the variability between subjects within a group. The variability within different groups can be compared to each other, even if the means and SDs are drastically different. The coefficient of variation of a specific group will become large when considerable variability exists. If data was available, the coefficient of variation ( (SD/mean) $x$ 100) was calculated for the patient and the control group separately. In this study the coefficient of variation in the chronic fatigue syndrome group was considered higher when the coefficient of variation of the chronic fatigue syndrome group was $\geq 1$. 2 times the coefficient of variation of the control group and lower when the coefficient of variation of the chronic fatigue syndrome group was $\leq 0.8$ times the coefficient of variation of the control group. In all other cases the coefficient of variations were considered equal. These boundaries were chosen as arbitrary, and were only used as a guideline for observing differences in variability. The overall mean coefficient of variation was calculated by pooling the coefficient of variations from all studies together from which a coefficient of variation could be calculated. Similar to the meta-analysis of daily physical activity, a random effect model was chosen for combining study estimates and the weighted least squares method was 
used to analyse the random effect model. Standard deviations of the coefficient of variations for each study were approximated by using a Taylor expansion. 27

\section{Results}

The literature search resulted in a total number of 100 articles which were retrieved for closer inspection. From this database, 17 articles met our inclusion criteria and were included in this review (figure 1). Main reasons for excluding articles from further analysis were lack of a control group, measuring physical capacity instead of physical activity level and usage of the same dataset used in an earlier article already included in this review. 


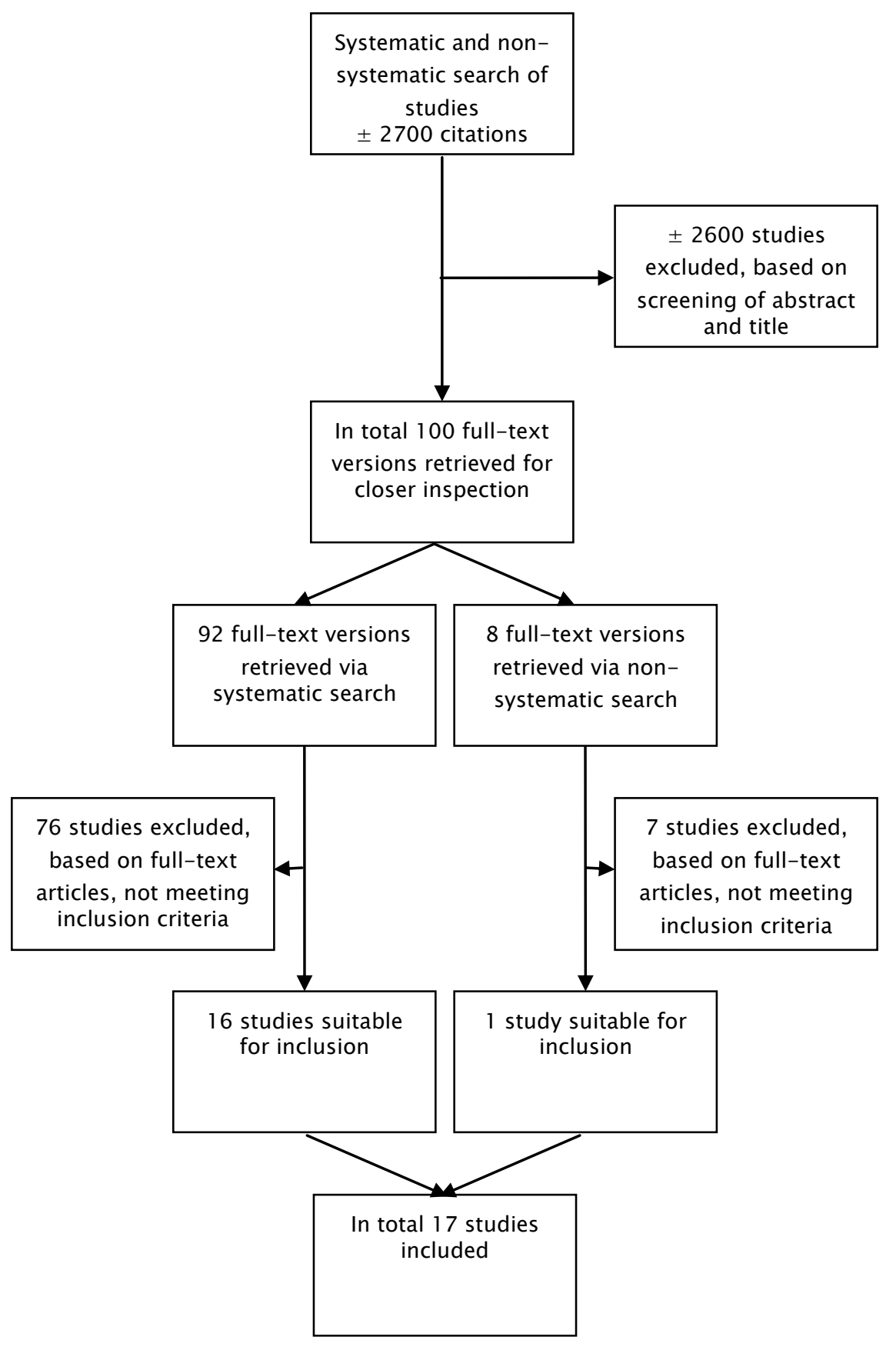

Figure 1 Flow diagram of included studies 
The characteristics and methodological quality of the included studies are displayed in table II. As can be seen, the number of patients and control subjects, the male to female ratio and the average age of the included subjects differed considerably between studies. Only three studies reported on work status of included chronic fatigue syndrome patients and control subjects. 283738 The mean duration of complaints was reported in six studies, varying from 2.8 years up to 5.8 years. $28-30$ 344244

The methodological quality varied between studies with a mean value of 7 (medium) out of 11 points, and an observed range between 2 and 9 points. No study was judged as having a 'high' methodological quality; thirteen studies had a 'medium' methodological quality29-41; and four studies had a 'low' methodological quality 28 42-44. In more detail; the descriptive characteristics was scored as 'high' for two studies36 40; 'medium' for fifteen studies28-35 37-3941-44; and no study had a 'low' score for descriptive characteristics. The internal validity was scored as 'high' in six studies29 3234383941 ; 'medium' in four studies31 3336 37; and 'low' in seven studies. $2830354042-44$ The statistical quality was judged as 'high' in fifteen studies2942 44; 'medium' in one study28; and 'low' in one study43. 
Table II Characteristics of included studies*

$\begin{array}{lllll}\begin{array}{l}\text { First author of } \\ \text { paper }\end{array} & \begin{array}{l}\text { Chronic fatigue syndrome } \\ \text { Subjects }\end{array} & \text { Control Subjects } & \begin{array}{l}\text { Number of } \\ \text { subjects working }\end{array} & \begin{array}{l}\text { Mean duration of } \\ \text { complaints }\end{array} \\ & & \text { (\%) } & \begin{array}{l}\text { Total score and score } \\ \text { subscales methodological } \\ \text { quality (criteria with 'yes' } \\ \text { score) }\end{array}\end{array}$

$\begin{array}{ll}\text { Bazelmans, } & \mathrm{N}=20 \\ \text { 200130a } & 4 \text { males } \\ & \begin{array}{l}16 \text { females } \\ \text { mean age 34.1 years (8.3) }\end{array} \\ \text { Black, 200531 } & \begin{array}{l}\mathrm{N}=6 \\ \text { number of males and females } \\ \text { unknown } \\ \text { mean age 43 years (4.6) }\end{array}\end{array}$

$\mathrm{N}=20$
4 males
16 females

Unknown $\quad 3.2$ years $(S D=2.5)$

Total score: 6

Subscales: D: 3 I: 1 S: 2

$\mathrm{N}=7$

number of males and

females unknown

mean age 43 years

(6.5)

$\begin{array}{lll}\text { Cook, 200632 } & \text { CFS only } & \underline{\mathrm{CFS}+\mathrm{FM}} \\ & \mathrm{N}=29 & \mathrm{~N}=23 \\ 9 \text { males } & 16 \text { males } \\ & 20 \text { females } & 7 \text { females } \\ \text { mean age 39.8 } & \text { mean age } \\ & \text { years (9) } & 40.9 \text { years }(8)\end{array}$

$\begin{array}{lll}\text { Farquhar, } & \mathrm{N}=17 & \mathrm{~N}=17 \\ 2002^{33} & 4 \text { males } & 5 \text { males } \\ & 13 \text { females } & 12 \text { females } \\ & \text { mean age } 39 \text { years (12) } & \text { mean age } 36 \text { years }\end{array}$

$\mathrm{N}=32$
17 males
15 females
mean age 37.0 years
$(12)$
$\mathrm{N}=17$
5 males
12 females
mean age 36 years

mean age 32.8 years

(7.2)

Unknown Unknown

Unknown

Unknown

Unknown

(1)

\author{
$(2,3,5,8,10,11)$
}

Total score: 6

Subscales: D: 2 I: 2 S: 2

$(1,5,7,9,10,11)$

Total score: 8

Subscales: D: 3 I: 3 S: 2

$(1,3,5,6,8,9,10,11)$

Unknown

Total score: 7

Subscales: D: 3 I: 3 S: 2

$(2,3,5,7,9,10,11)$

\section{$N$}


Table II Characteristics of included studies*

\begin{tabular}{|c|c|c|c|c|c|}
\hline $\begin{array}{l}\text { First author of } \\
\text { paper }\end{array}$ & $\begin{array}{l}\text { Chronic fatigue syndrome } \\
\text { Subjects }\end{array}$ & Control Subjects & $\begin{array}{l}\text { Number of } \\
\text { subjects working } \\
\text { (\%) }\end{array}$ & $\begin{array}{l}\text { Mean duration of } \\
\text { complaints }\end{array}$ & $\begin{array}{l}\text { Total score and score } \\
\text { subscales methodological } \\
\text { quality (criteria with 'yes' } \\
\text { score) }\end{array}$ \\
\hline Fry, $1996^{34 a}$ & $\begin{array}{l}\mathrm{N}=19 \\
10 \text { males } \\
9 \text { females } \\
\text { mean age } 14.3 \text { years (range } 11.8 \\
-16.4 \text { ) }\end{array}$ & $\begin{array}{l}\mathrm{N}=19 \\
10 \text { males } \\
9 \text { females } \\
\text { mean age } 14.7 \text { years } \\
\text { (range unknown) }\end{array}$ & $\begin{array}{l}\text { Not applicable, all } \\
\text { adolescents of } \\
\text { school age }\end{array}$ & $\begin{array}{l}5 \text { months to } 9.5 \\
\text { years }\end{array}$ & $\begin{array}{l}\text { Total score: } 7 \\
\text { Subscales: D: } 2 \text { I: } 3 \text { S: } 2 \\
(2,5,6,8,9,10,11)\end{array}$ \\
\hline $\begin{array}{l}\text { Gallagher, } \\
2005^{42}\end{array}$ & $\begin{array}{l}\mathrm{N}=41 \\
8 \text { males } \\
33 \text { females } \\
\text { mean age } 37.7 \text { years }(9.5)\end{array}$ & $\begin{array}{l}\mathrm{N}=42 \\
8 \text { males } \\
34 \text { females } \\
\text { mean age } 35.3 \text { years } \\
(8.7)\end{array}$ & Unknown & 5.8 years $(\mathrm{SD}=5.2)$ & $\begin{array}{l}\text { Total score: } 5 \\
\text { Subscales: D: } 3 \text { I: } 0 \text { S: } 2 \\
(1,2,3,10,11)\end{array}$ \\
\hline Kop, $2005^{35 b}$ & $\begin{array}{l}\mathrm{N}=38 \\
10 \text { males } \\
28 \text { females } \\
\text { mean age } 41.5 \text { years }(8.2)\end{array}$ & $\begin{array}{l}\mathrm{N}=27 \\
15 \text { males } \\
12 \text { females } \\
\text { mean age } 38.0 \text { years } \\
(8.6)\end{array}$ & Unknown & Unknown & $\begin{array}{l}\text { Total score: } 6 \\
\text { Subscales: D: } 3 \text { I: } 1 \text { S: } 2 \\
(1,3,5,7,10,11)\end{array}$ \\
\hline $\begin{array}{l}\text { Nagelkirk, } \\
2003^{36}\end{array}$ & $\begin{array}{l}\mathrm{N}=15 \\
12 \text { males } \\
3 \text { females } \\
\text { mean age } 41.9 \text { years }(7.8)\end{array}$ & $\begin{array}{l}\mathrm{N}=19 \\
16 \text { males } \\
3 \text { females } \\
\text { mean age } 43.1 \text { years } \\
(5.4)\end{array}$ & Unknown & Unknown & $\begin{array}{l}\text { Total score: } 8 \\
\text { Subscales: D: } 4 \text { I: } 2 \text { S: } 2 \\
(1,2,3,5,7,9,10,11)\end{array}$ \\
\hline
\end{tabular}


Table II Characteristics of included studies*

\begin{tabular}{|c|c|c|c|c|c|}
\hline $\begin{array}{l}\text { First author of } \\
\text { paper }\end{array}$ & $\begin{array}{l}\text { Chronic fatigue syndrome } \\
\text { Subjects }\end{array}$ & Control Subjects & $\begin{array}{l}\text { Number of } \\
\text { subjects working } \\
\text { (\%) }\end{array}$ & $\begin{array}{l}\text { Mean duration of } \\
\text { complaints }\end{array}$ & $\begin{array}{l}\text { Total score and score } \\
\text { subscales methodological } \\
\text { quality (criteria with 'yes' } \\
\text { score) }\end{array}$ \\
\hline Ohinata, $2008^{43}$ & $\begin{array}{l}\mathrm{N}=12 \\
3 \text { males } \\
9 \text { females } \\
\text { age between } 12 \text { to } 16 \text { years }\end{array}$ & $\begin{array}{l}\mathrm{N}=7 \\
2 \text { males } \\
5 \text { females } \\
\text { age between } 13 \text { to } \\
16 \text { years }\end{array}$ & Unknown & Unknown & $\begin{array}{l}\text { Total score: } 2 \\
\text { Subscales: D: } 2 \text { I: } 0 \text { S: } 0 \\
(3,5)\end{array}$ \\
\hline Packer, 199737a & $\begin{array}{l}\mathrm{N}=17 \\
3 \text { males } \\
14 \text { females } \\
\text { mean age } 43.9 \text { years (SD } \\
\text { unknown) }\end{array}$ & $\begin{array}{l}\mathrm{N}=11 \\
2 \text { males } \\
9 \text { females } \\
\text { mean age } 43.2 \text { years } \\
\text { (SD unknown) }\end{array}$ & $\begin{array}{l}\text { CFS: } 8 \text { (47) } \\
\text { Controls: } 2 \text { (18) }\end{array}$ & Unknown & $\begin{array}{l}\text { Total score: } 6 \\
\text { Subscales: D: } 2 \text { I: } 2 \text { S: } 2 \\
(4,5,6,7,10,11)\end{array}$ \\
\hline Packer, $199438 a$ & $\begin{array}{l}\mathrm{N}=13 \\
2 \text { males } \\
11 \text { females } \\
\text { mean age } 41 \text { years (SD unknown) }\end{array}$ & $\begin{array}{l}\mathrm{N}=11 \\
2 \text { males } \\
9 \text { females } \\
\text { mean age } 43 \text { years } \\
\text { (SD unknown) }\end{array}$ & $\begin{array}{l}\text { CFS: } 5 \text { (38) } \\
\text { Controls: } 2 \text { (18) }\end{array}$ & Unknown & $\begin{array}{l}\text { Total score: } 9 \\
\text { Subscales: D: } 3 \text { I: } 4 \text { S: } 2 \\
(1,4,5,6,7,8,9,10 \\
11)\end{array}$ \\
\hline Sisto, 199829 & $\begin{array}{l}\mathrm{N}=20 \\
0 \text { males } \\
20 \text { females } \\
\text { mean age } 33.6 \text { years }(7.0)\end{array}$ & $\begin{array}{l}\mathrm{N}=20 \\
0 \text { males } \\
20 \text { females } \\
\text { mean age } 33.0 \text { years } \\
(9.0)\end{array}$ & Unknown & $\begin{array}{l}3.7 \text { years } \\
(8 \text { months to } 6 \\
\text { years })\end{array}$ & $\begin{array}{l}\text { Total score: } 9 \\
\text { Subscales: D: } 3 \text { I: } 4 \text { S: } 2 \\
(2,3,4,6,7,8,9,10 \text {, } \\
11)\end{array}$ \\
\hline
\end{tabular}

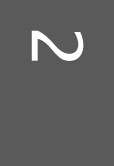


Table II Characteristics of included studies*

\begin{tabular}{|c|c|c|c|c|c|}
\hline $\begin{array}{l}\text { First author of } \\
\text { paper }\end{array}$ & $\begin{array}{l}\text { Chronic fatigue syndrome } \\
\text { Subjects }\end{array}$ & Control Subjects & $\begin{array}{l}\text { Number of } \\
\text { subjects working } \\
\text { (\%) }\end{array}$ & $\begin{array}{l}\text { Mean duration of } \\
\text { complaints }\end{array}$ & $\begin{array}{l}\text { Total score and score } \\
\text { subscales methodological } \\
\text { quality (criteria with 'yes' } \\
\text { score) }\end{array}$ \\
\hline Smith, $2006^{39 c}$ & $\begin{array}{l}\mathrm{N}=33 \\
7 \text { males } \\
26 \text { females } \\
\text { mean age } 45.6 \text { years }(11.8)\end{array}$ & $\begin{array}{l}\mathrm{N}=33 \\
5 \text { males } \\
28 \text { females } \\
\text { mean age } 44.1 \text { years } \\
(13.1)\end{array}$ & Unknown & Unknown & $\begin{array}{l}\text { Total score: } 9 \\
\text { Subscales: D: } 3 \text { I: } 4 \text { S: } 2 \\
(2,3,5,6,7,8,9,10 \text {, } \\
11)\end{array}$ \\
\hline Tryon, 200440a & $\begin{array}{l}\mathrm{N}=10 \\
2 \text { males } \\
8 \text { females } \\
\text { age between } 39 \text { to } 59 \text { years }\end{array}$ & $\begin{array}{l}\mathrm{N}=10 \\
2 \text { males } \\
8 \text { females } \\
\text { age between } 39 \text { to } \\
59 \text { years }\end{array}$ & Unknown & Unknown & $\begin{array}{l}\text { Total score: } 7 \\
\text { Subscales: D: } 4 \text { I: } 1 \text { S: } 2 \\
(1,2,3,5,7,10,11)\end{array}$ \\
\hline $\begin{array}{l}\text { Van de Putte, } \\
2005^{44}\end{array}$ & $\begin{array}{l}\mathrm{N}=32 \\
4 \text { males } \\
28 \text { females } \\
\text { mean age } 16.0 \text { years }(1.7)\end{array}$ & $\begin{array}{l}\mathrm{N}=167 \\
67 \text { males } \\
100 \text { females } \\
\text { mean age } 15.5 \text { years } \\
(1.6)\end{array}$ & $\begin{array}{l}\text { Not applicable, all } \\
\text { adolescents of } \\
\text { school age }\end{array}$ & $\begin{array}{l}33 \text { months } \\
\text { (6 to } 192 \text { months) }\end{array}$ & $\begin{array}{l}\text { Total score: } 5 \\
\text { Subscales: D: } 2 \text { I: } 1 \text { S: } 2 \\
(1,3,8,10,11)\end{array}$ \\
\hline $\begin{array}{l}\text { Van der Werf, } \\
2000^{41}\end{array}$ & $\begin{array}{l}\mathrm{N}=277 \\
59 \text { males } \\
218 \text { females } \\
\text { mean age } 37.5 \text { years (range } 18- \\
60 \text { ) }\end{array}$ & $\begin{array}{l}\mathrm{N}=47 \\
24 \text { males } \\
23 \text { females } \\
\text { mean age } 40.1 \text { years } \\
\text { (range } 19-63 \text { ) }\end{array}$ & Unknown & Unknown & $\begin{array}{l}\text { Total score: } 7 \\
\text { Subscales: D: } 2 \text { I: } 3 \text { S: } 2 \\
(3,5,6,8,9,10,11)\end{array}$ \\
\hline
\end{tabular}


Table II Characteristics of included studies*

\begin{tabular}{|c|c|c|c|c|c|}
\hline $\begin{array}{l}\text { First author of } \\
\text { paper }\end{array}$ & $\begin{array}{l}\text { Chronic fatigue syndrome } \\
\text { Subjects }\end{array}$ & Control Subjects & $\begin{array}{l}\text { Number of } \\
\text { subjects working } \\
\text { (\%) }\end{array}$ & $\begin{array}{l}\text { Mean duration of } \\
\text { complaints }\end{array}$ & $\begin{array}{l}\text { Total score and score } \\
\text { subscales methodological } \\
\text { quality (criteria with 'yes' } \\
\text { score) }\end{array}$ \\
\hline $\begin{array}{l}\text { Vercoulen, } \\
199728\end{array}$ & $\begin{array}{l}\mathrm{N}=51 \\
12 \text { males } \\
39 \text { females } \\
\text { mean age } 36.3 \text { years (range } 19- \\
54 \text { ) }\end{array}$ & $\begin{array}{l}\mathrm{N}=53 \\
13 \text { males } \\
40 \text { females } \\
\text { mean age } 37.1 \text { years } \\
\text { (range } 19-63 \text { ) }\end{array}$ & $\begin{array}{l}\text { CFS: } 14(27) \\
\text { Controls: } 25 \text { (47) }\end{array}$ & $\begin{array}{l}5 \text { years } \\
\text { ( } 1 \text { to } 48 \text { years) }\end{array}$ & $\begin{array}{l}\text { Total score: } 5 \\
\text { Subscales: D: } 3 \text { I: } 1 \text { S: } 1 \\
(2,4,5,9,11)\end{array}$ \\
\hline
\end{tabular}

"Except where indicated otherwise, values are the mean \pm SD. CFS = chronic fatigue syndrome; FM = fibromyalgia

a Details about subjects in the total sample population do not equal to details of the sample population included in table IV and figure 2 , due to missing data in daily physical activity measurements

b Patient group consisted of a mixed population of subjects with chronic fatigue syndrome only (9), fibromyalgia (8), or chronic fatigue syndrome + fibromyalgia (21)

c Patient group consisted of a mixed population of subjects; chronic fatigue syndrome (25 subjects), idiopathic chronic fatigue (7 subjects), or fibromyalgia only ( 1 subject), and fibromyalgia + chronic fatigue syndrome or idiopathic chronic fatigue ( 8 subjects) 
In the 17 studies included in this review 21 different outcome assessments about the physical activity level were found and 22 different comparisons were made between chronic fatigue syndrome patients and control subjects. One study used the same subjective outcome assessment in two different patient populations, one patient population with chronic fatigue syndrome only and one patient population with chronic fatigue syndrome and fibromyalgia. 32

Data extraction was done for all different methods used to measure physical activity levels (table III) with their outcomes (table IV) presented in each study. From the 17 studies included in this review, 14 studies 28-34 37-41 4344 showed significantly lower physical activity levels in the chronic fatigue syndrome group as compared to the control group; and four studies $34-3642$ did not show significant differences. Ten studies used objective outcome assessments with measurement periods varying from 1 to 14 days; seven studies showed significantly lower average daily physical activity levels in chronic fatigue syndrome patients as compared to control subjects 28-31 404143 ; and three studies did not show significant differences 343542 . Ten studies used subjective outcome assessment; nine studies reported significantly lower physical activity levels in chronic fatigue syndrome patients as compared to control subjects28 32-34 37-3941 44; and one study did not found a significant difference ${ }^{36}$. Three studies used both subjective as well as objective outcome assessments, two showed with both methods significantly lower physical activity levels in chronic fatigue syndrome patients as compared to control subjects 2841 ; while one study did not show a significant difference with an objective outcome assessment but did show a significant difference with a subjective outcome assessment 34 . 
Table III Methods of measuring physical activity levels

\begin{tabular}{|c|c|c|c|}
\hline $\begin{array}{l}\text { First author of } \\
\text { paper }\end{array}$ & Measurement device & Measurement period & Outcome measure \\
\hline $\begin{array}{l}\text { Bazelmans, } \\
2001^{30}\end{array}$ & $\begin{array}{l}\text { Objective; Actometer; triaxial sensitive } \\
\text { in } 3 \text { directions }{ }^{28}\end{array}$ & 14 days & $\begin{array}{l}\text { Mean number of accelerations during daytime, } \\
5 \text { min epochs, ankle mounted }\end{array}$ \\
\hline Black, $2005^{31}$ & $\begin{array}{l}\text { Objective; Actigraphy (Computer } \\
\text { Science and Applications (CSA/MTI)), } \\
\text { uniaxial sensitive in vertical direction }{ }^{54} \\
55\end{array}$ & 14 days & $\begin{array}{l}\text { Mean number of accelerations during day and } \\
\text { night time, } 2 \text { min epochs, waist mounted }\end{array}$ \\
\hline Cook, $2006^{32}$ & $\begin{array}{l}\text { Subjective; Godin leisure-time exercise } \\
\text { questionnaire }\end{array}$ & Measured at 1 time point & $\begin{array}{l}\text { Average number of times participated in certain } \\
\text { activities for more than } 15 \text { minutes over a usual } \\
\text { 1-week }\end{array}$ \\
\hline $\begin{array}{l}\text { Farquhar, } \\
2002^{33}\end{array}$ & $\begin{array}{l}\text { Subjective; College alumnus health } \\
\text { questionnaire } 56\end{array}$ & Measured at 1 time point & Weekly energy expenditure in kcal/week \\
\hline $\begin{array}{l}\text { Fry, } 1996^{34} \\
\text { Part A }\end{array}$ & $\begin{array}{l}\text { Objective; Gaehwiler electronic activity } \\
\text { monitor; uniaxial sensitive in vertical } \\
\text { direction }\end{array}$ & $\begin{array}{l}3 \text { days (Tuesday, Wednesday } \\
\text { and thursday) }\end{array}$ & $\begin{array}{l}\text { Mean score of activity in percentage of active } \\
\text { epochs during daytime, } 1 \text { min epochs, ankle } \\
\text { mounted }\end{array}$ \\
\hline
\end{tabular}

\section{$N$}


Table III Methods of measuring physical activity levels

\begin{tabular}{|c|c|c|c|}
\hline $\begin{array}{l}\text { First author of } \\
\text { paper }\end{array}$ & Measurement device & Measurement period & Outcome measure \\
\hline Fry, $1996^{34}$ & Subjective; $100 \mathrm{~mm}$ visual analogue & 3 days, at the end of each & Rating of daily activity by the child \\
\hline Part B & scale & $\begin{array}{l}\text { day, given by child and } \\
\text { parent }\end{array}$ & Rating of daily activity by the parent \\
\hline $\begin{array}{l}\text { Gallagher, } \\
2005^{42}\end{array}$ & $\begin{array}{l}\text { Objective; Accelerometer, type, model } \\
\text { and measurement details were not } \\
\text { specified }\end{array}$ & 1 day & $\begin{array}{l}\text { Median of arbitrary counts registered by use of } \\
\text { an accelerometer, details not further specified }\end{array}$ \\
\hline Kop, $2005^{35}$ & $\begin{array}{l}\text { Objective; Actigraphy (Ambulatory } \\
\text { Monitoring Inc. (AMI)), triaxial sensitive } \\
\text { in } 3 \text { directions }{ }^{57}\end{array}$ & 5 days & $\begin{array}{l}\text { Mean number of accelerations during daytime, } \\
5 \text { min epochs, wrist mounted }\end{array}$ \\
\hline $\begin{array}{l}\text { Nagelkirk, } \\
2003^{36}\end{array}$ & $\begin{array}{l}\text { Subjective; Baecke physical activity } \\
\text { questionnaire }^{58}\end{array}$ & Measured at 1 time point & $\begin{array}{l}\text { Total Baecke score (sum of work, sport and } \\
\text { leisure time indices) }\end{array}$ \\
\hline $\begin{array}{l}\text { Ohinata, } \\
2008^{43}\end{array}$ & $\begin{array}{l}\text { Objective; Actigraphy (AMI), triaxial } \\
\text { sensitive in } 3 \text { directions }{ }^{57}\end{array}$ & $1-2$ weeks & $\begin{array}{l}\text { Mean number of accelerations while awake, } 1 \\
\text { min epochs, wrist mounted }\end{array}$ \\
\hline Packer, 199737 & $\begin{array}{l}\text { Subjective; Human activity profile, } \\
\text { adjusted activity score }\end{array}$ & Measured at 1 time point & $\begin{array}{l}\text { Average metabolic equivalents (MET) level in a } \\
\text { typical day }\end{array}$ \\
\hline
\end{tabular}


Table III Methods of measuring physical activity levels

\begin{tabular}{|c|c|c|c|}
\hline $\begin{array}{l}\text { First author of } \\
\text { paper }\end{array}$ & Measurement device & Measurement period & Outcome measure \\
\hline Packer, 199438 & $\begin{array}{l}\text { Subjective; Human activity profile, } \\
\text { adjusted activity score }\end{array}$ & Measured at 1 time point & $\begin{array}{l}\text { Average metabolic equivalents (MET) level in a } \\
\text { typical day }\end{array}$ \\
\hline Sisto, $1998^{29}$ & $\begin{array}{l}\text { Objective; Actigraphy (CSA/MTI), } \\
\text { uniaxial sensitive in vertical direction }{ }^{54} \\
55\end{array}$ & $\begin{array}{l}7 \text { days (prior to a maximal } \\
\text { exercise test) }\end{array}$ & $\begin{array}{l}\text { Mean number of accelerations during daytime, } \\
1 \text { min epochs, waist mounted }\end{array}$ \\
\hline Smith, $2006^{39}$ & $\begin{array}{l}\text { Subjective; Chronic fatigue activity } \\
\text { questionnaire }\end{array}$ & Measured at 1 time point & $\begin{array}{l}\text { Rating of activity level during past week as } \\
\text { compared to that of an average healthy person, } \\
\text { on a } 10 \text { point scale from extremely low till } \\
\text { extremely high }\end{array}$ \\
\hline Tryon, 200440 & $\begin{array}{l}\text { Objective; Actigraphy }(\mathrm{CSA} / \mathrm{MTI}) \\
\text { uniaxial sensitive in vertical direction }{ }^{54} \\
55\end{array}$ & 7 days & $\begin{array}{l}\text { Mean number of accelerations during daytime } \\
\text { (diurnal) } 6.00 \text { to } 24.00 \mathrm{~h}, 1 \mathrm{~min} \text { epochs, waist } \\
\text { mounted }\end{array}$ \\
\hline $\begin{array}{l}\text { Van de Putte, } \\
2005^{44}\end{array}$ & $\begin{array}{l}\text { Subjective; Physical activity } \\
\text { questionnaire }\end{array}$ & Measured at 1 time point & Hours of physical activity per week \\
\hline
\end{tabular}

\section{$N$}


Table III Methods of measuring physical activity levels

\begin{tabular}{|c|c|c|c|}
\hline $\begin{array}{l}\text { First author of } \\
\text { paper }\end{array}$ & Measurement device & Measurement period & Outcome measure \\
\hline \multicolumn{4}{|l|}{ Part A } \\
\hline \multicolumn{4}{|l|}{ Part B } \\
\hline $\begin{array}{l}\text { Vercoulen, } \\
199728\end{array}$ & $\begin{array}{l}\text { Objective; Actometer, triaxial sensitive } \\
\text { in } 3 \text { directions }{ }^{28}\end{array}$ & 12 days & $\begin{array}{l}\text { Mean number of accelerations during day- and } \\
\text { night time, } 5 \text { min epochs, ankle mounted }\end{array}$ \\
\hline \multicolumn{4}{|l|}{ Part A } \\
\hline $\begin{array}{l}\text { Vercoulen, } \\
1997^{28}\end{array}$ & $\begin{array}{l}\text { Subjective; Self observation score daily } \\
\text { activity }\end{array}$ & 12 days, 1 time a day & $\begin{array}{l}\text { Mean score of the } 2 \text { week period scored on a } \\
7 \text {-point scale }\end{array}$ \\
\hline \multicolumn{4}{|l|}{ Part B } \\
\hline $\begin{array}{l}\text { Vercoulen, } \\
199728\end{array}$ & $\begin{array}{l}\text { Subjective; Physical activities rating } \\
\text { scale }\end{array}$ & $\begin{array}{l}12 \text { days, measured at } 1 \text { time } \\
\text { point }\end{array}$ & $\begin{array}{l}\text { Mean score of time spent on } 20 \text { different } \\
\text { activities, during the past } 2 \text { weeks scored on a }\end{array}$ \\
\hline Part C & & & 5-point scale \\
\hline
\end{tabular}




\begin{tabular}{|c|c|c|c|c|c|c|}
\hline $\begin{array}{l}\text { First author of } \\
\text { paper }\end{array}$ & \multicolumn{2}{|c|}{$\begin{array}{l}\text { Mean (SD) chronic fatigue } \\
\text { syndrome subjects (Unit of } \\
\text { measurement) }\end{array}$} & $\begin{array}{l}\text { Mean control subjects (SD) } \\
\text { (Unit of measurement) }\end{array}$ & \multicolumn{2}{|c|}{ Statistical difference } & Conclusion \\
\hline Bazelmans, $200^{30}$ & \multicolumn{2}{|c|}{$\begin{array}{l}58.2(27.2) \\
\text { (Counts per } 5 \mathrm{~min})\end{array}$} & $\begin{array}{l}99.5(25.0) \\
\text { (Counts per } 5 \mathrm{~min})\end{array}$ & \multicolumn{2}{|l|}{$\mathrm{P}<0.001$} & $\begin{array}{l}\text { Significant lower daily physical } \\
\text { activity in CFS patients } \\
\text { compared to controls }\end{array}$ \\
\hline Black, $2005^{31}$ & \multicolumn{2}{|c|}{$\begin{array}{l}162.5 \times 10^{3}\left(51.7 \times 10^{3}\right) \\
\text { (Counts per day) }\end{array}$} & $\begin{array}{l}267.2 \times 10^{3}\left(79.5 \times 10^{3}\right) \\
\text { (Counts per day) }\end{array}$ & \multicolumn{2}{|l|}{$P=0.017$} & $\begin{array}{l}\text { Significant lower daily physical } \\
\text { activity in CFS patients } \\
\text { compared to controls }\end{array}$ \\
\hline Cook, $2006^{32}$ & $\begin{array}{l}\text { CFS only } \\
14.9(18.0) \\
\text { (Arbitrary } \\
\text { units) }\end{array}$ & $\begin{array}{l}\text { CFS + FM } \\
22.3 \\
(24.8) \\
\text { (Arbitrary } \\
\text { units) }\end{array}$ & $\begin{array}{l}37.5(22.4) \\
\text { (Arbitrary units) }\end{array}$ & $\begin{array}{l}\text { CFS only vs. } \\
\text { controls } \\
\mathrm{P}<0.05\end{array}$ & $\begin{array}{l}\text { CFS }+ \\
\text { FM vs. } \\
\text { controls } \\
\mathrm{P}<0.05\end{array}$ & $\begin{array}{l}\text { CFS only and CFS + FM } \\
\text { patients reported significant } \\
\text { less physical activity on a } \\
\text { weekly basis than healthy } \\
\text { control subjects }\end{array}$ \\
\hline Farquhar, $2002^{33}$ & \multicolumn{2}{|c|}{$\begin{array}{l}1018(\mathrm{SE}=225) \\
(\mathrm{kcal} / \mathrm{wk})\end{array}$} & $\begin{array}{l}5468(\mathrm{SE}=1301) \\
(\mathrm{kcal} / \mathrm{wk})\end{array}$ & \multicolumn{2}{|l|}{$\mathrm{P}<0.01$} & $\begin{array}{l}\text { CFS patients reported } \\
\text { significant less physical activity } \\
\text { on a weekly basis than healthy } \\
\text { controls }\end{array}$ \\
\hline $\begin{array}{l}\text { Fry, } 1996^{34} \\
\text { Part A }\end{array}$ & \multicolumn{2}{|c|}{$\begin{array}{l}68.2(8.0) \\
\text { (Percentage active epochs) }\end{array}$} & $\begin{array}{l}77.1 \text { (9.7) } \\
\text { (Percentage active epochs) }\end{array}$ & \multicolumn{2}{|l|}{ NS } & $\begin{array}{l}\text { No significant difference in } \\
\text { daily physical activity between } \\
\text { CFS patients and controls }\end{array}$ \\
\hline
\end{tabular}


Table IV Outcome physical activity level

\begin{tabular}{|c|c|c|c|c|}
\hline $\begin{array}{l}\text { First author of } \\
\text { paper }\end{array}$ & $\begin{array}{l}\text { Mean (SD) chronic fatigue } \\
\text { syndrome subjects (Unit of } \\
\text { measurement) }\end{array}$ & $\begin{array}{l}\text { Mean control subjects (SD) } \\
\text { (Unit of measurement) }\end{array}$ & Statistical difference & Conclusion \\
\hline $\begin{array}{l}\text { Fry, } 1996^{34} \\
\text { Part B }\end{array}$ & $\begin{array}{l}\text { Child rate } 38.6(16.6) \\
\text { Parent rate } 34.4(16.1) \\
(100 \mathrm{~mm} \text { visual analogue } \\
\text { scale) }\end{array}$ & $\begin{array}{l}\text { Child rate } 56.4(17.6) \\
\text { Parent rate } 56.5(10.1) \\
(100 \mathrm{~mm} \text { visual analogue } \\
\text { scale) }\end{array}$ & $\begin{array}{l}\text { Child rate } \mathrm{P}<0.01 \\
\text { Parent rate } \mathrm{P}<0.01\end{array}$ & $\begin{array}{l}\text { Child- and parent ratings of } \\
\text { daily physical activity were } \\
\text { significantly lower for the CFS } \\
\text { group than for the control } \\
\text { group }\end{array}$ \\
\hline Gallagher, $2005^{42}$ & $\begin{array}{l}\text { Median }=6.9 \text { (interquatile } \\
\text { range }=4.4-10.5 \text { ) } \\
\text { (Arbitrary units) }\end{array}$ & $\begin{array}{l}\text { Median }=8.4 \text { (interquatile } \\
\text { range }=7.2-10.1 \text { ) } \\
\text { (Arbitrary units) }\end{array}$ & $P=0.10$ & $\begin{array}{l}\text { No significant difference in } \\
\text { daily physical activity between } \\
\text { CFS patients and controls }\end{array}$ \\
\hline Kop, $2005^{35}$ & $\begin{array}{l}1525(\mathrm{SEM}=63) \\
(\text { Counts per } 5 \mathrm{~min})\end{array}$ & $\begin{array}{l}1602(\mathrm{SEM}=89) \\
(\text { Counts per } 5 \mathrm{~min})\end{array}$ & NS & $\begin{array}{l}\text { No significant difference in } \\
\text { daily physical activity between } \\
\text { CFS and/or FM patients and } \\
\text { controls }\end{array}$ \\
\hline Nagelkirk, $2003^{36}$ & $\begin{array}{l}7.5(2.4) \\
\text { (index) }\end{array}$ & $\begin{array}{l}7.3(2.1) \\
\text { (index) }\end{array}$ & NS & $\begin{array}{l}\text { No significant difference in } \\
\text { regular physical activity }\end{array}$ \\
\hline Ohinata, $2008^{43}$ & $\begin{array}{l}\text { No counts shown, only } \\
\text { graphs } \\
\text { (counts per min) }\end{array}$ & $\begin{array}{l}\text { No counts shown, only } \\
\text { graphs } \\
\text { (counts per min) }\end{array}$ & $\mathrm{P}<0.01$ & $\begin{array}{l}\text { Significant lower daily physical } \\
\text { activity in CFS patients } \\
\text { compared to controls }\end{array}$ \\
\hline Packer, 199737 & $\begin{array}{l}3.69 \text { (9.91) } \\
\text { \% MET level average day) }\end{array}$ & $\begin{array}{l}57.00 \text { (31.33) } \\
\text { (\% MET level average day) }\end{array}$ & $\mathrm{P}<0.001$ & $\begin{array}{l}\text { CFS patients reported } \\
\text { significant less physical activity } \\
\text { for a typical day than healthy } \\
\text { control subjects }\end{array}$ \\
\hline
\end{tabular}


Table IV Outcome physical activity level

\begin{tabular}{|c|c|c|c|c|}
\hline $\begin{array}{l}\text { First author of } \\
\text { paper }\end{array}$ & $\begin{array}{l}\text { Mean (SD) chronic fatigue } \\
\text { syndrome subjects (Unit of } \\
\text { measurement) }\end{array}$ & $\begin{array}{l}\text { Mean control subjects (SD) } \\
\text { (Unit of measurement) }\end{array}$ & Statistical difference & Conclusion \\
\hline Packer, 199438 & $\begin{array}{l}0.80(0.42) \\
(\% \text { MET level average day) }\end{array}$ & $\begin{array}{l}57.00 \text { (31.33) } \\
\text { (\% MET level average day) }\end{array}$ & $P=0.002$ & $\begin{array}{l}\text { CFS patients reported } \\
\text { significant less physical activity } \\
\text { for a typical day than healthy } \\
\text { control subjects }\end{array}$ \\
\hline Sisto, $1998^{29}$ & $\begin{array}{l}7.3(0.9) \\
\text { (Counts per min) }\end{array}$ & $\begin{array}{l}8.6(0.9) \\
\text { (Counts per min) }\end{array}$ & $\mathrm{P}<0.01$ & $\begin{array}{l}\text { Significant lower daily physical } \\
\text { activity in CFS patients } \\
\text { compared to controls }\end{array}$ \\
\hline Smith, $2006^{39}$ & $\begin{array}{l}3 \text { (interquartile range }=2-5 \text { ) } \\
(10 \text { point Likert scale) }\end{array}$ & $\begin{array}{l}8 \text { (interquartile } \\
\text { range }=6.5-8.5) \\
(10 \text { point Likert scale) }\end{array}$ & $\mathrm{P}<0.001$ & $\begin{array}{l}\text { CFS patients reported } \\
\text { significant less physical activity } \\
\text { on a weekly basis than healthy } \\
\text { controls }\end{array}$ \\
\hline Tryon, 200440 & $\begin{array}{l}159.25(4.51) \\
\text { (Counts per hour) }\end{array}$ & $\begin{array}{l}377.36 \text { ( } 113.75) \\
\text { (Counts per hour) }\end{array}$ & $\mathrm{P}<0.001$ & $\begin{array}{l}\text { Significant lower diurnal daily } \\
\text { physical activity in CFS patients } \\
\text { compared to controls }\end{array}$ \\
\hline $\begin{array}{l}\text { Van de Putte, } \\
2005^{44}\end{array}$ & $\begin{array}{l}2.3(3.3) \\
\text { (hours per week) }\end{array}$ & $\begin{array}{l}8.0(3.9) \\
\text { (hours per week) }\end{array}$ & $\mathrm{P}<0.05$ & $\begin{array}{l}\text { CFS patients reported } \\
\text { significant less physical activity } \\
\text { on a weekly basis than healthy } \\
\text { controls }\end{array}$ \\
\hline $\begin{array}{l}\text { Van der Werf, } \\
2000^{41} \\
\text { Part A }\end{array}$ & $\begin{array}{l}66(22) \\
\text { (Counts per } 5 \mathrm{~min})\end{array}$ & $\begin{array}{l}91(25) \\
\text { (Counts per } 5 \mathrm{~min})\end{array}$ & $\mathrm{P}<0.01$ & $\begin{array}{l}\text { Significant lower daily physical } \\
\text { activity in CFS patients } \\
\text { compared to controls }\end{array}$ \\
\hline
\end{tabular}




\begin{tabular}{|c|c|c|c|c|}
\hline $\begin{array}{l}\text { First author of } \\
\text { paper }\end{array}$ & $\begin{array}{l}\text { Mean (SD) chronic fatigue } \\
\text { syndrome subjects (Unit of } \\
\text { measurement) }\end{array}$ & $\begin{array}{l}\text { Mean control subjects (SD) } \\
\text { (Unit of measurement) }\end{array}$ & Statistical difference & Conclusion \\
\hline $\begin{array}{l}\text { Van der Werf, } \\
2000^{41} \\
\text { Part B }\end{array}$ & $\begin{array}{l}4.6(1.7) \\
(5 \text { point Likert scale) }\end{array}$ & $\begin{array}{l}6.1(2.4) \\
(5 \text { point Likert scale) }\end{array}$ & $P<0.01$ & $\begin{array}{l}\text { Significant lower reported daily } \\
\text { physical activity in CFS patients } \\
\text { compared to controls }\end{array}$ \\
\hline $\begin{array}{l}\text { Vercoulen, } 1997^{28} \\
\text { Part A }\end{array}$ & $\begin{array}{l}23.3(10.7) \\
\text { (Counts per } 5 \mathrm{~min})\end{array}$ & $\begin{array}{l}35.5(10.8) \\
\text { (Counts per } 5 \mathrm{~min})\end{array}$ & $\mathrm{P}<0.05$ & $\begin{array}{l}\text { Significant lower daily physical } \\
\text { activity in CFS patients } \\
\text { compared to controls }\end{array}$ \\
\hline $\begin{array}{l}\text { Vercoulen, } 1997^{28} \\
\text { Part B }\end{array}$ & $\begin{array}{l}3.8(1.3) \\
(7 \text { point Likert scale) }\end{array}$ & $\begin{array}{l}5.4(1.0) \\
(7 \text { point Likert scale) }\end{array}$ & $P<0.05$ & $\begin{array}{l}\text { Significant lower reported daily } \\
\text { physical activity in CFS patients } \\
\text { compared to controls }\end{array}$ \\
\hline $\begin{array}{l}\text { Vercoulen, } 1997^{28} \\
\text { Part C }\end{array}$ & $\begin{array}{l}2.1(0.4) \\
\text { (5-point Likert scale) }\end{array}$ & $\begin{array}{l}2.7(0.5) \\
(5-\text { point Likert scale) }\end{array}$ & $\mathrm{P}<0.05$ & $\begin{array}{l}\text { Significant lower reported daily } \\
\text { activities scores in CFS patients } \\
\text { compared to controls }\end{array}$ \\
\hline
\end{tabular}

CFS = chronic fatigue syndrome; FM = fibromyalgia 
Fourteen different measurement devices were used to measure physical activity levels and the reliability and validity of these devices are outlined in table V. Results about reliability and/or validity were obtained for seven measurement devices, for the other seven measurement devices no results were found. Four of the seven measurement devices for which information was available were evaluated as having good $(+)$ reliability and three with moderate $(+/-)$ reliability. In addition, two measurement devices were evaluated as having good (+) validity and four with moderate (+/-) validity. Judgements about reliability and validity purely concerned the devices used in the articles for measuring physical activity.

There was no relation between the reliability and validity of the measurement device used and the results about the physical activity level of chronic fatigue syndrome patients as compared to control subjects. However, it is striking that 11 outcome assessments (50\%) were performed by use of a measurement device of which the reliability and validity was unknown.

Those studies which found lower physical activity levels in chronic fatigue syndrome patients (table IV) were almost equally divided over the different methodological quality scores (table II) compared to studies reporting no differences in physical activity levels. As such, there is no relationship between the physical activity level in chronic fatigue syndrome patients as compared to control subjects, and the methodological quality.

Table V Reliability and validity of measurement device used"

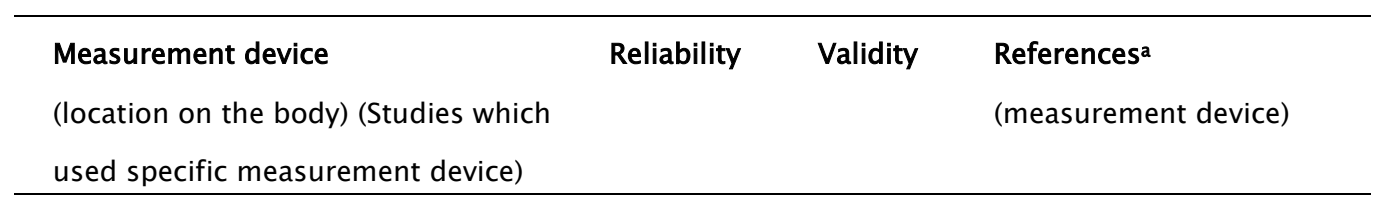

Objective methods

\begin{tabular}{|c|c|c|c|}
\hline Actometer, triaxial (ankle)28 3041 & $?$ & $?$ & 285960 \\
\hline CSA/MTI actigraphy, uniaxial (hip) 29 & +55 & +61 & 54556162 \\
\hline
\end{tabular}


Gaehwiler electronic activity

monitor, uniaxial (ankle) ${ }^{34}$

AMI actigraphy, triaxial (wrist) $3543 \quad+57$

Accelerometer, unspecified (thigh) 42 ?

Subjective methods

$\begin{array}{ll}+/-57 & 5765 \\ ? & \text { Unknown }\end{array}$

Godin questionnaire 32

College Alumnus Health

questionnaire 33

Baecke questionnaire ${ }^{36}$

Human Activity Profile - adjusted

activity score 3738

Chronic Fatigue Activity

questionnaire 39

Physical Activity questionnaire ${ }^{44}$

Physical Activity Rating Scale ${ }^{28}$

Visual Analogue Scale 34

Self Observation List 284

$$
+/-21
$$$$
+/-21
$$$$
+21
$$$$
+/-67
$$

$+/-21$

$+/-21$

21$$
\text { . }
$$$$
?
$$$$
\text { ? }
$$$$
+/-21
$$$$
21
$$$$
+68
$$

39

Unknown

28

Unknown

"This table reflects judgement made in studies testing reliability and/or validity of a specific measurement device for measuring physical activity levels.

a References with evaluations of reliability and validity

\section{Meta-analysis}

Of the ten studies using objective outcome assessments (by use of an accelerometer) seven studies 28-31 344041 could be pooled together and these results are shown in figure 2 . Three studies included in the meta-analysis did obtain physical activity levels from only a part of the total sample population in their study. 303440 The pooled mean ratio was 0.68 with a SD of 0.07 and a $95 \%$ 
confidence interval of $0.54-0.83$. Three studies were not included because of a mixed study population or missing SD and mean.354243 Six of the seven studies within the meta-analysis showed significantly lower physical activity levels in the chronic fatigue syndrome group as compared to the control group ( $p<0.05)$. Fry et al. ${ }^{34}$ was the only study with a non-significant lower physical activity level in the chronic fatigue syndrome group. The sample size of each study determines, indirectly, the weight of a study in the pooled mean. Van der Werf et al.41 and Vercoulen et al. 28 had, by far, the largest weight on the pooled mean because of their large sample size populations resulting in almost the same outcome as the pooled mean. 


\section{Daily Physical activity level}

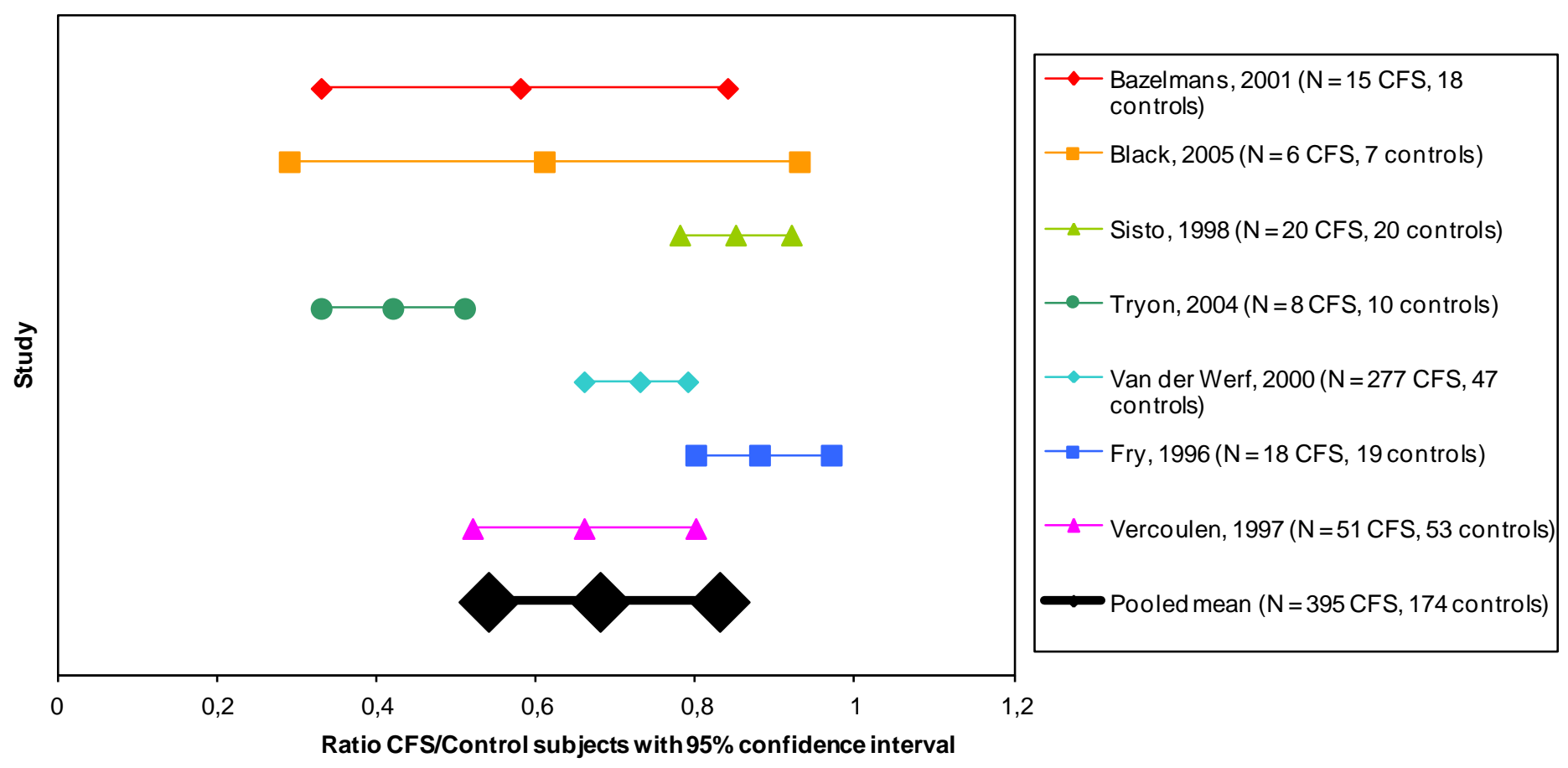

Figure 2 Meta-analysis of seven studies with objective outcome assessment 


\section{Coefficient of variation}

The coefficient of variation could be calculated in 14 of all included studies. In three studies the coefficient of variation could not be calculated because necessary parameters were missing. 394243 These 14 studies included 19 different outcome assessments for both the chronic fatigue syndrome and control groups (table VI). Nine outcome assessments (two studies with two outcome assessments) 2830323437 4144 showed a higher coefficient of variation in chronic fatigue syndrome groups; another nine outcome assessments28 2931 33-363841 showed an equal coefficient of variation in both groups; and only one outcome assessment 40 showed a lower coefficient of variation in the chronic fatigue syndrome group as compared to the control group. The pooled mean coefficient of variation in chronic fatigue syndrome patients was higher as compared to control subjects (chronic fatigue syndrome: mean 34.3\%, SD 4.5\%, 95\% confidence interval 25.5\%-43.1\%; Controls: mean 31.5\%, SD 3.1\%, 95\% confidence interval 25.4\%-37.5\%). However, this difference did not reach significance as the $95 \%$ confidence intervals of both mean coefficients of variations widely overlap each other. 
Table VI Coefficient of variation for CFS and control groups in nineteen different outcome assessments

\begin{tabular}{|c|c|c|c|}
\hline First author of paper & Measurement device & $\begin{array}{l}\text { Coefficient of } \\
\text { variation } \\
\text { CFS subjects }\end{array}$ & $\begin{array}{l}\text { Coefficient of } \\
\text { variation } \\
\text { Control } \\
\text { subjects }\end{array}$ \\
\hline Bazelmans et al, 2001 & Actometer & 46,7 & 25,1 \\
\hline Black et al, 2005 & CSI/MTI Actigraphy & 31,8 & 29,8 \\
\hline Cook et al, 2006 (CFS only) & Godin Q. & 120,8 & 59,7 \\
\hline Cook et al, 2006 (CFS + FM) & Godin Q. & 111,2 & 59,7 \\
\hline \multirow[t]{2}{*}{ Farquhar et al, 2002} & College Alumnus & & \\
\hline & Health Q. & 91,2 & 98,1 \\
\hline \multirow[t]{2}{*}{ Fry et al, 1996 Part A } & Gaehwiler & & \\
\hline & accelerometer & 11,7 & 12,6 \\
\hline \multirow[t]{2}{*}{ Fry et al, 1996 Part B } & Visual Analogue & & \\
\hline & Scale & 43,0 & 31,2 \\
\hline Gallagher et al, 2005a & Accelerometer & - & - \\
\hline Kop et al, 2005 & AMI Actigraphy & 25,4 & 28,8 \\
\hline Nagelkirk et al, 2003 & Baecke Q. & 32,0 & 28,8 \\
\hline Ohinata et al, 2008a & AMI Actigraphy & - & - \\
\hline Packer et al, 1997 & HAP & 268,6 & 55,0 \\
\hline Packer et al, 1994 & HAP & 52,5 & 55,0 \\
\hline Sisto et al, 1998 & CSI/MTI Actigraphy & 12,3 & 10,5 \\
\hline \multirow[t]{2}{*}{ Smith et al, 2006a } & Chronic Fatigeu & & \\
\hline & Activity Q. & - & - \\
\hline
\end{tabular}


Tryon et al, 2004

CSI/MTI Actigraphy

2,8

30,1

Van de Putte et al, 2005

Physical Activity Q.

143,5

48,8

Van der Werf et al, 2000

Actometer

Part A

33,3

27,5

Van der Werf et al, 2000

Self Observation

Part B

Score

37,0

39,3

Vercoulen et al. 1997

Actometer

Part A

45,9

30,4

Vercoulen et al. 1997

Self Observation

Part B

Score

34,2

18,5

Vercoulen et al. 1997

PARS

Part C

19,0

18,5

Mean (SD)

$34.3(4.5)$

$31.5(3.1)$

CFS = chronic fatigue syndrome

a Coefficient of variation could not be calculated because necessary parameters were missing 


\section{Discussion}

The main finding of this systematic review is that chronic fatigue syndrome patients seem to be less physically active in comparison with asymptomatic controls. Seventeen studies were included containing 22 different comparisons on the physical activity level between chronic fatigue syndrome patients and control subjects. Fourteen studies, including 18 comparisons, showed significantly lower physical activity levels in patients with chronic fatigue syndrome compared to control subjects, whereas four studies, including four comparisons, did not show differences between groups. One study obtained both significant and nonsignificant results when two different outcome assessments were used. ${ }^{34}$ The result of the meta-analysis indicates that the daily physical activity level in chronic fatigue syndrome patients is reduced in comparison with asymptomatic controls. The results found in the studies reviewed could be biased through weaknesses in the methodological quality. However, only four studies were judged as having a low overall score in the methodological quality and no relation was found between methodological quality and outcome of results. The descriptive characteristics and statistics were described quite well with only one study having a low score for the statistics, but the internal validity differed considerably between studies with seven studies having a low score. An important issue within the internal validity is the reliability and validity of the measurement device used for measuring the physical activity level. However, reliability and validity reports were available from only seven of the 14 different measurement devices used in the studies reviewed. No relation could be observed between the physical activity level of chronic fatigue syndrome patients and reliability and validity of the measurement device used.

This systematic review has accomplished a complete overview of the existing literature about the physical activity level of chronic fatigue syndrome patients as compared to asymptomatic controls, as much as possible, by its methodological preciseness. Nevertheless, some limitations of the review should be mentioned. In spite of the extensive literature search, omission of important studies and the presence of publication bias cannot be ruled out. Studies which found significant differences in the physical activity level between CFS patients and control subjects 
could have more chance to be published than studies without significant differences leading to publication bias. Furthermore, the large diversity of measurement devices used to measure physical activity levels limits the precision of the overall results. This also restricts the meta-analysis, as data was only pooled from seven studies. Moreover, the reliability and validity of some outcome assessments that were used are unknown limiting the interpretation of the results. The assessment of the methodological quality of observational studies was based on a part of the Cochrane criteria list with two items added from Ross et al. 1920 The Cochrane criteria list was developed for randomized controlled trials and not for observational studies. The use of quality assessment tools to appraise observational studies is less well established than for randomized controlled trials. We believe that the items we assessed are the most important in the assessment of the methodological quality of observational studies.

This is the first review oriented specifically towards the daily physical activity level in chronic fatigue syndrome. Existing literature about this topic does support our finding of low daily physical activity levels in chronic fatigue syndrome. ${ }^{18}$ While van Weering et al. found inconclusive results for the chronic pain and fatigue patients in general, the chronic fatigue syndrome as a subgroup did show lower physical activity levels as compared to asymptomatic controls. 18

The meta-analysis reflected an average daily physical activity level in chronic fatigue syndrome patients of only $68 \%$ of the physical activity level observed in control subjects. Six of the seven studies in the meta-analysis did show significantly lower daily physical activity levels in chronic fatigue syndrome subjects. Fry et al. ${ }^{34}$ was the only study in the meta-analysis with no significant difference between the chronic fatigue syndrome and control group. A possible explanation for this was the inclusion of only adolescents in their study, while the other studies included subjects with an average age between 30 and 50 years. Another explanation could be their short period of outcome measurement of only three days. Sisto et al. ${ }^{29}$ showed a relatively small difference in the daily physical activity level between the chronic fatigue syndrome and control groups. However, inclusion was specifically oriented towards less physically active control subjects and probably more active chronic fatigue syndrome patients, as only chronic 
fatigue syndrome patients with chronic fatigue syndrome less than 6 years and healthy subjects who exercised no more than once a week were included. Tryon et al. 40 showed a relatively large difference in the physical activity level between both groups. In their recruitment procedure, only a detailed description of the inclusion of chronic fatigue syndrome patients was given and less was known about the control group. Furthermore, they included a small sample size of which reliable datasets about daily physical activity levels were obtained from only six chronic fatigue syndrome patients and ten control subjects.

The coefficient of variation was measured to get more insight into the variability between subjects within the chronic fatigue syndrome and control group. The mean coefficient of variation showed more heterogeneity within the chronic fatigue syndrome group than the control group (34.3\% vs. $31.5 \%$ ) but the $95 \%$ confidence intervals widely overlap each other. Significant more heterogeneity in the physical activity level was expected between chronic fatigue syndrome patients as compared to controls because different activity patterns in chronic fatigue syndrome patients were reported indicating large differences in the physical activity levels between chronic fatigue syndrome patients. 41

In the course of the systematic review a closer look was taken towards the objective and subjective outcome assessments. Subjective outcome assessments resulted more often (92\%) in statistical significant lower physical activity levels in chronic fatigue syndrome patients, as compared to objective outcome assessments (70\%). Differences between outcome assessments could explain differences in outcome results, and might bias comparisons made between different outcome assessments. A first explanation could be that subjective outcome assessments result more often in significant lower physical activity levels due to misperception of physical activity levels in chronic fatigue syndrome subjects. ${ }^{18} \mathrm{~A}$ second shortcoming could be the length of measurement period in objective outcome assessments. It is remarkable that the three objective outcome assessments without statistical lower physical activity levels in chronic fatigue syndrome patients used the shortest measurement periods for determining daily physical activity levels (1, 3 and 5 days, respectively). The other studies using objective outcome assessments used at least seven days and all these studies obtained significant differences between chronic fatigue 
syndrome and control subjects. Subjects might be more aware of their physical activity level and behave more accordingly to the aim of the study during the first days of monitoring than after a couple of days. 4546 Measurement periods of at least seven days seem necessary to represent normal daily life. 1847

Subjective instruments may be biased in chronic fatigue syndrome patients by cognitions concerning illness and disability. 2841 Misperception of the physical activity level could magnify the feeling of ill health and possibly having a maintaining role in the course of the disorder. ${ }^{34}$ Such misperceptions can be controlled for by using subjective and objective outcome assessments simultaneously. This gives insight in patient's discrepancies; exploring between what they think they do and what they really do. In only three studies both objective and subjective outcome assessments were used.28 3441 Fry et al. 34 found a discrepancy between objective and subjective outcome assessments. Adolescent chronic fatigue syndrome patients as well as their parents reported reduced physical activity levels in comparison with control subjects while objective monitoring of the physical activity level did not reveal significant differences between the chronic fatigue syndrome and control group. ${ }^{34}$ The other two studies found low correlations between objective and subjective measures in chronic fatigue syndrome patients indicating discrepancies. 2841 More insight in this is important as improving awareness is a first important step in reaching behavioural changes, as aimed for in cognitive behavioural therapy. 48 It is important to break through the negative vicious circle of inadequate low physical activity levels in the chronic fatigue syndrome.15 In general, the risk for development of chronic diseases is increased when the physical activity level is inadequate low. Physical activity is often recommended as secondary prevention against chronic diseases and prescribed as therapeutic medicine. ${ }^{49-51}$ However, in order to treat inadequate low physical activity levels effectively in the chronic fatigue syndrome we need to know why patients with the chronic fatigue syndrome are less physically active. Van Houdenhove et al. 52 proposed reduced 'effort tolerance' as the primary disturbance in chronic fatigue syndrome resulting in low motor performance. Treating low 'effort tolerance' and low 'effort capacity' might be helpful in increasing physical activity levels and break through the negative 
vicious circle. Furthermore, we need to know how chronic fatigue syndrome patients have to increase their physical activity patterns to come to healthy patterns. This can be achieved with more knowledge about the physical activity pattern of chronic fatigue syndrome patients. Two studies included in this review studying physical activity patterns reported less intense and shorter activity peaks, less time spent in high level activities and longer average rest periods after peaks in chronic fatigue syndrome subjects as compared to control subjects. 3541 These differences could indicate disturbances in daily physical activity patterns in chronic fatigue syndrome patients, and targeting these disturbances might improve their physical activity patterns and decline their health complaints. In graded exercise therapy different therapeutic approaches are outlined specified to different fitness levels between chronic fatigue syndrome patients. 53 Differences in daily physical activity levels between chronic fatigue syndrome patients might also be of importance in determining more individualized treatment protocols and contributing to the optimization of treatment procedures like cognitive behavioural therapy and graded exercise therapy. However, more insight is needed in inadequate physical activity patterns in the chronic fatigue syndrome and the relation with symptoms and cognitions.

\section{Clinical Messages}

- Chronic fatigue syndrome patients appear to be less physically active in comparison with asymptomatic controls

- No differences in variation of physical activity levels were found between chronic fatigue syndrome patients and asymptomatic controls

\section{Acknowledgments}

This work is part of the ZonMw project 'chronisch vermoeidheidssyndroom' 
(http://www.zonmw.nl/nl/onderwerpen/alle-programma-s/cvs/gehonoreerdonderzoek/).

Competing interest and sources of funding

None declared.

\section{Contributors}

RE: Conception and design, analysis of the data, writing and editing of the manuscript (guarantor). MvW: Assessing methodological quality of included studies, editing the manuscript. KG: Statistician; analysis of the meta-analysis and coefficient of variation. MV: Initiating the study, conception and design, monitoring progress and editing of the manuscript. 


\section{References}

1. Reid S, Chalder T, Cleare A, Hotopf M, Wessely S. Chronic fatigue syndrome. BMJ Clin Evid 2005; 12(14):1101-18.

2. Afari N, Buchwald D. Chronic fatigue syndrome: a review. Am J Psychiatry 2003; 160(2):221-36.

3. Fukuda K, Straus SE, Hickie I, Sharpe MC, Dobbins JG, Komaroff A. The chronic fatigue syndrome: a comprehensive approach to its definition and study. International Chronic Fatigue Syndrome Study Group. Ann Intern Med 1994; $121(12): 953-9$.

4. Holmes GP, Kaplan JE, Gantz NM et al. Chronic fatigue syndrome: a working case definition. Ann Intern Med 1988; 108(3):387-9.

5. Lloyd AR, Hickie I, Boughton CR, Spencer O, Wakefield D. Prevalence of chronic fatigue syndrome in an Australian population. Med J Aust 1990; 153(9):522-8.

6. Sharpe MC, Archard LC, Banatvala JE et al. A report--chronic fatigue syndrome: guidelines for research. J R Soc Med 1991; 84(2):118-21.

7. Carruthers BM , Jain AK, De Meirleir KL et al. Myalgic Encephalomyelitis/Chronic Fatigue Syndrome: Clinical Working Case Definition, Diagnostic and Treatment Protocols. Journal of Chronic Fatigue Syndrome 2003; 11(1):7-116.

8. Wyller VB. The chronic fatigue syndrome--an update. Acta Neurol Scand Suppl 2007; 187:7-14.

9. Kim CH, Shin HC, Won CW. Prevalence of chronic fatigue and chronic fatigue syndrome in Korea: community-based primary care study. Journal of Korean Medical Science 2005 Vol:20 Iss:4 Pg:529 -34 2005; 20(4):529-34.

10. Reyes M, Nisenbaum R, Hoaglin DC et al. Prevalence and incidence of chronic fatigue syndrome in Wichita, Kansas. Arch Intern Med 2003; 163(13):1530-6.

11. Wessely S, Chalder T, Hirsch S, Wallace P, Wright D. The prevalence and morbidity of chronic fatigue and chronic fatigue syndrome: a prospective primary care study. Am J Public Health 1997; 87(9):1449-55. 
12. Jason LA, Richman JA, Rademaker AW et al. A community-based study of chronic fatigue syndrome. Arch Intern Med 1999; 159(18):2129-37.

13. Armstrong $\mathrm{T}$, Bauman A, Bull $\mathrm{F}$ et al. A guide for population-based approaches to increasing levels of physical activity. Implementation of the WHO global strategy on diet, physical activity and health. 2007.

14. Philips HC. Avoidance behaviour and its role in sustaining chronic pain. Behav Res Ther 1987; 25(4):273-9.

15. Surawy C, Hackmann A, Hawton K, Sharpe M. Chronic fatigue syndrome: a cognitive approach. Behav Res Ther 1995; 33(5):535-44.

16. Wessely S, David A, Butler S, Chalder T. Management of chronic (post-viral) fatigue syndrome. J R Coll Gen Pract 1989; 39(318):26-9.

17. Rimes KA, Chalder T. Treatments for chronic fatigue syndrome. Occup Med 2005; 55(1):32-9.

18. Van Weering M, Vollenbroek-Hutten MM, Kotte EM, Hermens HJ. Daily physical activities of patients with chronic pain or fatigue versus asymptomatic controls. A systematic review. Clin Rehabil 2007 Nov; 21(11):1007-23.

19. Van Tulder MW, Assendelft WJJ, Koes BW, Bouter LM. Method Guidelines for Systematic Reviews in the Cochrane Collaboration Back Review Group for Spinal Disorders. Spine 1997; 22(20):2323-30.

20. Ross SD, Levine C, Ganz N et al. Systematic review of the current literature related to disability and chronic fatigue syndrome. Evid Rep Technol Assess 2002; (66): 1-3.

21. Jacobs DR Jr, Ainsworth BE, Hartman TJ, Leon AS. A simultaneous evaluation of 10 commonly used physical activity questionnaires. Med Sci Sports Exerc 1993; 25(1):81-91.

22. Berger MPF, Imbos Tj, Janssen MPE. Methodologie en statistiek. 2 edition. Maastricht: Datawyse/Universiteit Pers Maastricht, 2000.

23. Moher D, Cook DJ, Eastwood S, Olkin I, Rennie D, Stroup DF. Improving the quality of reports of meta-analyses of randomised controlled trials: the QUOROM statement. Quality of Reporting of Meta-analyses. Lancet 1999; 354(9193): 1896-900. 
24. Friedrich JO, Adhikari NK, Beyene J. The ratio of means method as an alternative to mean differences for analyzing continuous outcome variables in meta-analysis: a simulation study. BMC Med Res Methodol 2008; 8:32.

25. Armitage P, Berry G, Matthews JNS. Statistical Methods in Medical Research. Blackwell Science, 2002.

26. Sutton AJ, Abrams KR, Jones DR, Sheldon TA, Song F. Methods for MetaAnalysis in Medical Research. Chichester, England: John Wiley \& Sons Ltd, 2002.

27. Miller GE. Asymptotic test statistics for coefficients of variation. Communications in Statistics - Theory and Methods 1991; 20(10):3351-63.

28. Vercoulen JH, Bazelmans E, Swanink CM et al. Physical activity in chronic fatigue syndrome: assessment and its role in fatigue. J Psychiatr Res 1997; 31(6):661-73.

29. Sisto SA, Tapp WN, LaManca JJ et al. Physical activity before and after exercise in women with chronic fatigue syndrome. QJM 1998; 91(7):465-73.

30. Bazelmans E, Bleijenberg G, Van Der Meer JW, Folgering H. Is physical deconditioning a perpetuating factor in chronic fatigue syndrome? A controlled study on maximal exercise performance and relations with fatigue, impairment and physical activity. Psychol Med 2001; 31(1):107-14.

31. Black CD, O'connor PJ, McCully KK. Increased daily physical activity and fatigue symptoms in chronic fatigue syndrome. Dyn Med 2005; 4(1):3.

32. Cook DB, Nagelkirk PR, Poluri A, Mores J, Natelson BH. The influence of aerobic fitness and fibromyalgia on cardiorespiratory and perceptual responses to exercise in patients with chronic fatigue syndrome. Arthritis Rheum 2006; 54(10):3351-62.

33. Farquhar WB, Hunt BE, Taylor JA, Darling SE, Freeman R. Blood volume and its relation to peak $\mathrm{O}(2)$ consumption and physical activity in patients with chronic fatigue. Am J Physiol Heart Circ Physiol 2002; 282(1):H66 -H71.

34. Fry AM, Martin M. Cognitive idiosyncrasies among children with the chronic fatigue syndrome: anomalies in self-reported activity levels. J Psychosom Res 1996; 41 (3):213-23. 
35. Kop WJ, Lyden A, Berlin AA et al. Ambulatory monitoring of physical activity and symptoms in fibromyalgia and chronic fatigue syndrome. Arthritis Rheum 2005; 52(1):296-303.

36. Nagelkirk PR, Cook DB, Peckerman A et al. Aerobic capacity of Gulf War veterans with chronic fatigue syndrome. Mil Med 2003; 168(9):750-5.

37. Packer TL, Foster DM, Brouwer B. Fatigue and activity patterns of people with chronic fatigue syndrome. Occupational Therapy Journal of Research 1997; 17(3):186-99.

38. Packer TL, Sauriol A, Brouwer B. Fatigue secondary to chronic illness: postpolio syndrome, chronic fatigue syndrome, and multiple sclerosis. Arch Phys Med Rehabil 1994; 75(10):1122-6.

39. Smith WR, White PD, Buchwald D. A case control study of premorbid and currently reported physical activity levels in chronic fatigue syndrome. BMC Psychiatry 2006; 6:53.

40. Tryon WW, Jason L, Frankenberry E, Torres-Harding S. Chronic fatigue syndrome impairs circadian rhythm of activity level. Physiol Behav 2004; 82(5):849-53.

41. Van der Werf SP, Prins JB, Vercoulen JH, van der Meer JW, Bleijenberg G. Identifying physical activity patterns in chronic fatigue syndrome using actigraphic assessment. J Psychosom Res 2000; 49(5):373-9.

42. Gallagher AM, Coldrick AR, Hedge B, Weir WR, White PD. Is the chronic fatigue syndrome an exercise phobia? A case control study. J Psychosom Res 2005; $58(4): 367-73$

43. Ohinata J, Suzuki N, Araki A, Takahashi S, Fujieda K, Tanaka H. Actigraphic assessment of sleep disorders in children with chronic fatigue syndrome. Brain Dev 2008; 30(5):329-33.

44. Van de Putte EM, Uiterwaal CS, Bots ML, Kuis W, Kimpen JL, Engelbert RH. Is chronic fatigue syndrome a connective tissue disorder? A cross-sectional study in adolescents. Pediatrics 2005; 115(4):e415-22.

45. van Sluijs EM, van Poppel MN, Twisk JW, van Mechelen W. Physical activity measurements affected participants' behavior in a randomized controlled trial. J Clin Epidemiol 2006; 59(4):404-11. 
46. Rooney B, Smalley K, Larson J, Havens S. Is knowing enough? Increasing physical activity by wearing a pedometer. WMJ 2003; 102(4):31-6.

47. Matthews CE, Ainsworth BE, Thompson RW, Bassett DR Jr. Sources of variance in daily physical activity levels as measured by an accelerometer. Med Sci Sports Exerc 2002; 34(8):1376-81.

48. Ronda G, Van Assema P, Brug J. Stages of change, psychological factors and awareness of physical activity levels in The Netherlands. Health Promot Int $2001 ; 16(4): 305-14$.

49. Pedersen BK, Saltin B. Evidence for prescribing exercise as therapy in chronic disease. Scand J Med Sci Sports 2006; 16 Suppl 1:3-63.

50. Karmisholt K, Gotzsche PC. Physical activity for secondary prevention of disease. Systematic reviews of randomised clinical trials. Dan Med Bull 2005; 52(2):90-4.

51. Durstine JL, Painter P, Franklin BA, Morgan D, Pitetti KH, Roberts SO. Physical activity for the chronically ill and disabled. Sports Med 2000; 30(3):207-19.

52. Van Houdenhove B, Verheyen L, Pardaens K, Luyten P, Van Wambeke P. Rehabilitation of decreased motor performance in patients with chronic fatigue syndrome: should we treat low effort capacity or reduced effort tolerance? Clin Rehabil 2007; 21(12):1121-42.

53. Pardaens K, Haagdorens L, Van Wambeke P, Van Den Broeck A, Van Houdenhove B. How relevant are exercise capacity measures for evaluating treatment effects in chronic fatigue syndrome? Results from a prospective, multidisciplinary outcome study. Clin Rehabil 2006; 20(1):55-66.

54. Freedson PS, Melanson E, Sirard J. Calibration of the Computer Science and Applications, Inc. Accelerometer. Medicine and Science in Sports and Exercise 1998; 30(5):777-81.

55. Tryon WW, Williams R. Fully Proportional Actigraphy: a New Instrument. Behavior Research Methods Instruments \& Computers 1996; 28(3):392-403.

56. Lee IM, Paffenbarger RS Jr. Associations of light, moderate, and vigorous intensity physical activity with longevity. The Harvard Alumni Health Study. Am J Epidemiol 2000; 151 (3):293-9. 
57. Patterson SM, Krantz DS, Montgomery LC, Deuster PA, Hedges SM, Nebel LE. Automated Physical-Activity Monitoring - Validation and Comparison With Physiological and Self-Report Measures. Psychophysiology 1993; 30(3):296305.

58. Baecke JA, Burema J, Frijters JE. A short questionnaire for the measurement of habitual physical activity in epidemiological studies. Am J Clin Nutr 1982; 36(5):936-42.

59. Morrell EM, Keefe FJ. The actometer: an evaluation of instrument applicability for chronic pain patients. Pain 1988; 32(3):265-70.

60. Tryon WW. Activity measurement in psychology and medicine. New York : Plenum Press, 1991.

61. Melanson EL Jr, Freedson PS. Validity of the Computer Science and Applications, Inc. (CSA) activity monitor. Med Sci Sports Exerc 1995; 27(6):934-40.

62. Janz KF. Validation of the Csa Accelerometer for Assessing Childrens Physical-Activity. Medicine and Science in Sports and Exercise 1994; 26(3):369-75.

63. Pollak CP, Stokes PE, Wagner DR. Direct comparison of two widely used activity recorders. Sleep 1998; 21(2):207-12.

64. Singh S, Morgan MD. Activity monitors can detect brisk walking in patients with chronic obstructive pulmonary disease. J Cardiopulm Rehabil 2001; $21(3): 143-8$.

65. Puyau MR, Adolph AL, Vohra FA, Butte NF. Validation and Calibration of Physical Activity Monitors in Children. Obesity Research 2002; 10(3):150-7.

66. Godin G, Shephard RJ. A simple method to assess exercise behavior in the community. Can J Appl Sport Sci 1985; 10(3):141-6.

67. Davidson M, de Morton N. A systematic review of the Human Activity Profile. Clin Rehabil 2007; 21(2):151-62.

68. Daughton DM, Fix AJ, Kass I, Bell CW, Patil KD. Maximum oxygen consumption and the ADAPT quality-of-life scale. Arch Phys Med Rehabil 1982; 63(12):620-2. 
Appendix 1: Electronic search strategy and results

\begin{tabular}{|c|c|c|}
\hline $\begin{array}{l}\text { Electronic } \\
\text { database }\end{array}$ & Search method & $\begin{array}{l}\text { Results } \\
\text { number of } \\
\text { items }\end{array}$ \\
\hline Pubmed & $\begin{array}{l}\text { (((daily activity[TW]\$) OR (activities of daily living) OR } \\
\text { (accelerometer) OR (accelerometer*) OR (actometer) OR } \\
\text { (actometer*) OR (actigraphy)) OR (monitoring[ALL]) OR } \\
\text { (physical activity)) AND ((chronic fatigue syndrome) OR } \\
\text { (myalgic encephalomyelitis) OR (myalgic } \\
\text { encephalopathy) OR (chronic fatigue syndrom*)) }\end{array}$ & 389 \\
\hline Web of Science & $\begin{array}{l}\text { Topic }=(\text { chronic fatigue syndrome) } \text { AND Topic=(physical } \\
\text { activity) } \\
\text { Databases=SCI-EXPANDED, SSCI, A\&HCI Timespan=All } \\
\text { Years }\end{array}$ & 213 \\
\hline Embase & $\begin{array}{l}\text { (((daily AND activity) OR (activities AND of AND daily } \\
\text { AND living) OR ('accelerometer'/exp) OR } \\
\text { (accelerometer*) OR (actometer) OR (actometer*) OR } \\
\text { ('actigraphy'/exp)) OR ('monitoring'/exp) OR (physical } \\
\text { AND activity)) AND ((chronic AND 'fatigue'/exp AND } \\
\text { 'syndrome'/exp) OR (myalgic AND } \\
\text { 'encephalomyelitis'/exp) OR (myalgic AND } \\
\text { 'encephalopathy'/exp) OR (chronic AND 'fatigue'/exp } \\
\text { AND syndrom*)) AND [humans]/lim }\end{array}$ & 2611 \\
\hline \multirow[t]{2}{*}{ Psycinfo } & $\begin{array}{l}\text { MJ Chronic fatigue syndrome and AB Physical activity } \\
\text { Search modes - Boolean/Phrase }\end{array}$ & 32 \\
\hline & $\begin{array}{l}\text { ((DE "Activities of Daily Living" or DE "Activity Level") or } \\
\text { (DE "Physical Activity")) and (DE "Chronic Fatigue } \\
\text { Syndrome") } \\
\text { Search modes - Boolean/Phrase }\end{array}$ & 34 \\
\hline
\end{tabular}


Appendix 2: Operationalisation of the criteria list for methodological quality assessment

\section{Descriptive characteristics}

1. Description of the population from which subjects are included: general population, primary care, etc. In- or exclusion of chronic fatigue syndrome patients with psychological co-morbidity.

2. To receive a 'yes' groups must be similar at baseline regarding age, duration of complaints, percentage and value of main outcome measure(s).

3. Definition of chronic fatigue syndrome according to the CDC 1988, CDC 1994, Oxford criteria, or the Australian criteria.

4. Full time or part time at work, reason why chronic fatigue syndrome patients do not work at all.

5. Adequate description of type, modality, application technique and duration of the outcome assessment.

\section{Internal validity}

6. Determining when the compliance to the primary outcome measure is acceptable, based on the reported number of days for measuring daily physical activity.

7. Determining whether the assessment methods were reliable and valid for measuring daily physical activity.

8. Participants included in the study but who did not complete the observation period or were not included in the analysis must be described. If the percentage of withdrawals and drop-outs does not exceed $20 \%$ (short-term follow up), and does not lead to substantial bias, a 'yes' is scored.

9. Timing of outcome assessment should be identical for all intervention groups and for all important outcome assessments.

\section{Statistics}

10. To be presented for each group for the most important outcome assessments; NB, this means that there is no pre-set cut-off point to determine whether the sample size is sufficient. 
11. Both point estimates and measures of variability should be presented (to be scored for each important outcome parameter separately). Point estimates are: means, modes, etc. Measures of variability are: standard deviation, 95\% confidence intervals, etc. 


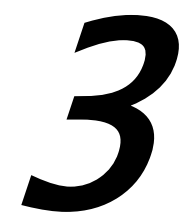

Deviations in daily physical activity patterns in patients with the chronic fatigue syndrome: a case control study

Evering RMH, Tonis TM, Vollenbroek-Hutten MMR. Deviations in daily physical activity patterns in patients with the chronic fatigue syndrome: A case control study. J Psychosom Res. 2011 Sep; 71 (3): 129-35. 


\section{Abstract}

Objectives: Deviations in daily physical activity patterns may play an important role in the development and maintenance of fatigue in the chronic fatigue syndrome (CFS). The aim of this study is to gain insight into the objective daily physical activity pattern of patients with CFS in comparison with healthy controls. The secondary objective is studying the awareness in performing physical activities.

Methods: The objective daily physical activity pattern was measured with a tri-axial accelerometer in 35 patients with CFS and in 35 age- and gender-matched healthy controls. The objective daily physical activity level and distribution of physical activities at low, medium and high intensity levels during the day were measured. Moreover, variability in performing physical activities within and between subjects was computed. Subjective ratings of self-reported daily physical activity levels were assessed at a visual analogue scale.

Results: CFS patients were significantly less physically active in the afternoon and evening, and spent fewer activities at high intensity levels and more at low intensity levels. Moreover, CFS patients showed more variability in their own physical activity pattern during the afternoon. The heterogeneity in the physical activity pattern between subjects within the CFS and control group did not differ. Finally, CFS patients were more aware about their daily physical activity level than healthy controls.

Conclusion: CFS patients showed deviations in the objectively measured daily physical activity pattern. Future research should elucidate the relation between impaired balances in daily physical activity patterns and fatigue severity in CFS. 


\section{Introduction}

It is generally believed that physical activity has important health benefits, and that physical inactivity is a key risk factor for chronic diseases. 1101928 Chronic fatigue syndrome (CFS) is a chronic disease accompanied with low levels of physical activity. 113644 CFS is characterized by severe, disabling chronic fatigue lasting for at least six months. Other symptoms can include musculoskeletal pain, sleep disturbance, impaired concentration, and headaches. 29 Wessely et al. (1989) constructed a model with inactivity as a key factor for the development of CFS. 48 In this model, CFS starts with an acute illness accompanied by a period of inactivity. This is followed by experiencing fatigue after exertion resulting in further avoidance of activity. At the same time there is a loss of tolerance to everyday activity owing to a decreased fitness level. In the end, symptoms develop at increasingly lower levels of exercise, and activities previously undertaken become more difficult. As such, the model reflects a negative vicious circle. 48 Non-acceptance and demanding cognitions might cause bursts of activities attempting to perform at pre-morbid levels, resulting in exacerbation of CFS symptoms followed by a return of inactivity. 34 In line with the constructed model for the development of CFS, several studies have shown that CFS patients are less physically active.112034 36 However, contradictory results have been found about decreased physical fitness and deconditioning in CFS.2 7-9 121316172425273032333747 In addition much heterogeneity exists in physical activity levels and functional capacity levels between CFS patients indicating that there might also be some patients that have comparable or even higher physical activity levels compared to healthy controls. 3642 It is also shown that CFS patients perform less intensive physical activities, reported shorter activity peaks in time and duration, and longer rest periods after peaks as compared to healthy controls. 2036 Moreover, less complexity in physical activity patterns were observed in CFS patients. ${ }^{6}$ Based on this knowledge a focus on physical activities is a key aspect in treatment and considered very essential in learning the patient to deploy a regular and balanced daily activity pattern. However, looking at the knowledge reported above then still very little is known about how the physical activity pattern of CFS 
patients over the day looks like, making it difficult to exactly define where to focus on in treatment. In contrast for chronic low back pain patients an unbalanced activity pattern has been found that is represented by a decreased activity level in the afternoon and evening with respect to the morning and this might also be the case in CFS. 41

In addition to balancing of activities over the day, awareness concerning activities is considered important. Several studies indicate that subjects often misinterpret their own physical activity level.22 31 Misperception and a negative self perception in the physical activity level in CFS patients may cause a distorted physical activity pattern and possibly have a maintaining role in the course of the disorder. 1114 Moreover, to improve physical activity behaviour awareness about inadequate physical activity behaviour seems to be an important aspect. 3138 As such the objective of this study is to gain insight into the objective physical activity pattern during the whole day of CFS patients in comparison with healthy controls as well as to study the awareness of CFS patients in performing physical activities. 


\section{Methods}

\section{Participants}

Experiments were approved at the accredited Medical Research Ethics Committee of the hospital 'Medisch Spectrum Twente' in Enschede, The Netherlands. CFS Participants were recruited from the Roessingh Rehabilitation Centre in Enschede, The Netherlands, or responded to an article published in a local newspaper and flyers spread around to general practitioners in the eastern part of The Netherlands. Diagnosis of CFS by a general practitioner or a physician was required for inclusion, following the criteria for CFS of the Centres for Disease Control and Prevention of 1994.15 Other inclusion/exclusion criteria for CFS patients were: (1) fatigue as primary complaint (2) aged between 18 and 65 years; (3) no structural pathology explaining the fatigue complaints; (4) not yet in treatment with clinical intake; (5) not bounded to a wheelchair; (6) not being pregnant. Control subjects were apparently healthy, other inclusion/exclusion criteria for healthy control subjects were: (1) aged between 18 and 65 years; (2) not bounded to a wheelchair; (3) not being pregnant.

Control subjects were recruited by means of advertising in the eastern part of the Netherlands. Care was taken to match the two groups in terms of age and gender, to avoid differences between groups. The body mass index (BMI) was assessed in the control group as an indicator of body composition.

\section{Study design and outcome measures}

A cross-sectional study was performed, and measurements were performed between November 2008 and February 2010. Participants were instructed about measurement procedures one day before the start of measuring objective and subjective daily physical activities. Fatigue severity at baseline, duration of CFS complaints and work status were obtained for the CFS participants. Fatigue severity was measured with the Checklist Individual Strength (CIS). The CIS consists of 20 items with a total score, and scoring on 4 subscales; 'subjective experience of fatigue', 'concentration', 'motivation' and 'physical activity level'. 46 Work status was assessed with a questionnaire asking for current employment status, mean amount 
of hours a week employed, employment status in combination with invalidity benefits and sick leave, and current unpaid activities in daily live.

Daily physical activities were objectively measured with the $\mathrm{mtx}-\mathrm{w}$ sensor, a triaxial piezoelectric accelerometer (XSens; The Netherlands) which measured accelerations in the anteroposterior, mediolateral and longitudinal axes of the trunk. The acceleration (sampled with a frequency of $100 \mathrm{~Hz}$ ) was bandpass filtered with a 4th order butterworth filter with cut-off frequencies of 0.11 and $20 \mathrm{~Hz}$. The absolute value of the acceleration was integrated over time periods of 60 seconds and thereafter summed over the three axes. 13 The tri-axial accelerometer was worn at the waist and data was transmitted through Bluetooth connection to a PDA on which data was stored. The resulting measure of physical activity was expressed as mean acceleration per minute. ${ }^{4}$ Oral and written instructions were provided regarding proper accelerometer placement, wearing schedule and user instructions of the accelerometer and PDA. Participants wore the activity monitor as much as possible for seven consecutive days during daytime between 8.00 and 22.00 , excluding time spent bathing or participating in water activities. Measurements were performed in the daily environment of the participant and they were instructed to continue their daily activities. All measurements were performed before the patients started their rehabilitation programs and therefore no interference with treatment occurred.

Subjective rating of daily physical activities was performed in the evening for every measurement day. Subjects rated their daily physical activity level on a visual analogue scale between 0 'not active' till 10 'maximal active'.

\section{Data analysis}

Data files contained the data obtained from the subject consisting of activity data per minute for all minutes the accelerometer was worn. Three days per subject with at least 420 minutes per day was set as minimum to include the subject in the data analysis. The inclusion criterion was set at a minimum number of three measurement days and this was considered sufficient as a comparison with seven measurement days with an independent t-test pointed out that no statistical significant differences exist in the mean physical activity pattern. An algorithm was 
written using Matlab to allow calculation of: mean objective activity level per day, per hour and per quarter of an hour; variability within subjects; variability between subjects.

\section{Physical activity pattern}

The objectively measured physical activity pattern of each group was evaluated by calculating the mean and standard error of the mean (SEM) per hour between 8.00 and 22.00. Furthermore, the mean per hour was used for calculating the mean per day part; morning (8.00 - 12.00), afternoon (12.00 - 18.00) and evening (18.00 22.00). A minimum was set at 30 minutes for each hour with measurement data for inclusion in the data analysis.

\section{Activity intensity}

The objectively measured activity level per hour expressed in mean acceleration per minute was classified into three categories; high (>1150), moderate (between 900 and 1150), or low (<900). The classification of these levels relied on a validation study performed with a tri-axial accelerometer with the same algorithm as the accelerometer used in this study and also worn at the waist. ${ }^{4}$ The number of hours in each category as percentage of the total number of hours in the three categories together was calculated for each group.

\section{Variability within subjects}

Per subject the objectively measured physical activity level per quarter of an hour was measured for several days, and variability between days (per subject) was calculated. To include data points: 1) each quarter of an hour had to be measured for at least two days at the same time point; 2) for measuring a quarter of an hour, a minimum was set at 8 minutes. Subsequently, the variability in the performance of physical activities within subjects for each quarter of an hour between 8.00 and 22.00 was calculated. Firstly, the mean physical activity level and SD per quarter of an hour for all measured days was calculated per subject. Secondly, the coefficient of variation was calculated per subject being 100x (SD/mean). 2340 
Differences between groups were evaluated for variability per day (8.00 - 22.00) and per day part (morning: 8.00 - 12.00, afternoon: 12.00 - 18.00, evening: 18.00 - 22.00), as well as for each quarter of an hour separately.

\section{Variability between subjects}

Variability in the performance of objectively measured physical activities between subjects was calculated to evaluate heterogeneity between subjects within the CFS and control group in the performance of daily physical activities. The overall mean and SD of the physical activity level per group was calculated for each quarter of an hour between 8.00 and 22.00. Subsequently, these means and standard deviations were used to calculate the coefficient of variation between subjects for each group (100x (SD/mean)).

\section{Awareness and relationship with fatigue}

The 'awareness' in performing physical activities, was assessed by calculating the correlation between objective (mean daily physical activity per minute measured with the $m t x-w$ sensor) and subjective (subjective ratings on the visual analogue scale) measured daily physical activity level. Daily objective assessments were compared with daily subjective assessments rated in the evening of the same day. Data for evaluating the 'awareness' was obtained for all subjects who accomplished both objective and subjective measurements. Fatigue severity might influence the awareness in performing daily physical activities. Therefore the correlation of fatigue severity measured with the CIS fatigue score with objective and subjective daily physical activity levels was investigated.

\section{Statistical Analysis}

The Statistical Package for the Social Sciences (SPSS18) was used for statistical analysis. The $\alpha$ level was set at 0.05 for all analyses. Difference between groups for age, mean objective and subjective daily physical activity level was tested with an independent t-test. Levene's test for equality of variances was used for testing equality of variances between groups. Difference between groups for gender was tested with a Pearson chi-square test. Differences in the daily physical activity level 
related to work status in the CFS group was checked for with a one-way anova and the Sidak correction was used for multiple comparisons between groups.

\section{Physical activity pattern}

The objectively measured physical activity pattern was analyzed using linear mixed models with restricted maximum likelihood; physical activity level was used as dependent variable; group, time and the interaction group*time as fixed factors; and subject as grouping factor for paired measures. In the comparisons between groups at different time points the Sidak correction was used for multiple comparisons.

The same linear mixed model was used for analyzing differences in the objectively measured physical activity pattern per day part instead of per hour by changing the factor 'time' consisting of 14 categories (14 hours between 8.00 - 22.00) into the factor 'day part' consisting of 3 categories (3 day parts; morning $8.00-12.00$, afternoon $12.00-18.00$ and evening $18.00-22.00$ ).

\section{Activity intensity}

Difference between groups in homogeneity in the distribution of hours during the day in 'low', 'moderate' or 'high' objectively measured activity levels was tested with a Pearson chi-square test.

\section{Variability within subjects}

A linear mixed model was used for analyzing the variability within subjects in performing objectively measured physical activities, with the coefficient of variation per quarter of an hour per subject as dependent variable; group, time and the interaction group*time as fixed factors; and subject as grouping factor for paired measures in time. In the comparisons between groups at different time points, the Sidak correction was used for multiple comparisons. The same linear mixed model was used for analyzing differences in the variability within subjects per day part instead of per quarter of an hour by changing the factor 'time' from 56 categories (56 quarters of an hour between 8.00 - 22.00) into 'day part' with 3 categories (3 
day parts; morning 8.00 - 12.00, afternoon 12.00 - 18.00 and evening 18.00 22.00).

Variability between subjects

The Shapiro-Wilk test was used for testing normality per group in the distribution of the coefficient of variation between subjects. Difference between groups in coefficient of variation between subjects was tested with an independent t-test if test of normality was not significant; otherwise the Mann-Whitney U test was used.

\section{Awareness and relationship with fatigue}

The awareness in the performance of physical activities was analyzed with the Spearman's correlation coefficient between objective and subjective measured daily physical activity level, and between the daily physical activity level and the CIS fatigue in the CFS group. 


\section{Results}

\section{Group characteristics}

Number of subjects, number of males and females, and the mean age for each group is shown in table I. Gender, age and subjective rating of the daily physical activity level did not differ significantly between the two groups. CFS subjects were on average significantly less physically active than healthy control subjects ( $p=$ 0.013 ), as measured objectively with the $m t x-w$ sensor. The objectively measured physical activity level was higher in employed CFS patients as compared to CFS patients receiving disability benefits/sick leave and other CFS patients not employed, however these differences were not statistically different. The total score of the CIS-fatigue questionnaire in the CFS group (106.2) is comparable to other CFS samples and differentiates the current CFS sample from being healthy. ${ }^{53} \mathrm{~A}$ score of 49.2 on the subscale fatigue indicates the existence of severe fatigue. 3543 The mean BMI of the control group was 26.0 which indicate a low to moderate fitness level. The mean objective daily activity level in the control group was 1129 counts per minute; this was equal to the activity level of a group of healthy subjects ( 1133 counts per minute; 30 subjects; mean age of 27.1; mean BMI of 24.1) as measured in a validation study for measuring physical activities with a comparable tri-axial accelerometer, and the activity level of our control group falls into the category of a moderate physical activity level. 4 
Table I Characteristics study population

\begin{tabular}{|c|c|c|}
\hline Group & CFS subjects $(\mathrm{N}=35)$ & Healthy subjects $(\mathrm{N}=35)$ \\
\hline \multirow[t]{2}{*}{ Gender } & 3 men & 3 men \\
\hline & 32 women & 32 women \\
\hline Age (SD) & $39.1( \pm 9.4)$ & $40.7( \pm 13.1)$ \\
\hline $\begin{array}{l}\text { Mean objective daily } \\
\text { activity level (SD)* }\end{array}$ & 957 counts / $\min ( \pm 266)$ & 1129 counts / min $( \pm 300)$ \\
\hline $\begin{array}{l}\text { Mean subjective daily } \\
\text { activity level (SD) }\end{array}$ & $5.6( \pm 1.3)$ & $\begin{array}{l}5.4( \pm 1.5) \\
(\mathrm{N}=30 ; 5 \text { subjects did not fill } \\
\text { in the VAS) }\end{array}$ \\
\hline Mean BMI & - & $\begin{array}{l}26.0(\mathrm{~N}=30 ; 5 \text { subjects } \\
\text { unknown })\end{array}$ \\
\hline CIS-fatigue score & 106.2 & - \\
\hline - $\quad$ Fatigue & 49.1 & \\
\hline - Concentration & 28.2 & \\
\hline - Motivation & 14.9 & \\
\hline - $\quad$ Physical activity & 14.1 & \\
\hline $\begin{array}{l}\text { Duration of } \\
\text { complaints }\end{array}$ & $\begin{array}{l}9.4 \text { years } \\
(\mathrm{N}=33 ; 2 \text { subjects unknown })\end{array}$ & - \\
\hline Work status & $\begin{array}{l}\text { Employed } 12 \\
\text { - } \quad \text { Part-time/full-time } 12 / 0 \\
\text { - } \quad \text { Mean hours a week } 19 \\
\text { Invalidity benefits/sick leave } 15 \\
\text { Else (housekeeping, studying, } \\
\text { volunteer work, unemployed) } 8\end{array}$ & - \\
\hline
\end{tabular}

"Significant different; $\mathrm{t}=-2.537, \mathrm{p}=0.013$ 


\section{Physical activity pattern}

The mean objective physical activity level per hour for each group is shown in figure 1 .

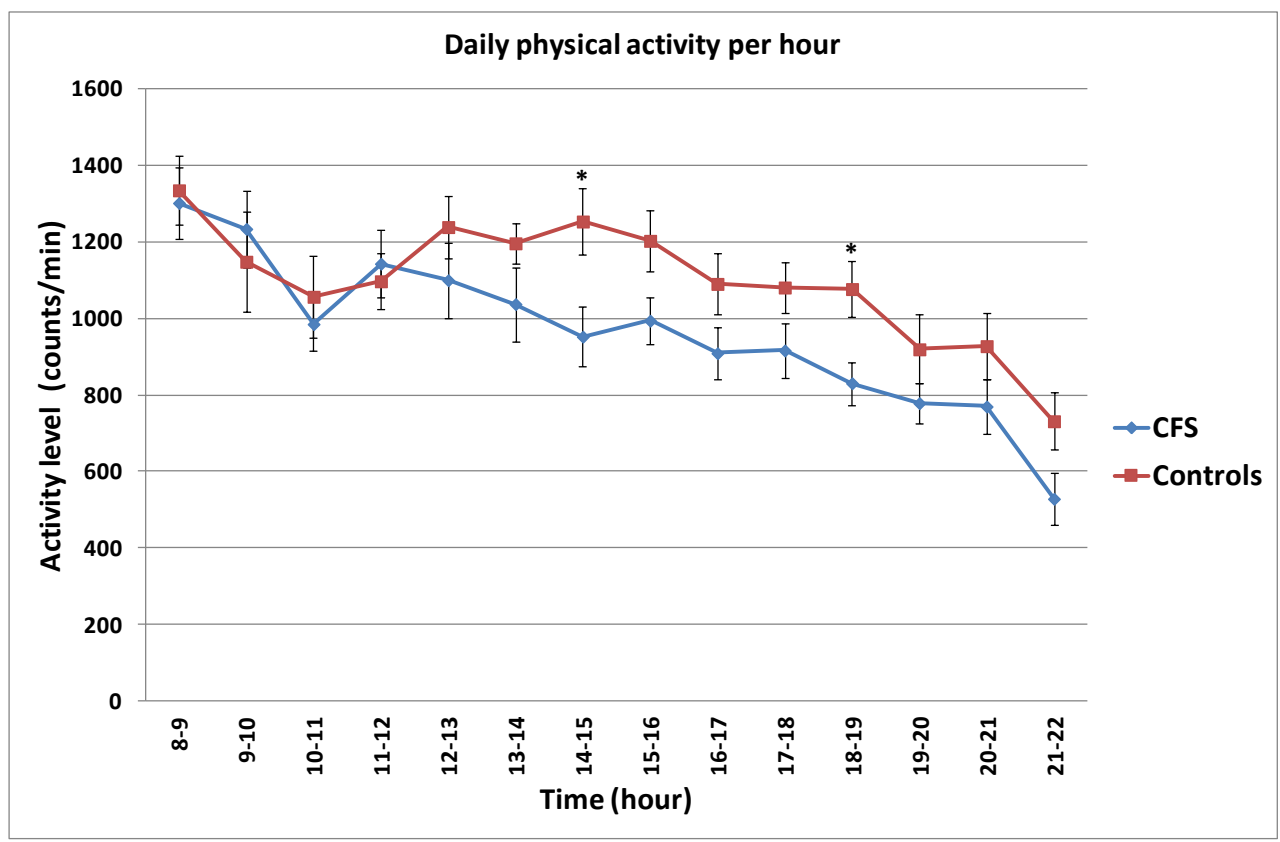

Figure 1 Physical activity pattern (mean and SEM per hour)

*Indicates significant differences between CFS and control group

The linear mixed model showed that the factor time $(p<0.001)$ had a significant effect on the objectively measured physical activity level and group reached the level of significance $(p=0.050)$, meaning that the physical activity level per hour varied during the day and that differences seem to exist between the CFS and control group. Pairwise comparisons indicated that CFS subjects were significantly less physically active at $14.00-15.00$ and 18.00 - 19.00 compared to controls. However, no significant interaction was found in the mixed model for time by group, meaning that differences in the physical activity level per hour during the day was not associated to group differences (figure 1).

The mean objective physical activity level per day part for each group is shown in figure 2 . 


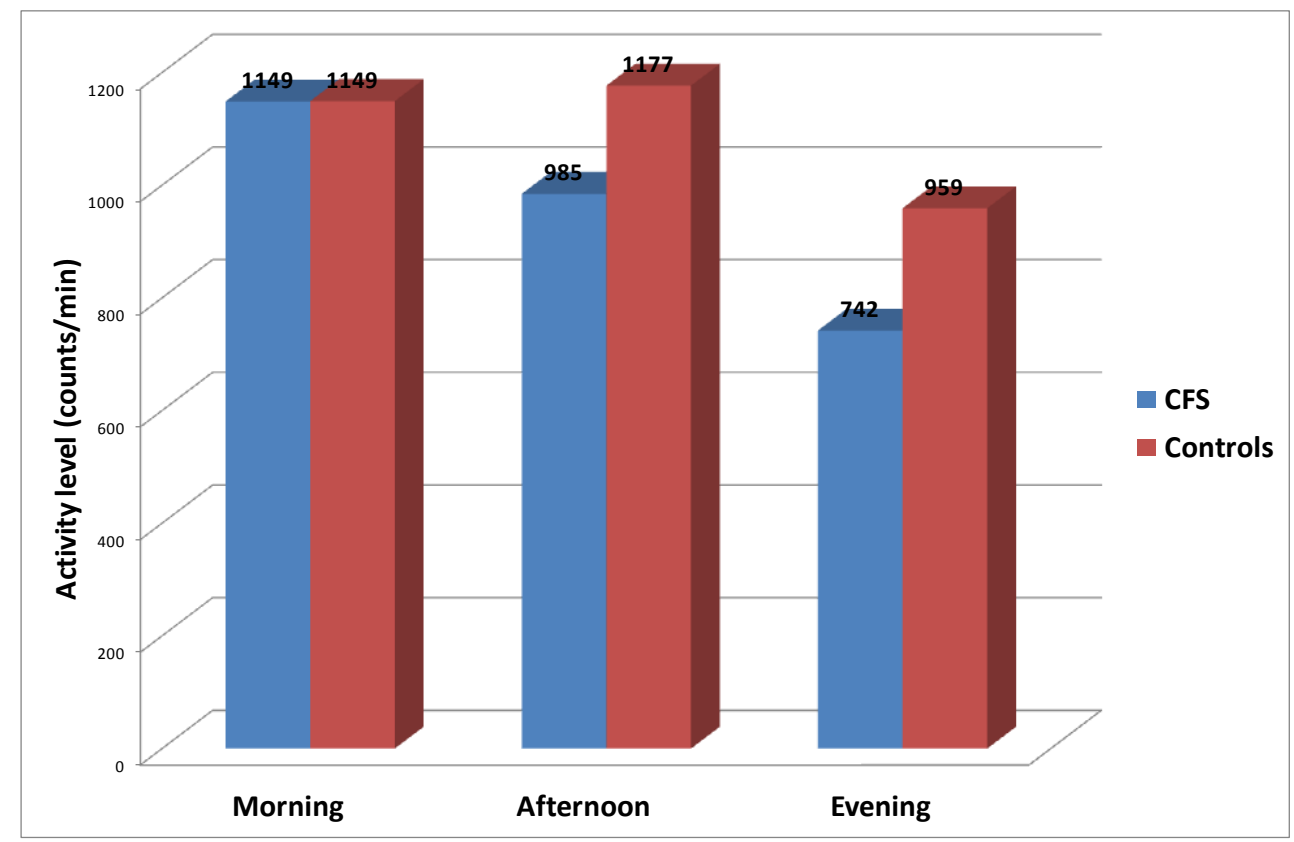

Figure 2 Physical activity levels per day part

The linear mixed model used for investigating the difference between the different day parts showed again significant effects for the factors day part $(p<0.001)$ and group ( $p=0.038)$, and also for the interaction day part*group $(p=0.014)$ on the objectively measured physical activity level. This means that the physical activity level per day part varied during the day, differed between the CFS and control group and differences per day part were related to group differences. Pairwise comparisons indicated that CFS subjects were significantly less physically active during the afternoon $(p=0.010)$ and evening $(p=0.011)$ as compared to control subjects, while during the morning no significant difference was found (figure 2).

\section{Activity intensity}

The distribution of objectively measured activity levels over the various intensity levels are shown in figure 3. For each group the numbers of hours in each intensity level are given as percentage of the total number of hours for all categories together. Theoretically, 14 hours were measured during the day per subject resulting in 490 hours per group but using the inclusion criteria for analysis 459 
hours in the CFS group and 434 hours in the control group were considered valid and were incorporated.

The Pearson chi-square test indicated a significant difference in the distribution over the intensity levels between the CFS and control group ( $<<0.001)$. CFS patients spend relatively more hours in the category 'low activity level', equal number of hours in the category 'moderate activity level' and less hours in the category 'high activity level' as compared to control subjects.

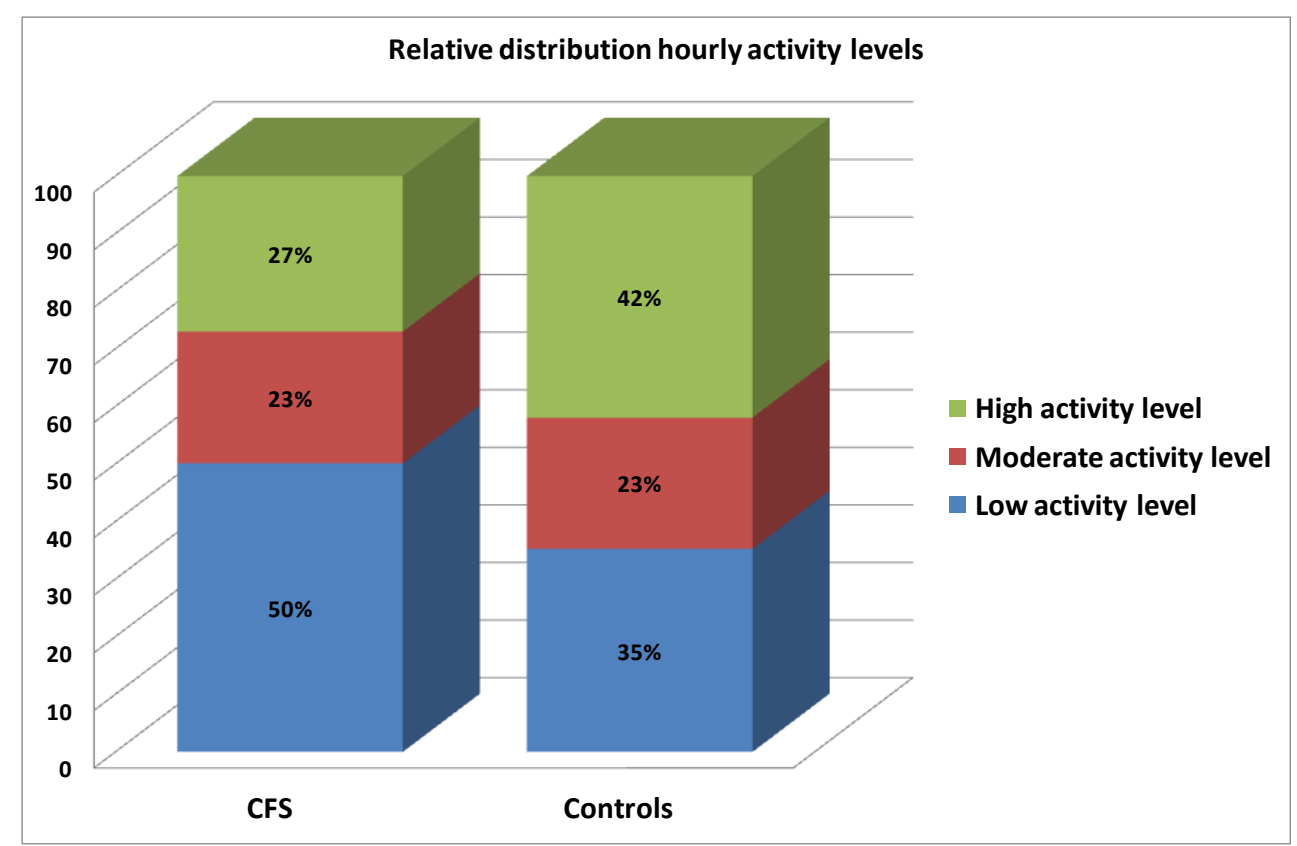

Figure 3 Distribution of hourly activity levels during the day in 3 categories

\section{Variability within subjects}

The linear mixed model showed a significant main effect of time $(p<0.001)$ on the coeffcient of variation within subjects, but not for group and the interaction time*group. This means that the coefficient of variation within subjects differ during the day, but not between groups and differences during the day were not related to group differences.

The adapted linear mixed model with day part as factor instead of time, showed significant main effects of day part $(p<0.001)$ and the interaction group*day part 
( $p=0.011)$, meaning that the coefficient of variation within subjects differed significant between the 3 day parts and these differences were related to group differences. The mean coeffcient of variation within subjects per day part was 61 , 74 and 68 in the CFS group and 62, 68 and 62 in the control group for the morning, afternoon and evening, respectively. Pairwise comparisons between groups per day part revealed significant differences in the afternoon $(p=0.029)$.

\section{Variability between subjects}

Test of normality for the distribution of the coefficient of variation between subjects was significant for both groups. The Mann-Whitney $U$ test indicates that the coefficient of variation between subjects during the day did not differ between the CFS and control group $(p=0.740)$. This means that there was no difference between groups in the variability of objectively measured physical activities during the day between subjects.

\section{Awareness daily physical activity and relation with fatigue}

The awareness about someone's own physical activity level was evaluted by means of the correlation between the objective daily physical activity level and subjective rating of the daily physical activity level (figure 4). Measurements with objective and subjective physical activity levels at the same measurement day were obtained in 33 subjects of the CFS group (mean of 952 counts per minute and rating of 5.6) and 19 subjects of the control group (mean of 1081 counts per minute and rating of 5.8). The Spearman's correlation coefficient did show a significant correlation in the CFS group $(0.411, p=0.018)$, but not in the control group $(0.023, p=0.926)$. 


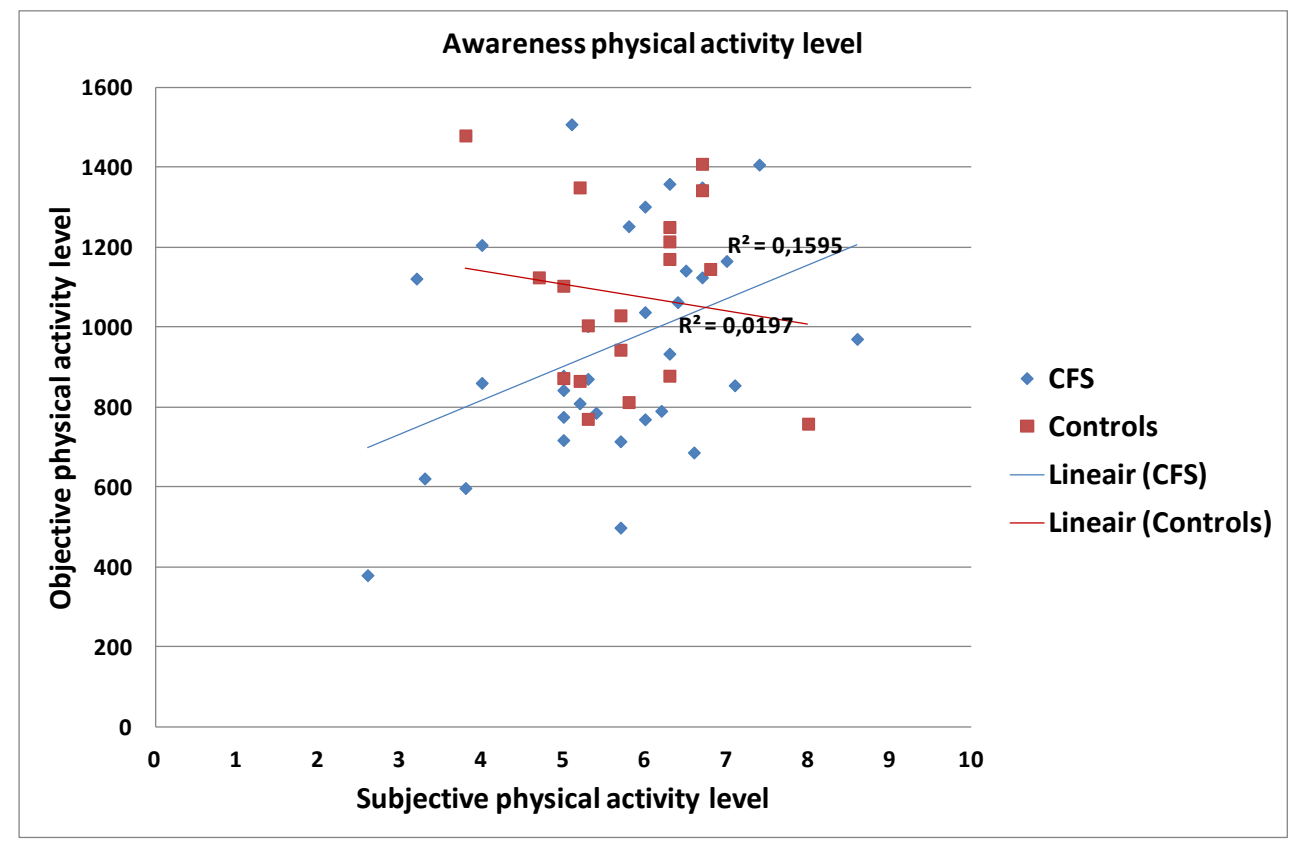

Figure 4 Correlation objective and subjective physical activity level

In the same 33 subjects of the CFS group the correlation was calculated between the objective daily physical activity level and CIS fatigue, and between the subjective daily physical activity level and CIS fatigue. The mean CIS fatigue for these 33 CFS subjects was 49.1 and was negatively correlated with objective and subjective daily physical activity levels (Spearman's correlation coefficient $=-0.193$ and -0.308 respectively), however, these correlations were not significant. 


\section{Discussion}

This study investigates differences in objectively measured daily physical activity patterns between CFS patients and control subjects, and whether CFS patients and control subjects are aware about their own daily physical activity level. This study shows that CFS patients have a significant different objective daily physical activity pattern as compared to control subjects. CFS patients have equal objective physical activity levels in the morning but reduced objective physical activity levels in the afternoon and evening. Moreover, CFS patients spend far more daily hours at low intensity levels and less at high intensity levels. The variability in the objectively measured physical activity pattern within subjects is also significantly different in CFS subjects as compared to control subjects. CFS patients show more variability in their objective physical activity pattern between different days during the afternoon as compared to controls. The variability in the objective physical activity level between subjects was not different between the CFS and control group, meaning that the heterogeneity in the physical activity pattern within groups did not differ between groups. Finally, CFS subjects seem to be more aware about their daily physical activity levels than control subjects. No significant correlation was found between fatigue severity and, objective and subjective, daily physical activity levels in the CFS group. Fatigue severity seems not to be of influence on the awareness in performing physical activities in the CFS group.

A limitation of this study is that we could not correct for daily physical activities performed outside the measured time period and for differences in sleeping patterns between subjects, as these factors could be of influence in the measured activity patterns. However, other studies found no relation between sleeping pattern and physical activity level and no differences were observed in total sleeping time during the night between CFS patients and control subjects. 4445 The existence of selection bias in the control group cannot be excluded. We did not match healthy control subjects to CFS patients based on physical activity levels nor on physical capacity levels. The physical activity pattern of the control group could be less high in the afternoon and evening if we had matched on physical activity levels. However, we matched the control group on age and gender towards the CFS 
group. Moreover, the activity level of the control group was comparable towards a healthy control group in a validation study of activity measurements with a comparable tri-axial accelerometer, both control groups can be categorized as moderately physical active. 4

This study demonstrates normal levels of physical activity in the morning and reduced levels in afternoon and evening. Reduced activity levels during the afternoon and evening have been observed also in patients with chronic lower back pain, probably caused by increased pain intensity during the day. ${ }^{41}$ It could be that reduced activity levels in CFS are caused by increased fatigue intensity during the day. However, no significant correlations were found between daily physical activity levels and fatigue severity in the present study. Some studies did show significant correlations of low physical activity levels with high fatigue levels 204445 , others did not find a correlation 36 . The timing of measuring fatigue severity might be important in studying the correlation with physical activity levels. We measured fatigue severity only once, shortly after measuring daily physical activities. Therefore, it is not possible to check for correlations in fluctuating fatigue levels and physical activity levels during the day. It could be hypothesized that CFS patients are less fatigued in the morning and are able to do a lot, but when the levels of fatigue increases during the day the ability to be active decreases. A study by Kop et al. is strengthening this assumption in which increased fatigue severity was associated with concurrent and subsequent decreased activity levels. 20 CFS patients show also more variability between different days within their own activity patterns during the afternoon. CFS patients might perform more physical activities of higher intensity levels during the afternoon when having a 'good day', and fewer when having a 'bad day'. The alteration of 'good' and 'bad days' might cause higher variability in physical activity patterns as well as decreased mean physical activity levels in the afternoon. This is in line with clinical observations from others that in CFS short periods of rest are interrupted by short periods of marked activity during which patients perform at 'normal levels'.34 44 More research needs to be done to elucidate the relation between fatigue levels during the day, and subsequent deviations in physical activity levels. 
Another explanation of low activity levels in CFS patients could be the avoidance of activities at high intensity levels. CFS patients spend more hours in low activity levels and fewer hours in high activity levels. This finding is in accordance with the existing literature.20 36 It is found that CFS patients perform less frequently activities which were expected to result in high fatigue levels than activities which were expected to produce less fatigue. ${ }^{44}$ The variability between subjects in the mean physical activity level did not differ between groups. This is in accordance with Van der Werf et al. (2000) who did not found significant differences in day-to-day fluctuations between CFS patients and control subjects, however, sub typing of CFS patients based on their physical activity patterns was suggested for improving the success of cognitive behavioural therapy. 36

CFS patients were more aware about their daily physical activity levels than healthy controls. However, the correlation in the awareness data of the CFS group was only moderate meaning that patients are still only moderately aware of their activity pattern. Van der Werf et al. (2000) also found a positive relation in CFS patients between objective physical activity patterns and subjective reported daily activity levels. ${ }^{36}$ Research is needed to get more insight into the awareness of CFS patients about their own physical activity level, and the consequences of this on their physical activity behaviour and self perception.

Based on the result of this study we can conclude that CFS patients have an imbalanced daily physical activity pattern and based on this it might be considered that restoration in this balance might improve their health status. One way of doing this is providing ambulant feedback on levels of physical activity over a prolonged time period in the daily environment of the patient. This feedback could be given as complement to existing treatment strategies like cognitive behavioural therapy and graded exercise training, in which a rationale can be provided why it is necessary to change the physical activity pattern. It is already shown for patients with chronic low back pain that a feedback in the home situation on deviations in the physical activity pattern seem to increase the awareness in performing physical activities and that it possibly motivates them to change their pattern.3941 Also, Nijs et al. (2009) studied the effect of 3 weeks of pacing self-management treatment on the physical activity behaviour and health status in CFS patients and found an improved 
ability to perform daily physical activities, decreased severity of CFS symptoms and improved concentration difficulties, mood swings, muscle weakness and intolerance to bright light. ${ }^{26}$ Jason et al. (2009) found that helping CFS patients in maintaining expended energy levels at the same level as available energy levels improved physical functioning and decreased fatigue severity. ${ }^{18}$ The perspectives, needs and experiences towards physical activity of CFS patients are important in modelling and providing adequate feedback. Larun \& Malterud (2010) explored the context of experiences of physical activity perceived as beneficial or harmful for CFS patients. ${ }^{21}$ Physical activity was experienced as helpful and enjoyable, and strategies to review energy usage in daily life could adjust expectations, diminish stress load and assist in approaching a more appropriate priority in getting a balanced physical activity pattern.21 They concluded that 'self-management, body awareness and physical activity of choice combined with facilitation and advice from health care professionals is essential to achieve positive outcomes'. ${ }^{21}$

\section{Acknowledgments}

This work is part of the ZonMw project 'chronisch vermoeidheidssyndroom' (http://www.zonmw.nl/nl/onderwerpen/alle-programma-s/cvs/gehonoreerdonderzoek/). 


\section{References}

1. Armstrong T, Bauman A, Bull F et al. A guide for population-based approaches to increasing levels of physical activity. Implementation of the WHO global strategy on diet, physical activity and health. 2007. World Health Organization, 20 Avenue Appia, 1211 Geneva 27, Switzerland.

2. Bazelmans E, Bleijenberg G, Van Der Meer JW, Folgering H. Is physical deconditioning a perpetuating factor in chronic fatigue syndrome? A controlled study on maximal exercise performance and relations with fatigue, impairment and physical activity. Psychol Med 2001; 31(1):107-14.

3. Bouten CV, Westerterp KR, Verduin M, Janssen JD. Assessment of EnergyExpenditure for Physical-Activity Using a Triaxial Accelerometer. Medicine and Science in Sports and Exercise 1994; 26(12):1516-23.

4. Bouten CVC, Verboeket-van de Venne WPHG, Westerterp KR, Verduin M, Janssen JD. Daily Physical Activity Assessment: Comparison Between Movement Registration and Doubly Labeled Water. Journal of Applied Physiology 1996; 81(2):1019-26.

5. Bultmann U, de Vries M, Beurskens AJ, Bleijenberg G, Vercoulen JH, Kant I. Measurement of prolonged fatigue in the working population: determination of a cutoff point for the checklist individual strength. J Occup Health Psychol 2000; 5(4):411-6.

6. Burton C, Knoop H, Popovic N, Sharpe M, Bleijenberg G. Reduced complexity of activity patterns in patients with Chronic Fatigue Syndrome: a case control study. Biopsychosoc Med 2009; 3:7.

7. Cook DB, Nagelkirk PR, Poluri A, Mores J, Natelson BH. The influence of aerobic fitness and fibromyalgia on cardiorespiratory and perceptual responses to exercise in patients with chronic fatigue syndrome. Arthritis Rheum 2006; 54(10):3351-62.

8. De Becker P, Roeykens J, Reynders M, McGregor N, De Meirleir K. Exercise capacity in chronic fatigue syndrome. Arch Intern Med 2000; 160(21):32707. 
9. De Lorenzo F, Xiao H, Mukherjee $\mathrm{M}$ et al. Chronic fatigue syndrome: physical and cardiovascular deconditioning. QJM 1998; 91(7):475-81.

10. Durstine JL, Painter P, Franklin BA, Morgan D, Pitetti KH, Roberts SO. Physical activity for the chronically ill and disabled. Sports Med 2000; 30(3):207-19.

11. Evering RM, van Weering MG, Groothuis-Oudshoorn KC, Vollenbroek-Hutten MM. Daily physical activity of patients with the chronic fatigue syndrome: A systematic review. Clinical Rehabil 2010.

12. Farquhar WB, Hunt BE, Taylor JA, Darling SE, Freeman R. Blood volume and its relation to peak $\mathrm{O}(2)$ consumption and physical activity in patients with chronic fatigue. Am J Physiol Heart Circ Physiol 2002; 282(1):H66 -H71.

13. Fischler B, Dendale P, Michiels V, Cluydts R, Kaufman L, De Meirleir K. Physical fatigability and exercise capacity in chronic fatigue syndrome: association with disability, somatization and psychopathology. J Psychosom Res 1997; 42(4):369-78.

14. Fry AM, Martin M. Cognitive idiosyncrasies among children with the chronic fatigue syndrome: anomalies in self-reported activity levels. J Psychosom Res 1996; $41(3): 213-23$.

15. Fukuda K, Straus SE, Hickie I, Sharpe MC, Dobbins JG, Komaroff A. The chronic fatigue syndrome: a comprehensive approach to its definition and study. International Chronic Fatigue Syndrome Study Group. Ann Intern Med 1994; $121(12): 953-9$.

16. Fulcher KY, White PD. Strength and physiological response to exercise in patients with chronic fatigue syndrome. J Neurol Neurosurg Psychiatry 2000; 69(3):302-7.

17. Inbar O, Dlin R, Rotstein A, Whipp BJ. Physiological responses to incremental exercise in patients with chronic fatigue syndrome. Med Sci Sports Exerc 2001; 33(9):1463-70.

18. Jason L, Benton M, Torres-Harding S, Muldowney K. The impact of energy modulation on physical functioning and fatigue severity among patients with ME/CFS. Patient Educ Couns 2009; 77(2):237-41. 
19. Karmisholt K, Gotzsche PC. Physical activity for secondary prevention of disease. Systematic reviews of randomised clinical trials. Dan Med Bull 2005; 52(2):90-4.

20. Kop WJ, Lyden A, Berlin AA et al. Ambulatory monitoring of physical activity and symptoms in fibromyalgia and chronic fatigue syndrome. Arthritis Rheum 2005; 52(1):296-303.

21. Larun L, Malterud K. Finding the right balance of physical activity $A$ focus group study about experiences among patients with chronic fatigue syndrome. Patient Educ Couns 2010.

22. Lechner L, Bolman C, Van Dijke M. Factors related to misperception of physical activity in The Netherlands and implications for health promotion programmes. Health Promot Int 2006; 21(2):104-12.

23. Manns PJ, Baldwin E. Ambulatory activity of stroke survivors: measurement options for dose, intensity, and variability of activity. Stroke 2009; 40(3):8647.

24. Montague TJ, Marrie TJ, Klassen GA, Bewick DJ, Horacek BM. Cardiac function at rest and with exercise in the chronic fatigue syndrome. Chest 1989; 95(4):779-84.

25. Nagelkirk PR, Cook DB, Peckerman A et al. Aerobic capacity of Gulf War veterans with chronic fatigue syndrome. Mil Med 2003; 168(9):750-5.

26. Nijs J, van Eupen I, Vandecauter J et al. Can pacing self-management alter physical behavior and symptom severity in chronic fatigue syndrome? A case series. J Rehabil Res Dev 2009; 46(7):985-96.

27. Pardaens K, Haagdorens L, Van Wambeke P, Van Den Broeck A, Van Houdenhove B. How relevant are exercise capacity measures for evaluating treatment effects in chronic fatigue syndrome? Results from a prospective, multidisciplinary outcome study. Clin Rehabil 2006; 20(1):55-66.

28. Pedersen BK, Saltin B. Evidence for prescribing exercise as therapy in chronic disease. Scand J Med Sci Sports 2006; 16 Suppl 1:3-63.

29. Reid SF, Chalder T, Cleare A, Hotopf M, Wessely S. Chronic fatigue syndrome. Clin Evid (Online) 2008; 2008. 
30. Riley MS, O'Brien CJ, McCluskey DR, Bell NP, Nicholls DP. Aerobic work capacity in patients with chronic fatigue syndrome. BMJ 1990; 301(6758):953-6.

31. Ronda G, Van Assema P, Brug J. Stages of change, psychological factors and awareness of physical activity levels in The Netherlands. Health Promot Int $2001 ; 16(4): 305-14$.

32. Sargent C, Scroop CC, Nemeth PM, Burnet RB, Buckley JD. Maximal oxygen uptake and lactate metabolism are normal in chronic fatigue syndrome. Med Sci Sports Exerc 2002; 34(1):51-6.

33. Sisto SA, LaManca J, Cordero DL et al. Metabolic and cardiovascular effects of a progressive exercise test in patients with chronic fatigue syndrome. Am J Med 1996; 100(6):634-40.

34. Surawy C, Hackmann A, Hawton K, Sharpe M. Chronic fatigue syndrome: a cognitive approach. Behav Res Ther 1995; 33(5):535-44.

35. Torenbeek M, Mes CA, van Liere MJ et al. [Favourable results of a rehabilitation programme with cognitive behavioural therapy and graded physical activity in patients with the chronic-fatigue syndrome]. Ned Tijdschr Geneeskd 2006; 150(38):2088-94.

36. Van der Werf SP, Prins JB, Vercoulen JH, van der Meer JW, Bleijenberg G. Identifying physical activity patterns in chronic fatigue syndrome using actigraphic assessment. J Psychosom Res 2000; 49(5):373-9.

37. Van Houdenhove B, Verheyen L, Pardaens K, Luyten P, Van Wambeke P. Rehabilitation of decreased motor performance in patients with chronic fatigue syndrome: should we treat low effort capacity or reduced effort tolerance? Clin Rehabil 2007; 21(12):1121-42.

38. van Sluijs EM, Griffin SJ, van Poppel MN. A cross-sectional study of awareness of physical activity: associations with personal, behavioral and psychosocial factors. Int J Behav Nutr Phys Act 2007; 4:53.

39. Van Weering M, Vollenbroek-Hutten MM, Hermens HJ. Potential value of an activity-based feedback system for treatment of patients with chronic low back pain. Submitted. 
40. Van Weering M, Vollenbroek-Hutten MM, Kotte EM, Hermens HJ. Daily physical activities of patients with chronic pain or fatigue versus asymptomatic controls. A systematic review. Clin Rehabil 2007 Nov; 21(11):1007-23.

41. van Weering MG, Vollenbroek-Hutten MM, Tonis TM, Hermens HJ. Daily physical activities in chronic lower back pain patients assessed with accelerometry. Eur J Pain 2009; 13(6):649-54.

42. Vanness JM, Snell CR, Strayer DR, Dempsey L 4th, Stevens SR. Subclassifying chronic fatigue syndrome through exercise testing. Med Sci Sports Exerc 2003; 35(6):908-13.

43. Vercoulen JH, Alberts M, Bleijenberg G. De checklist individual strength (CIS). Gedragstherapie 1999; 32(2):131-6.

44. Vercoulen JH, Bazelmans E, Swanink CM et al. Physical activity in chronic fatigue syndrome: assessment and its role in fatigue. J Psychiatr Res 1997; $31(6): 661-73$.

45. Vercoulen JH, Hommes OR, Swanink CM et al. The measurement of fatigue in patients with multiple sclerosis. A multidimensional comparison with patients with chronic fatigue syndrome and healthy subjects. Arch Neurol 1996; 53(7):642-9.

46. Vercoulen JH, Swanink CM, Fennis JF, Galama JM, van der Meer JW, Bleijenberg G. Dimensional assessment of chronic fatigue syndrome. J Psychosom Res 1994; 38(5):383-92.

47. Wallman KE, Morton AR, Goodman C, Grove R. Physiological responses during a submaximal cycle test in chronic fatigue syndrome. Med Sci Sports Exerc 2004; 36(10):1682-8.

48. Wessely S, David A, Butler S, Chalder T. Management of chronic (post-viral) fatigue syndrome. J R Coll Gen Pract 1989; 39(318):26-9. 


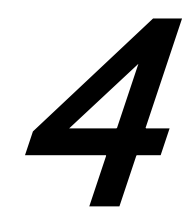

Ambulatory feedback at daily physical activities in treatment of the chronic fatigue syndrome

Evering RMH, Vollenbroek-Hutten MMR. Ambulatory feedback at daily physical activities in treatment of the chronic fatigue syndrome. Submitted. 


\begin{abstract}
Purpose: To study the compliance with an ambulatory feedback system and changes made in daily physical activity in patients with the chronic fatigue syndrome.
\end{abstract}

Method: The intervention arm of a randomized controlled trial was studied in which a feedback program was implemented into an existing rehabilitation program for treatment of chronic fatigue syndrome.

Feedback was provided at home with a personal digital assistant during four consecutive feedback periods. Feedback was based on the difference between the physical activity level of the patient and a predefined goal. Physical activity levels were measured with an accelerometer.

Results: Compliance with the feedback system was around $90 \%$ during each of the four feedback periods. Fifteen patients (50\%) complied with all four feedback periods. No differences were found at baseline between compliers vs. non compliers. The fifteen compliers changed their physical activity level significantly into the direction of the goal, especially in the morning and afternoon. Changes in physical activity were seen instantaneously from the first feedback day on.

Conclusions: Patients were able to change their daily physical activity into the direction of the goal. The compliance with all four feedback periods was low and might be related to the instantaneous effect of the feedback. 


\section{Introduction}

The chronic fatigue syndrome is characterized by severe debilitating fatigue lasting for at least six months. Other symptoms can include musculoskeletal pain, sleep disturbance, impaired concentration, and headaches [1]. Disturbances in physical activity patterns are hypothesised to be a key factor in the development and maintenance of chronic fatigue syndrome and from scientific studies it is known that patients are less physically active and show deviating patterns when compared to healthy controls [2-6]. Besides being an explanation for the development and maintenance of chronic fatigue syndrome, adjustments in the physical activity pattern is also considered to be a starting point for treatment. Cognitive behavioural therapy and graded exercise therapy are the most promising treatment modalities in chronic fatigue syndrome and both underline the importance of a regular and balanced daily physical activity pattern [1,7]. Studies that examined the effectiveness of graded exercise therapy showed mixed results, and high dropout rates suggested the ineffectiveness of graded exercise therapy for subpopulations [8]. As such it is expected that more individual tailoring of cognitive behavioural therapy and graded exercise therapy to individual needs may enhance treatment outcome [9-11]. Several studies have shown the potential value of telecommunication technology in improving physical activity levels in chronic patients [12-14]. Telecommunication technologies are often used for providing feedback on subjectively experienced physical activity behaviour [15]. The use of real time feedback on objectively measured physical activity behaviour would likely be more accurate in providing feedback than feedback based on patients' own experiences [12-14]. As such, a more effective way to create a regular and balanced daily physical activity pattern might be monitoring of actual physical activity behaviour and providing ambulatory feedback in everyday life. This is considered to be in line with the current trend of enhancing self management and it is hypothesised that ambulatory feedback can contribute to more effective and efficient care of chronic conditions [15-17].

In this study telecommunication technology is used to provide ambulatory feedback on the performance of daily physical activities in the home situation. The feedback 
is implemented as supplement to a rehabilitation program given to patients with chronic fatigue syndrome. Following the approach of DeChant et al. (1996), a stage 2 evaluation is performed focusing on accessibility and quality of the feedback system expressed as compliance with the feedback system as well as on changes made in physical activity [18]. Daily physical activity is measured in absolute counts per minute, and instantly feedback is provided aimed at a balanced daily physical activity pattern, as this is considered to be important in the treatment of chronic fatigue syndrome [1, 7]. Differences between compliers and non compliers are studied for baseline characteristics and changes made in daily physical activity levels. Moreover, in the group of compliers the number of days patients need to learn to change their daily physical activity level towards the goal is studied, as well as changes made in the balance of daily physical patterns. 


\section{Methods}

\section{Participants}

Experiments were approved at the accredited Medical Research Ethics Committee of the hospital 'Medisch Spectrum Twente' in Enschede, The Netherlands. Patients, with chronic fatigue syndrome who were considered for the clinical rehabilitation program in the Roessingh Rehabilitation Centre in Enschede (The Netherlands), were recruited for participation in the study. Inclusion and exclusion criteria were assessed in an intake procedure prior to the program. Diagnosis of chronic fatigue syndrome by a general practitioner or a physician was required for inclusion, following the criteria of the Centres for Disease Control and Prevention of 1994 [19]. Other inclusion criteria were: age between 18 and 65 years; severe fatigue (Checklist Individual Strength [20], subscale subjective fatigue $\geq 35$ ); being motivated to participate in a self-management program; being able to follow therapies for 5 hours a day. Exclusion criteria were: severe psychopathology (Symptom Checklist-90 [21, 22] > 295); extensive cognitive deficits; severe psychosocial problems of an acute nature that needed solution before treatment; enforced motivation by a legal procedure concerning financial benefit; bounded to a wheelchair; being pregnant.

\section{Study design and group characteristics}

The intervention arm of a randomized controlled trial was studied. Thirty-nine patients were at random allocated to the control arm (rehabilitation program alone) and forty-two patients to the intervention arm (rehabilitation program + feedback program). The rehabilitation program was offered at rehabilitation centre 'Het Roessingh' (Enschede, The Netherlands) and comprises combined cognitive behavioural therapy and graded exercise therapy with inpatient treatment in week 1, 3, 5, 7 and 9, as described in Torenbeek et al. (2006) [23]. The feedback program in the intervention arm of this study was implemented in week 2, 4, 6 and 8 , in which participants were at home and able to continue their daily activities. Results of the randomized controlled trial will be submitted separately. For the objectives of this study, data of the intervention group was used for which 
measurements were performed between November 2008 and February 2011. Demographics were obtained for gender, age, fatigue severity, duration of complaints and work status. Fatigue severity was measured with the Checklist Individual Strength which consists of 20 items with a total score, and scoring on 4 subscales; 'subjective experience of fatigue', 'concentration', 'motivation' and 'physical activity level' [20]. Physical activity was measured at baseline before treatment started for seven consecutive days with the same accelerometer as used in the feedback program (described below).

The monitoring and feedback intervention

The monitoring and feedback intervention was spread over four feedback periods in between the five weeks of inpatient treatment. Patients were asked to wear the feedback system five days per feedback period. The feedback system consisted of a tri-axial piezoelectric accelerometer ( $\mathrm{mtx}-\mathrm{w}$ sensor, XSense; The Netherlands) and a personal digital assistant (PDA). Daily physical activities were objectively measured with the accelerometer which measured accelerations in the anteroposterior, mediolateral and longitudinal axes of the trunk. The acceleration (sampled with a frequency of $100 \mathrm{~Hz}$ ) was bandpass filtered with a $4^{\text {th }}$ order butterworth filter with cut-off frequencies of 0.11 and $20 \mathrm{~Hz}$. The absolute value of the acceleration was integrated over time periods of 60 seconds and thereafter summed over the three axes [24]. The accelerometer was worn in a slip case at the waist and data was transmitted through Bluetooth connection to the PDA on which data was stored (figure 1a). The resulting measure of physical activity was expressed as mean acceleration per minute and defined as counts per minute [25]. 


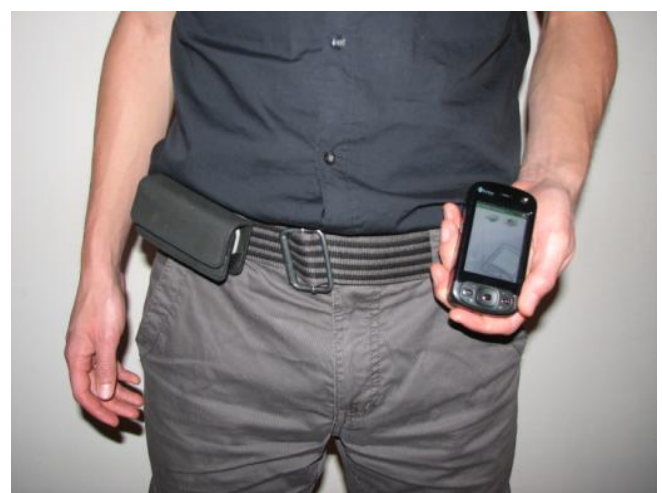

Figure 1a Wearing of the feedback system

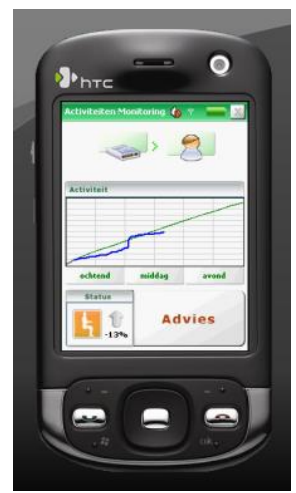

Figure $1 \mathrm{~b}$

Cumulative daily physical activity pattern

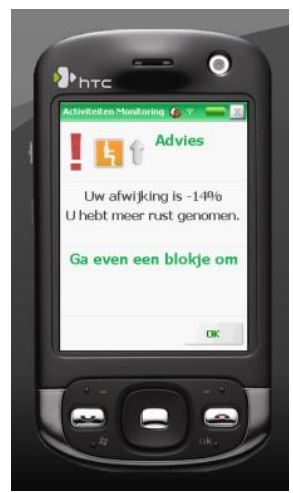

Figure 1c

Difference with the goal, activity judgement and advice

Feedback was given to the patient with the PDA and this feedback was based on the actual difference between the cumulative physical activity level of the patient and the goal pattern (figure $1 \mathrm{~b}$ and $1 \mathrm{c}$ ). The goal was based on the physical activity level of a healthy control group (data previously obtained of 56 healthy subjects aged between 18 and 65 years). The mean daily physical activity level of the goal was 1104 counts per minute and the mean per day part was 1269, 1093 and 953 counts per minute for the morning, afternoon and evening respectively. The mean daily activity level of the goal can be categorized as a moderate activity level [25]. Feedback was provided in two different ways: 1) The PDA continuously showed a graph (figure $1 \mathrm{~b}$ ) displaying the cumulative goal pattern for the whole day (8.00 22.00) together with the cumulative pattern of the patient drawn minute by minute. The difference between the cumulative activity level of the goal and the patient was displayed in percentages. 2) Three text lines were presented at the PDA (figure 1c) every two hours $(10.00,12.00,14.00,16.00,18.00$ and 20.00$)$ representing:

- The difference between the cumulative activity level of the goal and patient at that time

- A judgment about the performance of the last two hours. This judgement gave the patient insight in whether the changes in activity level during the last two hours was appropriate 
- An activity advice. The activity advice stimulated the patient to perform activities at the right intensity level the next two hours in order to decline the difference with the goal. The patient received discouraging activity advices when the cumulative activity level was above the goal (>110\%), encouraging activity advices if the cumulative activity level was below the goal $(<90 \%)$ and neutral advices if the cumulative activity level was between $90 \%$ and $110 \%$ of the goal.

The difference between the individual cumulative activity level and the goal could become very large if the patient was high or low physically active during a prolonged period of time. Insurmountable differences between the individual cumulative activity level and the goal, build up during the morning and/or afternoon, were prevented by resetting the difference to zero at 13.00 and 17.00 by placing the individual cumulative activity level back to the goal. Oral and written instructions were provided regarding proper accelerometer placement, wearing schedule and user instructions of the accelerometer and PDA. The baseline and feedback measurements took place during daytime between 8.00 and 22.00 , excluding time spent bathing or participating in water activities.

\section{Data analysis}

Participants with sufficient physical activity data available at baseline were included in the data analysis meaning that at least three days of data were obtained with 420 minutes of data between 8.00 and 22.00. Physical activity, as measured in counts per minute, was studied with the mean physical activity level per hour expressed as percentage of the goal.

\section{Compliance with the feedback system}

Compliance with the feedback system was assessed for each feedback period separately. A patient was considered compliant in case the system was worn for at least four days and at least seven hours per day. An hour was taken into account when at least 30 minutes of data was present. The number of patients that was compliant was expressed as percentage of the total number of patients who started that feedback period. The patients who were compliant in all four feedback periods 
were referred as compliers, and patients who stopped prematurely as non compliers. The non compliers were compared with the compliers by evaluating differences at baseline in gender, age, physical activity level per day and day part, scores at the Checklist Individual Strength, duration of complaints and work status.

\section{Changes in daily physical activity}

The mean physical activity level of the compliers and non compliers was calculated for the baseline period and the four feedback periods or, in case of non compliance, till the last feedback period with sufficient compliance. The baseline physical activity level was used as reference for evaluating changes in daily physical activity levels.

\section{Time of learning}

Time of learning was studied in the group of compliers and evaluated by studying if, and when, the mean physical activity level of the baseline period and twenty feedback days were in the range of the goal. Patients were performing well if the mean physical activity level was between the $90 \%$ and $110 \%$ of the level of the goal.

\section{Balance in daily physical activity}

Balance in the daily physical activity pattern was studied for the baseline period and four feedback periods in the group of compliers. Physical activity levels were calculated per day part for the morning (8.00 - 12.00), afternoon (12.00 - 18.00) and evening (18.00 - 22.00). At least $50 \%$ of the hours with sufficient measurement data were required for calculating a day part. The baseline physical activity pattern was used as reference for evaluating changes in physical activity patterns.

\section{Statistical analysis}

The Statistical Package for the Social Sciences (SPSS18) was used for statistical analysis. The Shapiro-Wilk test was used for testing normality of dependent variables, and the $\alpha$ level of significance was set at 0.05 for all analyses. Independent t-tests were performed for identifying differences at baseline in age, physical activity levels, scores at the Checklist Individual Strength and duration of 
complaints between compliers versus non compliers. Levene's test for equality of variances was used for testing equality of variances. The Mann-Whitney $U$ test was used instead of the independent t-test if the dependent variable was not normally distributed.

In the group of compliers repeated measures general linear model with multiple pairwise comparisons was performed for analyzing differences in physical activity levels between the baseline period and four feedback periods, and between the baseline period and twenty feedback days. The Friedman test was used instead of repeated measures general linear model if the dependent variable was not normally distributed. The Mauchly's test of sphericity was used for testing equality of variance between different pairs of the within subject variables, the GreenhouseGeisser correction if test of sphericity was significant, and the Sidak correction for multiple pairwise comparisons.

In the group of non compliers a paired t-test was used for testing the difference in the physical activity level at baseline and the last feedback period with sufficient compliance. The Wilcoxon signed ranks test was used instead of paired t-tests if the dependent variable was not normally distributed. 


\section{Results}

\section{Group characteristics}

Thirty of the forty-two patients of the intervention arm of the randomized controlled trial completed the physical activity measurement at baseline sufficiently and were included for further analysis (table 1). Twelve patients did not obtain sufficient physical activity data at baseline; seven patients stopped prematurely, three patients were not able to complete the baseline measurement, one patient did not obtain sufficient data and one patient used a defective accelerometer. The thirty patients with sufficient physical activity data at baseline consisted of four males and 26 females. The total score at the Checklist Individual Strength in this study group (104.1) is comparable to other study samples with chronic fatigue syndrome and differentiates this group from being healthy $[26,27]$. A score of 49.4 on the subscale fatigue indicates the existence of severe fatigue [23, 26]. Six patients were employed, seventeen received invalidity benefits or were on sick leave, and seven patients performed other daily activities such as housekeeping, studying or volunteer work. 
Table 1 Group characteristics $(n=30)$

$\begin{array}{ll}\text { Gender } & 4 \text { males and } 26 \text { females } \\ \text { Age (SD) } & 37.7 \text { years (11) } \\ \text { CIS* scores } & 104.1 \\ \quad \text { Overall } & 49.4 \\ \quad \text { Fatigue } & 26.7 \\ \text { Concentration } & 13.8 \\ \quad \text { Motivation } & 14.3 \\ \text { Physical activity } & 8.5 \text { years ( }=27 ; 3 \text { subjects unknown) } \\ \text { Duration of complaints } & \\ \text { Work status } & 6 \\ \text { Employed } & 6 / 0 \\ \quad \text { Part time/full time } & 16.8 \\ \quad \text { Mean hours a week } & 17 \\ \text { Invalidity benefits/ sick leave } & 7 \\ \text { Else } & \end{array}$

"CIS = Checklist Individual Strength

\section{Compliance with the feedback system}

The compliance per feedback period as percentage of the number of patients who started with the feedback period was around the $90 \%$ during the four feedback periods (figure 2). The compliance during the feedback program was as follow; $90 \%$ (27 of 30 patients) in the first feedback period, 92\% (23 of 25 patients) in the second feedback period, 90\% (19 of 21 patients) in the third feedback period and $89 \%$ (17 of 19 patients) in the fourth feedback period. 


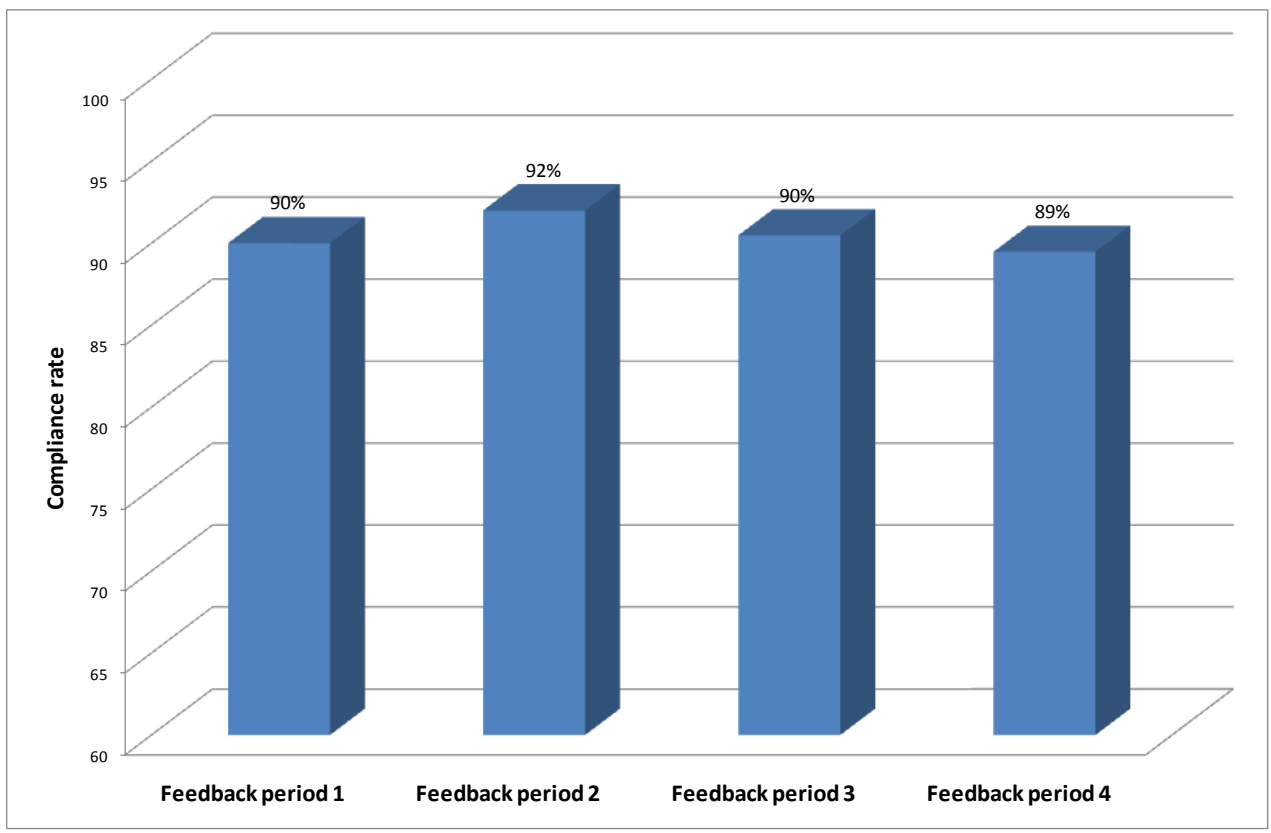

Figure 2 Compliance rate for each feedback period

In total fifteen patients (50\%) complied with all four feedback periods (compliers), while fifteen patients did not (non compliers). Of these fifteen non compliers, twelve patients (40\%) dropped out prematurely including one patient who did not comply sufficiently with any of the four feedback periods, and three patients completed the feedback program but complied not sufficiently with all four feedback periods. The most important reason for dropping out was the portability of the feedback system $(n=7)$. Other reasons for dropping out were experienced discrepancies between activity advices from the feedback system and from the rehabilitation centre $(n=2)$, the need of self control about planning daily physical activities without continuous interference from the feedback system $(n=2)$ and doubts about validity in activity monitoring of the feedback system $(n=1)$. No statistical differences at baseline were found between compliers versus non compliers for age, physical activity level, all five scores at the Checklist Individual Strength, and duration of complaints (table 2). However, the non compliers did approach the physical activity level of the goal at baseline more closely than the compliers (94\% vs. $84 \%$ ) and the patient without compliance to any feedback period 
had by far the highest physical activity level at baseline of all thirty patients included in the analysis (167\%). In the group of compliers ten patients had a physical activity level at baseline below the goal $(<90 \%)$ four patients within the range of the goal (between $90 \%$ and $110 \%$ ) and one patient above the goal (>110\%). In the group of non compliers seven patients had a physical activity level at baseline below the goal, five within the range of the goal and three above the goal. 
Table 2 Characteristics compliers versus non compliers

\begin{tabular}{|c|c|c|}
\hline & Compliers $(n=15)$ & Non compliers $(n=15)$ \\
\hline \multirow[t]{2}{*}{ Gender } & 1 male & 3 males \\
\hline & 14 females & 12 females \\
\hline Age (SD) & $40.0(11.1)$ & $35.5(10.6)$ \\
\hline Duration of complaints & 9.8 years $(n=13)$ & 7.2 years $(n=14)$ \\
\hline Work status & & \\
\hline Employed & 4 & 2 \\
\hline Part time/full time & $4 / 0$ & $2 / 0$ \\
\hline Mean hours a week & 16.4 & 17.5 \\
\hline Invalidity benefits / & 6 & 11 \\
\hline sick leave & & \\
\hline Else & 5 & 2 \\
\hline \multirow{3}{*}{\multicolumn{3}{|c|}{$\begin{array}{l}\text { Baseline physical activity } \\
\text { levels in } \mathrm{cpm}^{1} \text { and } \% \text { of } \\
\text { the goal (SD) }\end{array}$}} \\
\hline & & \\
\hline & & \\
\hline Day & 892 (243) and $84 \%(21)$ & 1020 (314) and 94\% (29) \\
\hline Morning & 982 (327) and $87 \%(25)$ & 1094 (440) and 97\% (40) \\
\hline Afternoon & 914 (263) and 86\% (24) & 989 (338) and 91\% (32) \\
\hline Evening & 737 (250) and $77 \%$ (26) & 826 (270) and 84\% (28) \\
\hline \multicolumn{3}{|l|}{$\mathrm{CIS}^{2}$ scores } \\
\hline Overall & 106.4 & 101.9 \\
\hline Fatigue & 50.8 & 47.9 \\
\hline Concentration & 27.0 & 26.3 \\
\hline Motivation & 13.4 & 14.1 \\
\hline Physical activity & 15.2 & 13.5 \\
\hline
\end{tabular}

${ }^{1} \mathrm{cpm}=$ counts per minute; ${ }^{2} \mathrm{CIS}=$ Checklist Individual Strength 


\section{Changes in daily physical activity}

Figure 3 shows the mean physical activity level of the baseline period and the four feedback periods for the fifteen compliers and the fifteen non compliers. The baseline physical activity level did not significantly differ between the groups. In the group of compliers a significant difference $(p<0.01)$ was found in the physical activity level between the four feedback periods and the baseline period. The Wilcoxon signed ranks test indicated that the physical activity level during feedback period $1(p<0.01)$, feedback period $2(p<0.01)$, feedback period $3(p<0.05)$ and feedback period $4(p<0.05)$ were significantly increased and closer towards the goal compared to the baseline period.

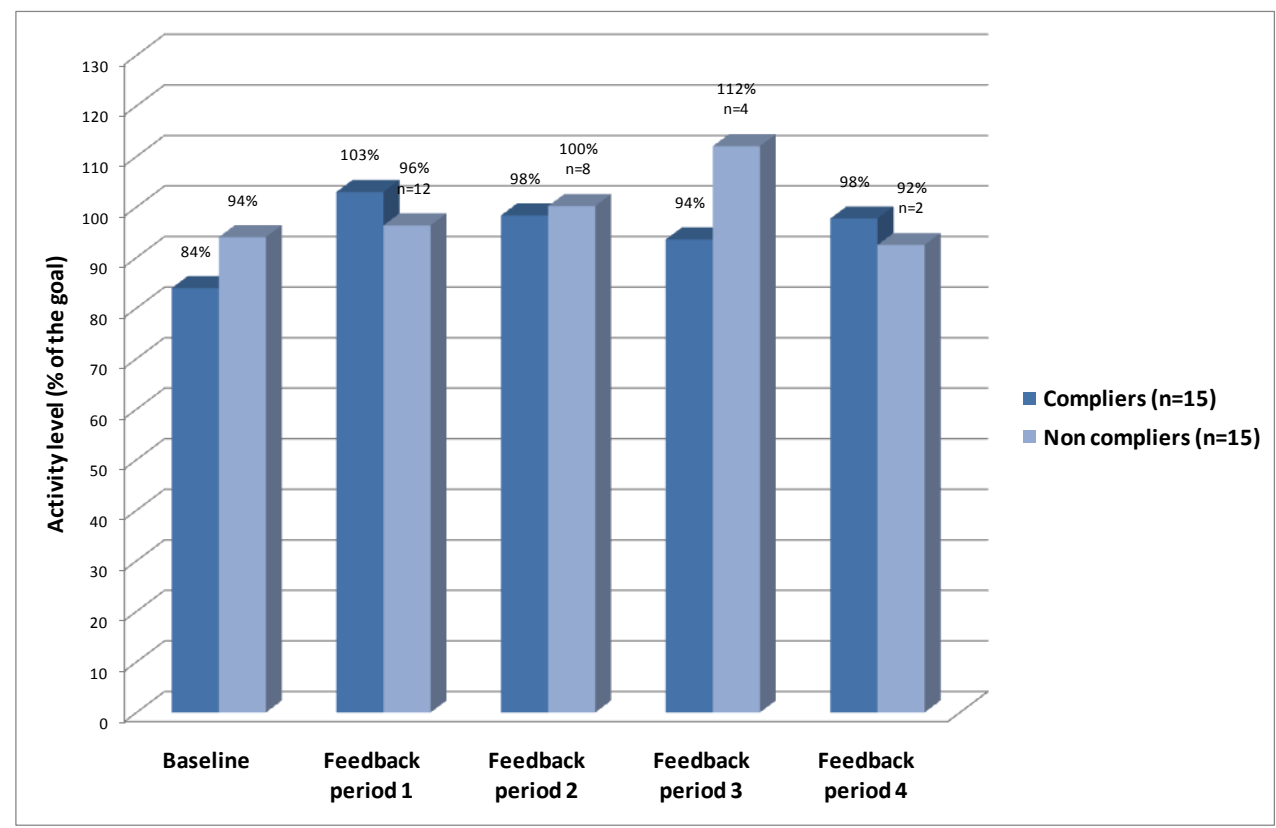

Figure 3 Physical activity level of compliers vs. non compliers during baseline and four feedback periods

Fourteen non compliers did comply sufficiently to at least one feedback period. The physical activity level of the last feedback period with sufficient compliance was significant increased $(p<0.05)$ with respect to baseline (increase from $89 \%$ at baseline to $101 \%$ at the last feedback period). 


\section{Time of learning}

In the group of compliers the mean physical activity level was within the range of the goal in nineteen of the twenty feedback days. The mean physical activity level was only beneath the goal at baseline (84\%) and at day 2 of feedback period 3 (88\%). Patients were instantaneous able to balance, or compensate, deviations in physical activity levels when receiving feedback. The Friedmans test indicated an 'overall' significant difference between the baseline and twenty feedback days $(p<0.05)$. The Wilcoxon signed ranks test indicated that the mean physical activity level was significantly increased $(\mathrm{p}<0.05)$ and closer towards the goal as compared to the baseline period at day 2, 3, 4 and 5 of feedback period 1; at day 1, 2, 3, 4 and 5 of feedback period 2; at day 1 of feedback period 3; and at day 4 of feedback period 4 . This indicated that patients were most accurate in balancing daily physical activity patterns during feedback period 1 and 2 .

\section{Balance in daily physical activity}

The balance of the physical activity pattern during the day was studied for the baseline period and the four feedback periods in the group of compliers and shown in figure 4 . The baseline pattern indicated decreased levels in the morning, afternoon and evening as compared to the goal pattern, with the lowest level in the evening. Differences in the physical activity pattern per day part between periods were studied with the Friedmans test and an 'overall' significant difference was found $(p<0.001)$. Wilcoxon signed ranks tests showed that the physical activity pattern was significantly increased $(p<0.05)$ during the morning and the afternoon of all four feedback periods compared to the baseline period. The differences found for the evening were not significant. 


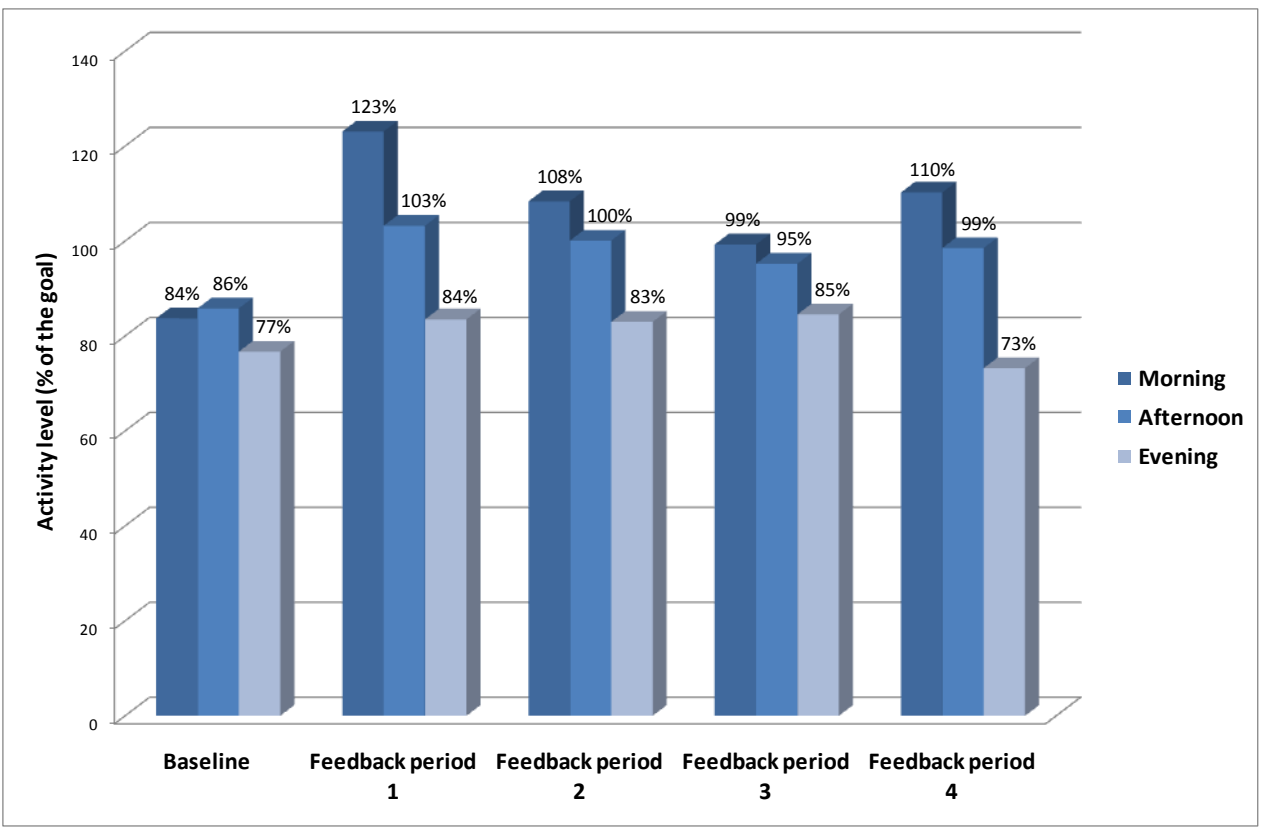

Figure 4 Physical activity pattern per day part of compliers $(n=15)$ during baseline and four feedback periods 


\section{Discussion}

The present study evaluated the potential value of an ambulant feedback system with regard to compliance and changes made in daily physical activity patterns in patients with chronic fatigue syndrome. The results indicate that $50 \%$ of the patients complied with the system for all four feedback periods of the feedback program. Results also indicate that those who complied with the feedback system significantly changed their daily physical activity in the direction of the goal, especially in the morning and afternoon. The changes were seen instantaneously meaning from the first feedback day on.

Fifteen patients (50\%) did not comply sufficiently with the feedback system, of which twelve patients (40\%) dropped out the feedback program. The dropout of $40 \%$ in this study seems high compared to a review published in the Cochrane Library (2004) that showed an overall dropout rate of $14 \%$ in intervention groups with exercise therapy in chronic fatigue syndrome versus an overall dropout rate of $8 \%$ in control groups, and compared to the median dropout rate of $26 \%$ reported in a systematic review about novel technologies for the management of chronic illnesses [15, 28]. However, the high dropout rate in this study might be caused by the intensity of the intervention. Patients were asked to comply with the feedback system at five days per feedback period from 8.00 till 22.00 , while other treatment protocols comprised 3 to 5 weekly sessions of exercise bouts with duration of 30 minutes per session. In addition, the feedback intervention might be too long as changes in daily physical activity were made directly. According to the Technology Acceptance Model, the compliance might also be influenced by perceived usefulness and perceived ease of use [29]. It might be that patients choose to not comply when the barriers outweigh the expected benefits [30]. Barriers in usability related to perceived usefulness and ease of use might be prevented with more involvement in design and testing of telecommunication technologies from patients, important persons in their social environment, and care givers who will be involved in the treatment of the patient [31, 32]. As such, more involvement of patients and professionals in user requirements and in fulfilment of clinical needs could improve the future use of an ambulatory feedback system [33, 34]. 


\section{Changes in daily physical activity}

In contrast with the results in regard to compliance, the results concerning the changes in physical activity were very promising. One of the reasons for this might be the objective measuring of physical activity. This excludes the possibility of misperceptions in activity levels with subjective outcome measures [35]. In addition, the feedback system is a very strong actuator through providing real time feedback in the home environment. This enables the opportunity of self-care management, likely improves the awareness in performing physical activity, and motivates to change [36, 37].

Compliers with the feedback system have changed their daily physical activity level in the direction of the goal. The physical activity level at baseline was beneath the goal and it has been changed within the range of the goal (90\%-110\%) instantaneously during nineteen of the twenty feedback days spread over the four feedback periods. This indicates that patients are able to response adequately to real time feedback for several weeks at home. Patients seem to learn from the feedback almost immediately with already a significant change towards the goal at the second feedback day. Only a small number of studies are reported in literature that investigated the effects of ambulant care in chronic fatigue syndrome. Jason et al. (2010) found positive effects on fatigue severity and vitality with a buddy intervention as compared to a control group with no treatment [38]. Positive outcomes are found also with pragmatic rehabilitation programs, which are intended to encourage a self managed graded exercise programme [39-41].

\section{Balance in daily physical activity}

The compliers have increased their physical activity levels in the morning and afternoon during all four feedback periods and, except for the morning of the first feedback period, these increased levels have resulted in patterns closer to the goal pattern. However, patients have not changed their activity levels in the evening and stayed below the level of the goal. The changes made in daily physical activity resulted in less balanced daily physical activity patterns. The role of fatigue seems to be an explanation for the low physical activity levels in the evening [6]. Patients with chronic fatigue syndrome might be able to increase activity levels during the 
morning and afternoon when fatigue levels are low, but are not able to increase activity levels during the evening when fatigue levels are high [3,6]. A second reason for the unchanged physical activity levels during the evening might be related to difficulties chronic patients have in behaviour change, as it likely requires the individual to restructure priorities in daily and social routines [32, 42]. A third reason might be a potential failure in the feedback in providing sufficient attention concerning balancing physical activities over the whole day. In according to the feedback, patients might be focused mainly on attempts to perform more or less physical activities to diminish existing gaps with the goal pattern. In future, more attention towards the importance of balancing daily physical activity patterns over the whole day might decrease the observed variability within daily physical activity patterns.

\section{Limitations}

A weakness of the current study is the selection bias caused by the dropout in the baseline measurements and the feedback program. Most patients who dropped out have reported problems with portability of the feedback system, and would likely not comply with the feedback system and change their physical activity pattern towards the goal. We have not found any significant difference at baseline between the fifteen compliers and fifteen non compliers. However, the mean physical activity level at baseline of the non compliers was, in contrast with the compliers, already within the range of the goal. In more detail, in the group of non compliers fewer patients have shown a baseline physical activity level below the goal and more patients within the range or above the goal. This could have decreased expectations towards usefulness of the feedback program in the group of non compliers. In future, better in- and exclusion based on baseline levels and patients expectations towards the feedback program might be important.

The feedback program was implemented in a current inpatient rehabilitation program consisting of cognitive behavioural therapy. In this way the feedback program is supplemental to the rehabilitation program by giving assistance in performing healthy physical activity patterns during the time patients are at home [3]. However, the rehabilitation program alone likely influences also the physical 
activity pattern at home. Therefore, changes made in physical activity patterns at home cannot be attributed only to the feedback program. In future, the influence of the treatment can be controlled for by including a control group without a feedback program and measuring physical activity patterns at home during the intermittent periods of the treatment program. Furthermore, therapists from the rehabilitation program were not involved in the feedback program. Involvement of therapists might decrease dropout rates and increase effectiveness of the feedback intervention [15].

\section{Acknowledgements}

This work is part of the ZonMw project 'chronisch vermoeidheidssyndroom' (http://www.zonmw.nl/nl/onderwerpen/alle-programma-s/cvs/gehonoreerdonderzoek/).

\section{Declaration of interest}

The authors report no declarations of interest. 


\section{References}

1. Reid SF, Chalder T, Cleare A, Hotopf M, Wessely S. Chronic fatigue syndrome. Clin Evid (Online) 2008;8:1101.

2. Wessely S, David A, Butler S, Chalder T. Management of chronic (post-viral) fatigue syndrome. J R Coll Gen Pract 1989; 39(318):26-9.

3. Evering RMH, Tonis TM, Vollenbroek-Hutten MM. Deviations in daily physical activity patterns in patients with the chronic fatigue syndrome: a case control study. J Psychosom Res 2011; 71(3):129-35.

4. Van der Werf SP, Prins JB, Vercoulen JH, van der Meer JW, Bleijenberg G. Identifying physical activity patterns in chronic fatigue syndrome using actigraphic assessment. J Psychosom Res 2000; 49(5):373-9.

5. Burton C, Knoop H, Popovic N, Sharpe M, Bleijenberg G. Reduced complexity of activity patterns in patients with Chronic Fatigue Syndrome: a case control study. Biopsychosoc Med (online) 2009; 3:7.

6. Kop WJ, Lyden A, Berlin AA et al. Ambulatory monitoring of physical activity and symptoms in fibromyalgia and chronic fatigue syndrome. Arthritis Rheum 2005; 52(1):296-303.

7. Rimes KA, Chalder T. Treatments for chronic fatigue syndrome. Occup Med $2005 ; 55(1): 32-9$.

8. Davenport TE, Stevens SR, VanNess MJ, Snell CR, Little T. Conceptual model for physical therapist management of chronic fatigue syndrome/myalgic encephalomyelitis. Phys Ther 2010; 90(4):602-14.

9. Van Houdenhove B, Luyten P. Customizing treatment of chronic fatigue syndrome and fibromyalgia: the role of perpetuating factors. Psychosomatics 2008:49(6):470-7.

10. Jason L, Benton M, Torres-Harding S, Muldowney K. The impact of energy modulation on physical functioning and fatigue severity among patients with ME/CFS. Patient Educ Couns 2009; 77(2):237-41.

11. Larun L, Malterud K. Finding the right balance of physical activity: a focus group study about experiences among patients with chronic fatigue syndrome. Patient Educ Couns 2011 ; 83(2):222-6. 
12. Weinstock RS, Brooks G, Palmas W et al. Lessened decline in physical activity and impairment of older adults with diabetes with telemedicine and pedometer use: results from the IDEATel study. Age Ageing 2011; 40(1):98-105.

13. Christian JG, Bessesen DH, Byers TE, Christian KK, Goldstein MG, Bock BC. Clinic-based support to help overweight patients with type 2 diabetes increase physical activity and lose weight. Arch Intern Med 2008; 168(2):141-6.

14. King DK, Estabrooks PA, Strycker LA, Toobert DJ, Bull SS, Glasgow RE. Outcomes of a multifaceted physical activity regimen as part of a diabetes self-management intervention. Ann Behav Med 2006; 31 (2):128-37.

15. Rosser BA, Vowles KE, Keogh E, Eccleston C, Mountain GA. Technologicallyassisted behaviour change: a systematic review of studies of novel technologies for the management of chronic illness. J Telemed Telecare $2009 ; 15(7): 327-38$.

16. Hermens HJ, Vollenbroek-Hutten MM. Towards remote monitoring and remotely supervised training. J Electromyogr Kinesiol 2008; 18(6):908-19.

17. Kairy D, Lehoux P, Vincent C, Visintin M. A systematic review of clinical outcomes, clinical process, healthcare utilization and costs associated with telerehabilitation. Disabil Rehabil 2009; 31(6):427-47.

18. DeChant HK, Tohme WG, Mun SK, Hayes WS, Schulman KA. Health systems evaluation of telemedicine: a staged approach. Telemed J 1996; 2(4):30312.

19. Fukuda K, Straus SE, Hickie I, Sharpe MC, Dobbins JG, Komaroff A. The chronic fatigue syndrome: a comprehensive approach to its definition and study. International Chronic Fatigue Syndrome Study Group. Ann Intern Med 1994; $121(12): 953-9$.

20. Vercoulen JH, Swanink CM, Fennis JF, Galama JM, van der Meer JW, Bleijenberg G. Dimensional assessment of chronic fatigue syndrome. J Psychosom Res 1994; 38(5):383-92. 
21. Derogatis LR, Liman RS, Covi L, Arrindell WA, Ettema JHM. 90-item Symptom Distress Checklist (SCL-90). Furer JW, König-Zahn C, Tax B. Het meten van de gezondheidstoestand, deel 3: psychische gezondheid. Assen: Van Gorcum, 1995, pp.147-70.

22. Arrindell WA, Ettema J.H.M. SCL-90: handleiding bij een multidimensionele psychopathologie-indicator. Lisse: Swets Test Publishers, 1986.

23. Torenbeek M, Mes CA, van Liere M] et al. [Favourable results of a rehabilitation programme with cognitive behavioural therapy and graded physical activity in patients with the chronic-fatigue syndrome]. Ned Tijdschr Geneeskd 2006; 150(38):2088-94.

24. Bouten CV, Westerterp KR, Verduin M, Janssen JD. Assessment of EnergyExpenditure for Physical-Activity Using a Triaxial Accelerometer. Medicine and Science in Sports and Exercise 1994; 26(12):1516-23.

25. Bouten CVC, Verboeket-van de Venne WPHG, Westerterp KR, Verduin M, Janssen JD. Daily Physical Activity Assessment: Comparison Between Movement Registration and Doubly Labeled Water. Journal of Applied Physiology 1996; 81(2):1019-26.

26. Vercoulen JH, Alberts M, Bleijenberg G. De checklist individual strength (CIS). Gedragstherapie 1999; 32(2):131-6.

27. Bultmann U, de Vries M, Beurskens AJ, Bleijenberg G, Vercoulen JH, Kant I. Measurement of prolonged fatigue in the working population: determination of a cutoff point for the checklist individual strength. J Occup Health Psychol 2000; 5(4):411-6.

28. Edmonds M, McGuire H, Price J. Exercise therapy for chronic fatigue syndrome. Cochrane Database Syst Rev 2004; (3):CD003200.

29. Taylor S, Todd PA. Understanding Information Technology Usage: a Test of Competing Models. Information Systems Research 1995; 6(2):144-76.

30. Huis in 't Veld RM, Kosterink SM, Barbe T, Lindegard A, Marecek T, Vollenbroek-Hutten MM. Relation between patient satisfaction, compliance and the clinical benefit of a teletreatment application for chronic pain. J Telemed Telecare 2010; 16(6):322-8. 
31. Arsand E, Tatara N, Ostengen G, Hartvigsen G. Mobile phone-based selfmanagement tools for type 2 diabetes: the few touch application. J Diabetes Sci Technol 2010; 4(2):328-36.

32. Klasnja P, Consolvo S, McDonald DW, Landay JA, Pratt W. Using mobile \& personal sensing technologies to support health behavior change in everyday life: lessons learned. In AMIA Annual Symposium Proceedings $2009 ; 338-42$.

33. Vollenbroek-Hutten MM, Hermens HJ. Remote care nearby. J Telemed Telecare 2010; 16(6):294-301.

34. Kennedy A, Rogers A, Bower P. Support for self care for patients with chronic disease. BMJ 2007; 335(7627):968-70.

35. Evering RM, van Weering MG, Groothuis-Oudshoorn KC, VollenbroekHutten MM. Daily physical activity of patients with the chronic fatigue syndrome: a systematic review. Clin Rehabil 2011; 25(2):112-33.

36. Van Weering M, Vollenbroek-Hutten MM, Kotte EM, Hermens HJ. Daily physical activities of patients with chronic pain or fatigue versus asymptomatic controls. A systematic review. Clin Rehabil 2007 Nov; 21(11):1007-23.

37. Van Weering M, Vollenbroek-Hutten MM, Hermens HJ. Chapter 6: Potential value of an activity-based feedback system for treatment of patients with chronic low back pain. In: Van Weering M. Towards a new treatment for chronic low back pain patients, using activity monitoring and personalized feedback. Enschede, The Netherlands: Gildeprint Drukkerijen, 2011 , pp. $115-42$.

38. Jason LA, Roesner N, Porter N, Parenti B, Mortensen J, Till L. Provision of social support to individuals with chronic fatigue syndrome. J Clin Psychol 2010; 66(3):249-58.

39. Powell P, Bentall RP, Nye FJ, Edwards RH. Randomised controlled trial of patient education to encourage graded exercise in chronic fatigue syndrome. BMJ 2001; 322(7283):387-90. 
40. Wearden AJ, Dowrick C, Chew-Graham C et al. Nurse led, home based self help treatment for patients in primary care with chronic fatigue syndrome: randomised controlled trial. BMJ 2010; 340:c1777.

41. Powell P, Edwards RHT, Bentall RP. The treatment of wheelchair-bound chronic fatigue syndrome patients: Two case studies of a pragmatic rehabilitation approach. Behavioural and Cognitive Psychotherapy 1999; 27(03):249-60.

42. Surawy C, Hackmann A, Hawton K, Sharpe M. Chronic fatigue syndrome: a cognitive approach. Behav Res Ther 1995; 33(5):535-44. 
122 Chapter 4 


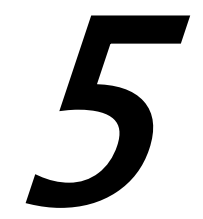

Ambulatory feedback at daily physical activities in treatment of chronic fatigue syndrome: A randomized controlled trial

Evering RMH, Drossaert CHC, and Vollenbroek-Hutten MMR. Ambulatory feedback at daily physical activities in treatment of chronic fatigue syndrome: A randomized controlled trial. Submitted 


\begin{abstract}
Objective: To study the effectiveness of providing real-time ambulatory activitybased feedback at daily physical activity patterns in the treatment of chronic fatigue syndrome (CFS). It was hypothesized that patients receiving ambulatory activitybased feedback in addition to rehabilitation treatment had significant more decrease in fatigue severity and improved physical functioning as compared to patients receiving rehabilitation treatment alone.
\end{abstract}

Methods: A randomized controlled trial was performed in which 81 CFS-patients eligible for treatment in rehabilitation centre 'Het Roessingh' were randomly assigned to a group receiving the ambulatory feedback intervention in addition to standard rehabilitation treatment comprising cognitive behavioural therapy (CBT) and graded exercise therapy (GET) or to a group receiving standard rehabilitation treatment alone. Primary outcome measures were fatigue severity and physical functioning. Secondary outcome measures were social functioning, patient specific complaints, self-efficacy, somatic attributions and psychological attributions.

Results: Forty-two patients were allocated to the intervention group and 39 patients to the control group. Both groups showed statistically significant improvements in fatigue severity, physical functioning, social functioning, patient specific complaints and self-efficacy directly after treatment and at follow up when compared to baseline. However, improvements in these primary and secondary outcome measures did not differ between groups. For somatic attributions and psychological attributions both groups improved directly after treatment but these values normalized at follow-up. Again there were no differences between both groups.

Conclusion: This study has not found an additional value of ambulatory activitybased feedback as supplement to an inpatient rehabilitation program comprising CBT and GET. 


\section{Introduction}

Chronic fatigue syndrome (CFS) is characterized by severe, disabling and unexplained chronic fatigue lasting for at least six months. Other symptoms can include musculoskeletal pain, sleep disturbance, impaired concentration, and headaches [1, 2]. The aetiology of CFS is unknown and only treatment of perpetuating factors in CFS seem to be effective in reducing CFS complaints as stated in a model of Vercoulen et al. (1998) [3]. This model explains the perpetuation of fatigue in CFS through cognitive factors (low level of sense of control, somatic attributions and somatic focus) and behavioural factors (low level of physical activity and physical impairment) [3]. The most promising treatment results are found for cognitive behavioural therapy (CBT) and graded exercise therapy (GET) $[1,4,5]$. However, despite the promising results found with CBT and GET, still a significant number of CFS patients do not encounter a reduction of CFS complaints after treatment [6-9].

Several studies have shown that CFS patients are less physically active and show deviating patterns as compared to healthy controls [3, 4, 10-14]. As such, a balanced daily physical activity pattern is considered to be important in the treatment of CFS [1, 15]. However, one explanation for the disappointing results in a number of patients might be that the current way CBT and GET pay attention to a balanced daily physical activity pattern is inadequate. Daily physical activities are often kept up by the CFS patient in a diary. However, the use of activity diaries as starting point may be inadequate as CFS patients may over- or underestimate their own physical activity level $[11,16,17]$. As such using objective monitoring tools as starting point for changing daily physical activity patterns may enhance treatment outcome [18-20]. One way of doing this, is by monitoring daily physical activities using accelerometers and providing adequate feedback on this during everyday life activities. It is expected that this will give the CFS patient more insight in his own physical activity pattern and inform about inadequate aspects. This will increase the patient's awareness and will motivate him to change activity behaviour in the direction of healthy patterns. The use of real time feedback on objectively measured physical activity behaviour in every day life would likely be more accurate 
in providing feedback than feedback based on patients' own experiences [21-24]. In addition, real time feedback is considered to be in line with the current trend of enhancing self management in chronic illnesses [25-27]. The aim of this study was to improve the treatment of CFS with the provision of real-time feedback at objectively assessed physical activity patterns in daily life.

In this study we have used an accelerometer for monitoring physical activity and a personal digital assistant (PDA) for providing ambulatory feedback at daily physical activity patterns in the home situation of CFS patients. This treatment module was added to an inpatient multi-component rehabilitation program consisting of combined CBT and GET delivered in a group therapy format [9]. The main study question was: can the effectiveness of traditional rehabilitation therapy based on CBT and GET be enhanced in decreasing fatigue severity and improving physical functioning with an ambulatory activity-based feedback module. 


\section{Methods}

\section{Design}

A randomized controlled trial was performed in which CFS patients were allocated to the intervention group with ambulatory activity-based feedback in addition to rehabilitation treatment or to the control group with rehabilitation treatment alone. The standard inpatient multi-component rehabilitation program was provided in rehabilitation centre 'het Roessingh' (Enschede, The Netherlands) and comprises combined CBT and GET [9]. Treatment consists of nine weeks in which patients are alternately five days in the rehabilitation centre (week 1, 3, 5, 7, and 9) and nine days at home. Subsequently, after week 9 patients are eleven weeks at home and finally they are treated for five full days at the rehabilitation centre during a followup week (week 21). The program is offered by a team consisting of a psychologist, a rehabilitation physician, a physiotherapist, an occupational therapist, a sports instructor and a social worker. The daily activities in the group are supervised by social workers educated in group supervision. The program consists of CBT interventions aimed at diminishing the influence of perpetuating factors, specified as high somatic (rather than psychological) attributions of complaints, low self efficacy and a low physical activity level $[9,28]$. Cognitive restructuring, problem solving, and individual goal setting, are part of the interventions of psychologists and social workers. GET is given by physiotherapists and sport instructors. Finally, interventions of occupational therapists are provided, aimed at optimising the level of daily activities. Data was obtained between November 2008 and May 2011 . The study was carried out in accordance with the declaration of Helsinki and approved by the accredited medical research ethics committee of the hospital 'Medisch Spectrum Twente' in Enschede, The Netherlands.

\section{Participants}

CFS patients who were diagnosed and referred to the inpatient rehabilitation program of rehabilitation centre 'Het Roessingh' by a general practitioner or a medical specialist in the period between November 2008 and November 2010 were considered for participation in the study. Inclusion and exclusion criteria were 
assessed in an intake procedure prior to the treatment. Diagnosis of CFS by a general practitioner or a medical specialist was performed following the criteria for CFS of the Centres for Disease Control and Prevention of 1994 and had to be confirmed at the rehabilitation centre [2]. Other inclusion criteria were: in the age of between 18 and 65 years; severe fatigue (Checklist Individual Strength-20 (CIS-20) subscale subjective fatigue $\geq 35$ ); being motivated to participate in a selfmanagement program; being able to follow therapies for 5 hours a day. Exclusion criteria were: severe psychopathology (Symptom Checklist-90 (SCL-90) > 295); extensive cognitive deficits; severe psychosocial problems of an acute nature that needed solution before treatment; enforced motivation by a legal procedure concerning financial benefit; bounded to a wheelchair; being pregnant. A total of 90 patients were assessed for eligibility in this study. One patient was pregnant and therefore not eligible, and eight patients refused to participate. This resulted in 81 patients who met the trial criteria, were willing to take part in the trial and signed informed consent. Patients were randomly assigned to either the control group or to the intervention group. Assessors of the intake procedure were blinded for randomization. As the treatment program is offered in groups of six patients, the randomisation took place at group level to prevent contamination within the same treatment group. The randomization was performed by a researcher who was not involved into the rehabilitation program. Patients and therapists were not informed about the outcome of the randomisation until the outcome measurements at start of the treatment were performed (T1). We aimed an extra decrease of 7 points at the fatigue severity subscale of the CIS-20 in the intervention group. This aim is based on results shown in other RCTs [6-8]. Power calculations showed that we needed 39 patients in each group to achieve $80 \%$ power to detect a difference of 7 points between $\mathrm{T} 1$ and T2 on the fatigue severity subscale of the CIS-20 with an $\alpha$ $<5 \%$.

\section{Intervention: Ambulatory activity-based feedback}

The ambulatory activity-based feedback was implemented in the four periods in between the first five weeks of inpatient rehabilitation when patients were at home. Patients allocated to the intervention group used the ambulatory activity-based 
feedback at home without involvement of therapists. Patients and therapists were blinded for the randomization before start of the treatment, but after start of treatment blinding was not possible because of dealing with the feedback system. Ambulatory feedback to daily activities was provided with a feedback system. The system consisted of a tri-axial piezoelectric accelerometer, and a personal digital assistant (PDA). The accelerometer was worn at the waist and measured physical activity in counts per minute. Data from the accelerometer was transmitted through Bluetooth connection to the PDA on which data was stored (figure 1a). The feedback was given to the patient at the PDA and this feedback was based on the actual difference between the cumulative physical activity level of the patient and the goal (figure $1 \mathrm{~b}$ and $1 \mathrm{c}$ ). The goal was based on the mean daily activity pattern at each hour between 8.00 and 22.00 of 57 healthy controls. The mean daily activity level of the goal can be categorized as a moderate activity level [29].

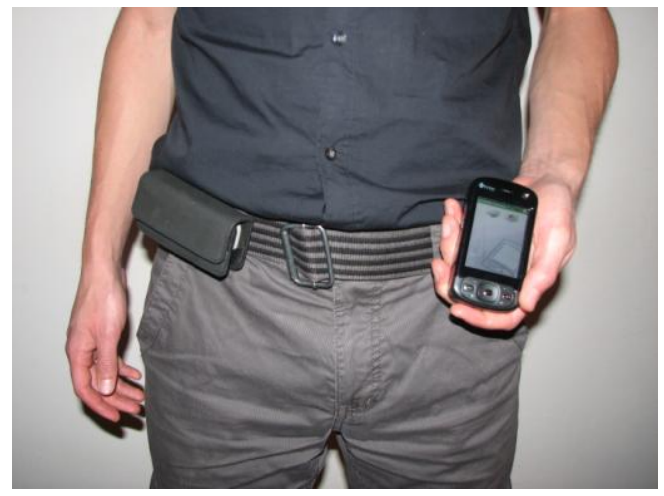

Figure 1a Wearing of the feedback system

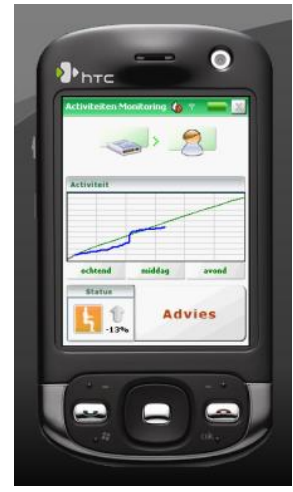

Figure $1 \mathrm{~b}$

Cumulative daily physical activity pattern

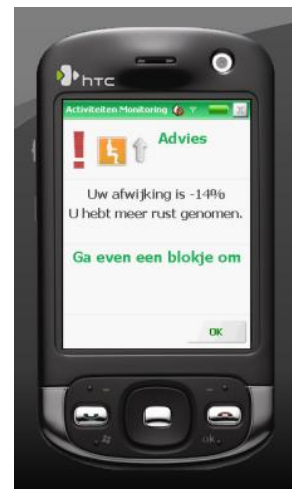

Figure 1c Difference with the goal, activity judgement and advice

Feedback was provided in two different ways: (1) The PDA showed continuously a graph (figure $1 \mathrm{~b}$ ) displaying the cumulative goal pattern for the whole day $(8.00$ 22.00) together with the cumulative physical activities of the patient drawn minute by minute. The difference between the cumulative activity level of the goal and the patient was displayed in percentages. (2) Every 2 hours $(10.00,12.00,14.00$, 
16.00, 18.00 and 20.00), three text lines were presented at the PDA (figure 1c) representing:

- The difference between the cumulative activity level of the goal and patient at that time.

- A judgment about the performance of the last two hours. This judgement gave the patient insight in whether the change in activity level during the last two hours was appropriate. Twelve different circumstances were distinguished in forming a judgement based on three factors; 1) The difference with the goal at start of the two hourly period (above the goal, equal with the goal, or beneath the goal); 2) The change in the difference with the goal during the two hourly period (decrease or increase); 3) The difference with the goal at the end of the two hourly period (above the goal, equal with the goal, or beneath the goal). Examples of written judgements were: 'You have taken more rest' and 'You have taken more activity'.

- An activity advice. The activity advice stimulated the patient to perform activities at the right intensity level the next two hours in order to decline the difference with the goal. The patient received a discouraging activity advice (e.g. Have you already read the newspaper?) when the cumulative activity level was above the goal (>110\%), an encouraging activity advice (e.g. Have a nice walk!) if the cumulative activity level was below the goal $(<90 \%)$ and a neutral advice (e.g. Keep continuing) if the cumulative activity level was between $90 \%$ and $110 \%$ of the goal.

The difference between the individual cumulative activity level and the goal could become very large if the patient was high or low physically active during a prolonged period of time. Insurmountable differences between the individual cumulative activity level and the goal, build up during the morning and/or afternoon, were prevented by resetting the difference to zero at 13.00 and 17.00 by placing the individual cumulative activity level back to the goal. Oral and written instructions were provided regarding proper accelerometer placement, wearing schedule and user instructions of the accelerometer and PDA. The feedback intervention took place during daytime between 8.00 and 22.00 , excluding time spent bathing or participating in water activities. 


\section{Measures}

Demographics and background variables were obtained at the intake (T0).

Demographics comprised gender, age and work status. Other personal background variables that were assessed at the intake included duration of CFS complaints, physical activity level, psychological distress and depression. Physical activity was assessed in counts per minute before and after treatment for one week with the same accelerometer as used in the feedback intervention. Physical activity measurements after treatment were not analysed as a limited number of patients complied with the activity measurements. Psychological distress was measured with the Symptom Checklist 90 (SCL-90) [30, 31]. This scale consists of 90 items scored on a five point scale loading on eight subscales (somatisation, obsessivecompulsive, depression, anxiety, hostility, phobic anxiety, paranoid ideation, and psychoticism) and a total score (range 90 - 450) with high scores reflecting high psychological distress. Depression was assessed with the subscale depression of the SCL-90, consisting of sixteen items and a total score range from 16 till 80 . Primary and secondary outcome measures were assessed at the start of the treatment in week 1 (T1), at the end of the treatment in week 9 (T2), and at followup in week 21 (T3). Primary outcome measures comprised fatigue severity and physical functioning; secondary outcome parameters comprised social functioning, patient specific complaints, self efficacy, somatic attributions and psychological attributions. Fatigue severity was measured with the subscale 'subjective experience of fatigue' of the Checklist Individual Strength (CIS-20) [32]. This subscale consists of eight items scored on a 7-point scale (range 7 - 56) with high scores reflecting higher levels of fatigue. Physical functioning was assessed with a subscale of the Dutch version of the SF-36 Health Survey [33, 34]. This subscale consists of ten items scored on a 3 -point scale (ranges 10 - 30, transformed to $0 \%$ - 100\%) and low scores reflect severe impairment of physical functioning. Social functioning was assessed with a subscale of the SF-36, and consists of two items scored on a 5-point scale (ranges 2 - 10, transformed to 0 - 100\%) [33, 34]. Low scores reflect severe restrictions in perceived social functioning. Patient specific complaints were assessed for evaluating individually reported perceived constraints in the performance of the three most important activities in daily life [35]. The three 
complaints were scored on a 100 millimetre VAS scale (ranges 0 - $100 \mathrm{~mm}$ ) and high scores reflected severe perceived constraints. Self efficacy was defined as the expectations patients have with regard to possibilities to influence their own complaints, and was assessed with the Self Efficacy Scale (SES) [7]. The SES consists of five items with four items scored on a 5-point scale and one item scored on a 4point scale (ranges 5 -24), high scores reflected high expectations of self efficacy. The Causal Attribution List (CAL) measured the extent in which patients attributed complaints to somatic or psychological attributions [36, 37]. The CAL consists of ten items loading on two subscales (5 items on somatic attributions and 5 items on psychological attributions), scored on a 4-point scale (range 5 - 20) and high scores reflected strong attributions.

\section{Statistical analysis}

The Statistical Package for the Social Sciences (SPSS18) was used for statistical analysis. The Shapiro-Wilk test was used for testing normality of dependent variables, and the $\alpha$ level of significance was set at $p<0.05$ for all analyses. Pearson chi square test was used for testing differences between groups at baseline for gender and work status. Independent t-test was used for testing differences between groups at baseline for age, physical activity level, duration of complaints, psychological distress, depression and the primary and secondary outcome measures. Levene's test was used for testing equality of variances. The MannWhitney $U$ test was used instead of the independent $t$-test if the dependent variable was not normally distributed.

Intention to treat analysis was performed with the use of a linear mixed model repeated measures with restricted maximum likelihood for analyzing differences in the primary and secondary outcome measures. Time (T1, T2, and T3), group (control group vs. intervention group) and the interaction time*group were included as fixed factors and subject as grouping factor for paired measures. 


\section{Results}

Eighty-one patients with the chronic fatigue syndrome (CFS) were included in the RCT (see figure 2 for flow of patients through this study), 9 males and 72 females with a mean age of 36.5 and mean duration of CFS complaints of 7.7 years.

Randomisation took place after the baseline measurements; thirty-nine patients were allocated to the control group and 42 to the intervention group. The physical activity level measurements at baseline were successfully obtained for 61 of the 81 patients. Reasons for not being successful were: insufficient data $(n=10)$; insufficient time for measuring physical activity before start of treatment $(n=6)$ or other reasons $(n=4)$.

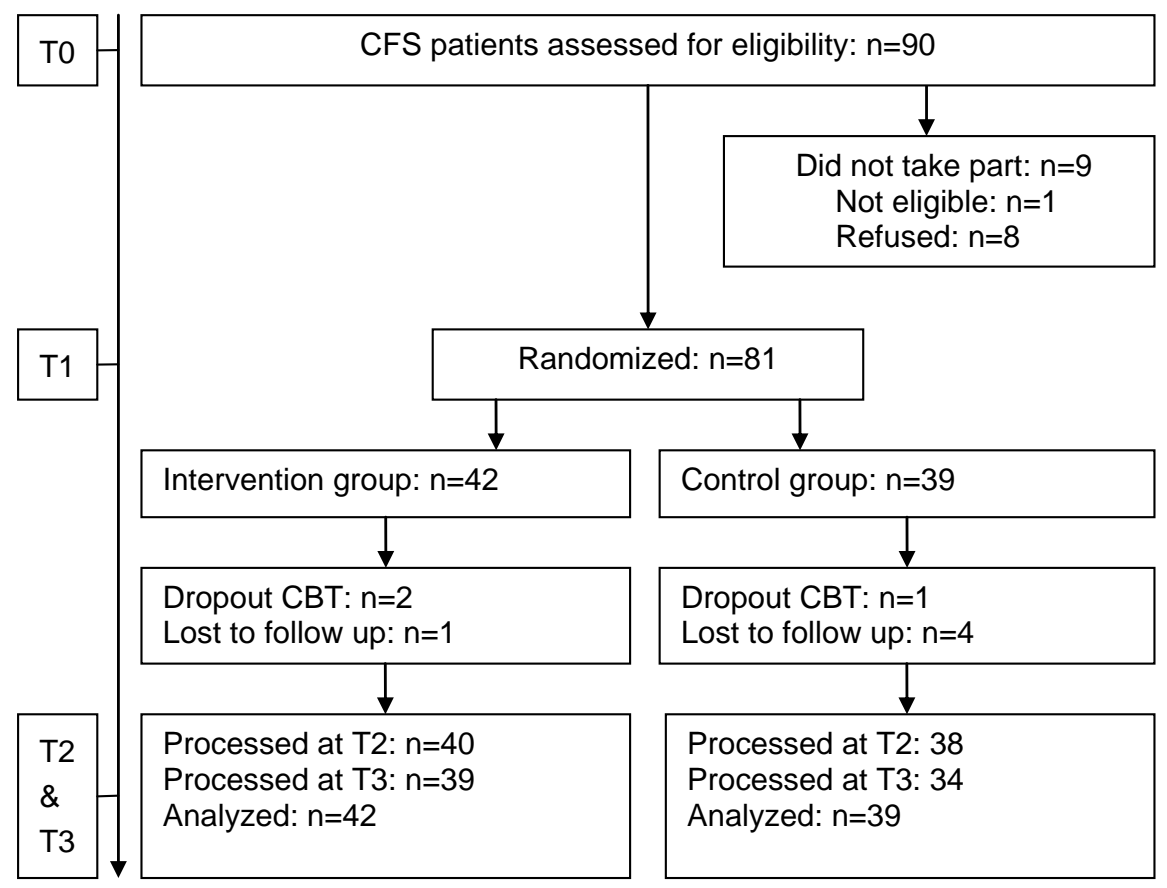

Figure 2 Flowchart number of CFS patients

a Guidelines of the CONSORT statement are taken into account [38].

Of the 42 patients that were randomised in the intervention group, 34 patients started the first intervention period, 29 patients the second intervention period, 23 the third intervention period and 21 the fourth intervention period. Patients' 
characteristics at baseline (table I) were not significant different between groups, except for depression.

Table I Group characteristics at baseline. Values are means (SD) unless stated otherwise

\begin{tabular}{|c|c|c|c|}
\hline & $\begin{array}{l}\text { Intervention group } \\
(\mathrm{n}=42)\end{array}$ & $\begin{array}{l}\text { Control group } \\
(n=39)\end{array}$ & $P$ value \\
\hline \multirow[t]{2}{*}{ Gender } & 4 male & 5 male & 0.637 \\
\hline & 38 female & 34 female & \\
\hline Age (years) & $36.3(10.5)$ & 36.7 (11.9) & 0.910 \\
\hline Work status (number of patients) & & & 0.152 \\
\hline 1. Working & 17 & 11 & \\
\hline 2. Sick leave/ invalidity benefits & 7 & 8 & \\
\hline 3. Combination of 1 and 2 & 5 & 10 & \\
\hline 4. Else & 12 & 6 & \\
\hline 5. Unknown & 1 & 4 & \\
\hline Physical activity level (counts per & $974(275)$ & $1037(279)$ & 0.356 \\
\hline minute) & $\mathrm{n}=34$ & $\mathrm{n}=27$ & \\
\hline \multirow[t]{2}{*}{ Duration of CFS complaints (years) } & $7.9(6.6)$ & $7.4(8.0)$ & 0.386 \\
\hline & $\mathrm{n}=40$ & $\mathrm{n}=38$ & \\
\hline Psychological distress (total score & $176.8(47.2)$ & $187.3(39.7)$ & 0.149 \\
\hline SCL-90) & $\mathrm{n}=40$ & $\mathrm{n}=35$ & \\
\hline \multirow[t]{2}{*}{ Depression (subscale SCL-90) } & $33.2(10.3)$ & $37.7(10.5)$ & 0.027 \\
\hline & $\mathrm{n}=40$ & $\mathrm{n}=35$ & \\
\hline
\end{tabular}

a Pearson chi square test was used for testing differences in gender and work status

b The Mann-Whitney $\mathrm{U}$ test was used for testing differences in age, physical activity level, duration of complaints, psychological distress and depression 


\section{Primary and secondary outcome measures}

Table II shows the primary and secondary outcome measures at T1, T2 and T3. The groups did not differ at baseline for all primary and secondary outcome measures, except for social functioning and self efficacy $(p=0.028$ and $p=0.014$ respectively). Patients in the intervention group had already a better score for social functioning and a higher self efficacy at baseline as compared to the control group. Differences in time were statistically different for all primary and secondary outcome measures (table II). In both groups the primary outcome measures improved at the end of treatment as compared to baseline. The scores at the primary outcome measures remained improved at follow-up in both groups. No significant time*group interactions were found, implying that differences in time were not related to the treatment received. This indicates that ambulatory activity-based feedback did not result in an extra improvement in fatigue severity and physical functioning. In both groups social functioning, patient specific complaint 1,2 and 3, and self efficacy improved at the end of treatment as compared to baseline. The scores at patients specific complaints 1,2 and 3, and self efficacy remained improved at follow-up in both groups. Social functioning improved also at follow-up as compared to the end of treatment in the control group, while in the intervention group this score somewhat deteriorated. In both groups somatic and psychological attributions changed significantly in time. In both groups the decrease in somatic attributions and increase in psychological attributions at the end of treatment as compared to baseline returned back to the baseline values at follow-up. No significant time*group interactions were found for any of the secondary outcome measures, implying that differences in time were not related to the treatment received. 


\begin{tabular}{|c|c|c|c|c|c|c|c|c|}
\hline \multirow[b]{3}{*}{ Outcome measure } & \multirow{2}{*}{\multicolumn{3}{|c|}{$\begin{array}{l}\text { Intervention group } \\
(n=42)\end{array}$}} & \multirow{2}{*}{\multicolumn{3}{|c|}{$\begin{array}{l}\text { Control group } \\
(n=39)\end{array}$}} & \multirow{3}{*}{$\begin{array}{l}\text { Time } \\
\text { P-value }\end{array}$} & \multirow{3}{*}{$\begin{array}{l}\text { Time* } \\
\text { group } \\
\text { P-value }\end{array}$} \\
\hline & & & & & & & & \\
\hline & $\mathrm{Tl}$ & $\mathrm{T} 2$ & T3 & $\mathrm{Tl}$ & $\mathrm{T} 2$ & T3 & & \\
\hline Fatigue severity & $47.9(9.9)$ & $41.3(14.5)$ & $41.9(15.4)$ & $51.6(10.3)$ & $42.9(15.1)$ & $41.8(16.4)$ & $<0.001$ & 0.349 \\
\hline Physical functioning & $56.4(24.0)$ & $62.0(27.2)$ & $62.3(25.6)$ & $52.6(25.9)$ & $61.3(28.3)$ & $66.7(27.3)$ & $<0.001$ & 0.992 \\
\hline Social Functioning & $34.2(27.8)$ & $47.7(28.2)$ & $44.8(29.9)$ & $24.6(28.8)$ & $38.7(29.3)$ & $47.1(32.1)$ & $<0.001$ & 0.083 \\
\hline $\begin{array}{l}\text { Patient specific } \\
\text { complaint } 1\end{array}$ & $72.6(21.3)$ & $54.6(32.5)$ & $52.7(34.5)$ & $72.8(22.1)$ & $53.4(33.3)$ & $49.3(37.0)$ & $<0.001$ & 0.845 \\
\hline $\begin{array}{l}\text { Patient specific } \\
\text { complaint } 2\end{array}$ & $71.6(26.5)$ & $59.2(30.7)$ & $54.9(31.7)$ & $72.1(27.5)$ & $56.0(31.9)$ & $53.5(34.0)$ & $<0.001$ & 0.845 \\
\hline $\begin{array}{l}\text { Patient specific } \\
\text { complaint } 3\end{array}$ & $69.2(22.9)$ & $57.1(27.3)$ & $55.5(29.9)$ & $73.8(23.5)$ & $55.3(28.5)$ & $50.5(31.8)$ & $<0.001$ & 0.223 \\
\hline Self efficacy & $16.8(4.8)$ & $18.4(5.1)$ & $17.9(5.7)$ & $14.8(5.0)$ & $17.7(5.2)$ & $17.2(6.1)$ & $<0.001$ & 0.354 \\
\hline Somatic attributions & $12.7(4.2)$ & $12.2(4.5)$ & $12.7(4.1)$ & $11.9(4.3)$ & $11.1(4.7)$ & $11.7(4.3)$ & $<0.01$ & 0.774 \\
\hline
\end{tabular}




\section{Discussion}

This study has investigated the additional value of ambulatory activity-based feedback at daily physical activities as supplement to an inpatient rehabilitation program comprising cognitive behavioural therapy (CBT) and graded exercise therapy (GET). The results do not support an additional value of ambulatory activity-based feedback. Improvements in fatigue severity and physical functioning did not differ between the intervention group and control group. Also improvements in the secondary outcome parameters; social functioning, patient specific complaints, self efficacy, somatic attributions and psychological attributions did not differ significantly between groups.

We expected that ambulatory activity-based feedback would be of supplemental value in decreasing fatigue severity and improving physical functioning, as disturbed physical activity patterns are thought to have an important role in the perpetuation of CFS $[1,3,15]$. Several reasons could explain why we have not found any supplemental value. First of all, it could be that the ambulatory activity-based feedback intervention needs to be optimized in assisting adequate activity behaviour in patients with CFS. One step in optimizing the feedback intervention could be incorporating a more individualised goal setting. The goal has been based on physical activity patterns of healthy controls while it could have been more adequate to adapt the goal to activity levels of the individual patient [20]. This belief is strengthened with the large differences in physical activity patterns recognized between patients with CFS [1 1 ]. A second reason in not finding a supplemental value could be the way the ambulatory activity-based feedback intervention was implemented and evaluated. The implementation of the feedback intervention has not been optimal as only 34 of the 42 patients wore the feedback system during the first feedback period and this number decreased in the subsequent feedback periods till 21 in the fourth feedback period. Patients reported problems with portability as the main reason for not wearing the feedback system. Another factor that could have negatively influenced the implementation and evaluation of the feedback intervention is that patients might have ignored the feedback. Patients might have experienced difficulties in changing activity 
behaviour as it likely requires the individual to restructure daily and social routines $[14,39]$. Another reason for ignoring the feedback could be that the feedback tips were insufficiently adapted to the patients' context and preferences, i.e. not tailored enough. More research is needed to investigate in which way the feedback intervention could be optimized and the way the implementation can be improved to optimize the compliance with the feedback intervention.

This is so far as we know the first study investigating the effectiveness of ambulatory activity-based feedback at real-time, objectively measured, daily physical activities. The goal of the feedback was assisting the patient in finding the right balance in performing daily physical activities. The physical activity data of the four feedback periods in the intervention group indicated more balanced daily physical activity patterns as compared to baseline (results will be presented in a subsequent article). However, the way we implemented the feedback intervention did not result in an improved treatment outcome. Nijs et al. (2009) also focussed on finding the right balance in daily physical activity patterns in CFS with a pacing self-management intervention [40]. Improvements were found in health status and the ability to perform physical activities and these improvements were related with a decrease in time spent on light activities, but were not related with the way physical activities were spread throughout the day as measured with an accelerometer [40]. Incorporation of pacing self-management principles by measuring the intensity of expended energy levels in the feedback intervention may be helpful in balancing daily physical activity as these principles may ensure that activities are conducted at the right intensity [41, 42]. Another way to improve the goal setting in the ambulatory activity-based feedback intervention could be incorporation of principles from the energy envelope theory that states that the perceived amount of energy available and perceived amount of energy expended play an important role in finding the right balance [43]. More favourable outcome with non pharmacological interventions were found on fatigue severity and physical functioning in patients with CFS who stayed within their energy envelope [19]. The improvements found in the intervention group as well as in the control group in fatigue severity and physical functioning could have been related to changes in daily physical activity patterns. However, we have not been able to study this 
relation, as we did not obtain physical activity measurements after treatment. Friedberg and Sohl (2009) found improvements in CFS after CBT among patients with increased, decreased as well as unchanged activity levels [44]. This suggests that improvements in CFS complaints may not be related to changes in daily physical activity patterns; however more research is needed to can draw conclusions about this relation.

This study is performed taken the CONSORT guidelines into account for reporting randomized trials [38]. However, we have not been able to perform the randomized controlled trial without any limitations. Firstly, it was not possible to blind patients and therapists after allocation of the intervention. Patients in the intervention group could deliberately ignore the ambulatory activity-based feedback intervention resulting in the same treatment as in the control group. Non-compliance in the intervention group could have diminished effects of the intervention on the outcome measures. Secondly, therapists were not directly involved in providing the ambulatory activity-based feedback intervention. This could have diminished the urgency for patients to comply with the feedback intervention. Involvement of therapists might have decreased dropout rates and increased effectiveness of the feedback intervention [27]. Moreover, cognitions about activity behaviour could be of more importance in the treatment of CFS than changing real-time objectively measured activity levels [45]. The feedback system has been developed to assist in reaching balanced physical activity levels, but has not the intention to change cognitions about activity behaviour. Cognitions about physical activity play an important role in the well being of patients with CFS as patients may fear to become more active or have catastrophic beliefs about the performance of physical activity [46-49]. Involvement of psychologists in the feedback intervention could have integrated the feedback intervention more adequately in the treatment of CFS as cognitions about physical activity would have been taken into account. Thirdly, potential selection bias can not be ruled out as only patients who were assigned to and capable of following an inpatient rehabilitation program were included into this study.

In summary, this study has not found additional value of ambulatory activity-based feedback as supplement to an inpatient rehabilitation program comprising CBT and 
GET. More research is needed to explore if the feedback intervention will be helpful when cognitions about activity behaviour are taken into account, goal setting strategies are adapted to the individual patient and therapists are involved in implementing the intervention.

\section{Acknowledgements}

This work is part of the ZonMw project 'chronisch vermoeidheidssyndroom' (http://www.zonmw.nl/nl/onderwerpen/alle-programma-s/cvs/gehonoreerdonderzoek/).

\section{Competing interests}

The authors have no competing interests to report. 


\section{References}

1. Reid SF, Chalder T, Cleare A, Hotopf M, Wessely S: Chronic fatigue syndrome. Clin Evid (Online) 2008, 2008.

2. Fukuda K, Straus SE, Hickie I, Sharpe MC, Dobbins JG, Komaroff A: The chronic fatigue syndrome: a comprehensive approach to its definition and study. International Chronic Fatigue Syndrome Study Group. Ann Intern Med 1994, $121(12): 953-959$.

3. Vercoulen JH, Swanink CM, Galama JM, Fennis JF, Jongen PJ, Hommes OR, van der Meer JW, Bleijenberg G: The persistence of fatigue in chronic fatigue syndrome and multiple sclerosis: development of a model. J Psychosom Res 1998, 45(6):507-517.

4. Wessely S, David A, Butler S, Chalder T: Management of chronic (post-viral) fatigue syndrome. J R Coll Gen Pract 1989, 39(318):26-29.

5. Price JR, Mitchell E, Tidy E, Hunot V: Cognitive behaviour therapy for chronic fatigue syndrome in adults. Cochrane Database Syst Rev 2008(3):CD001027.

6. Bazelmans E, Prins JB, Lulofs R, van der Meer JW, Bleijenberg G: Cognitive behaviour group therapy for chronic fatigue syndrome: a non-randomised waiting list controlled study. Psychother Psychosom 2005, 74(4):21 8-224.

7. Prins JB, Bleijenberg G, Bazelmans E, Elving LD, de Boo TM, Severens JL, van der Wilt GJ, Spinhoven P, van der Meer JW: Cognitive behaviour therapy for chronic fatigue syndrome: a multicentre randomised controlled trial. Lancet 2001, 357(9259):841-847.

8. Stulemeijer M, de Jong LW, Fiselier TJ, Hoogveld SW, Bleijenberg G:

Cognitive behaviour therapy for adolescents with chronic fatigue syndrome: randomised controlled trial. BMJ 2005, 330(7481):14.

9. Torenbeek M, Mes CA, van Liere MJ, Schreurs KM, ter Meer R, Kortleven GC, Warmerdam CG: [Favourable results of a rehabilitation programme with cognitive behavioural therapy and graded physical activity in patients with the chronic-fatigue syndrome]. Ned Tijdschr Geneeskd 2006, 150(38):2088-2094. 
10. Evering RMH, Tonis TM, Vollenbroek-Hutten MMR: Deviations in daily physical activity patterns in patients with the chronic fatigue syndrome: A case control study. J Psychosom Res 2011, 71(3):129-135.

11. Van der Werf SP, Prins JB, Vercoulen JH, van der Meer JW, Bleijenberg G: Identifying physical activity patterns in chronic fatigue syndrome using actigraphic assessment. J Psychosom Res 2000, 49(5):373-379.

12. Burton C, Knoop H, Popovic N, Sharpe M, Bleijenberg G: Reduced complexity of activity patterns in patients with Chronic Fatigue Syndrome: a case control study. Biopsychosoc Med 2009, 3:7.

13. Kop WJ, Lyden A, Berlin AA, Ambrose K, Olsen C, Gracely RH, Williams DA, Clauw DJ: Ambulatory monitoring of physical activity and symptoms in fibromyalgia and chronic fatigue syndrome. Arthritis Rheum 2005, 52(1):296-303.

14. Surawy C, Hackmann A, Hawton K, Sharpe M: Chronic fatigue syndrome: a cognitive approach. Behav Res Ther 1995, 33(5):535-544.

15. Rimes KA, Chalder T: Treatments for chronic fatigue syndrome. Occup Med (Lond) 2005, 55(1):32-39.

16. Fry $A M$, Martin M: Cognitive idiosyncrasies among children with the chronic fatigue syndrome: anomalies in self-reported activity levels. J Psychosom Res 1996, 41(3):213-223.

17. Vercoulen JH, Bazelmans E, Swanink CM, Fennis JF, Galama JM, Jongen PJ, Hommes O, Van der Meer JW, Bleijenberg G: Physical activity in chronic fatigue syndrome: assessment and its role in fatigue. J Psychiatr Res 1997, 31(6):661-673.

18. Van Houdenhove B, Luyten P: Customizing treatment of chronic fatigue syndrome and fibromyalgia: the role of perpetuating factors. Psychosomatics 2008, 49(6):470-477.

19. Jason L, Benton M, Torres-Harding S, Muldowney K: The impact of energy modulation on physical functioning and fatigue severity among patients with ME/CFS. Patient Educ Couns 2009, 77(2):237-241. 
20. Larun L, Malterud K: Finding the right balance of physical activity: a focus group study about experiences among patients with chronic fatigue syndrome. Patient Educ Couns 2011, 83(2):222-226.

21. Weinstock RS, Brooks G, Palmas W, Morin PC, Teresi JA, Eimicke JP, Silver S, Izquierdo R, Goland R, Shea S: Lessened decline in physical activity and impairment of older adults with diabetes with telemedicine and pedometer use: results from the IDEATel study. Age Ageing 2011, 40(1):98-105.

22. Christian JG, Bessesen DH, Byers TE, Christian KK, Goldstein MG, Bock BC: Clinic-based support to help overweight patients with type 2 diabetes increase physical activity and lose weight. Arch Intern Med 2008, 168(2):141-146.

23. King DK, Estabrooks PA, Strycker LA, Toobert DJ, Bull SS, Glasgow RE: Outcomes of a multifaceted physical activity regimen as part of a diabetes self-management intervention. Ann Behav Med 2006, 31(2):128-137.

24. Evering RMH, van Weering MGH, Groothuis-Oudshoorn KCGM, Vollenbroek-Hutten MMR: Daily physical activity of patients with the chronic fatigue syndrome: a systematic review. Clin Rehabil 2011 , 25(2): 112-133.

25. Kairy D, Lehoux P, Vincent C, Visintin M: A systematic review of clinical outcomes, clinical process, healthcare utilization and costs associated with telerehabilitation. Disabil Rehabil 2009, 31(6):427-447.

26. Hermens HJ, Vollenbroek-Hutten MM: Towards remote monitoring and remotely supervised training. J Electromyogr Kinesiol 2008, 18(6):908-919.

27. Rosser BA, Vowles KE, Keogh E, Eccleston C, Mountain GA: Technologicallyassisted behaviour change: a systematic review of studies of novel technologies for the management of chronic illness. J Telemed Telecare 2009, 15(7):327-338.

28. Bleijenberg G, Bazelmans E, Prins P: Chronisch vermoeidheidssyndroom. Houten: Bohn Stafleu Van Loghum; 2001. 
29. Bouten CV, Verboeket-van de Venne WP, Westerterp KR, Verduin M, Janssen JD: Daily physical activity assessment: comparison between movement registration and doubly labeled water. J Appl Physiol 1996, 81(2):10191026.

30. Arrindell WA, Ettema JHM: SCL-90 : handleiding bij een multidimensionele psychopathologie-indicator Lisse: Swets Test Publishers; 1986.

31. Derogatis LR, Liman RS, Covi L, Arrindell WA, Ettema JHM: 90-item Symptom Distress Checklist (SCL-90). In Het meten van de gezondheidstoestand, deel 3: psychische gezondheid. Assen: Van Gorcum; 1995:147-170.

32. Vercoulen JH, Swanink CM, Fennis JF, Galama JM, van der Meer JW, Bleijenberg G: Dimensional assessment of chronic fatigue syndrome. J Psychosom Res 1994, 38(5):383-392.

33. Van der Zee KI, Sanderman R: Het meten van de algemene gezondheidstoestand met de RAND-36 : een handleiding. In NCG reeks meetinstrumenten. Volume 3. Groningen: Noordelijk Centrum voor Gezondheidsvraagstukken, Rijksuniversiteit Groningen; 1993.

34. Aaronson NK, Muller M, Cohen PD, Essink-Bot ML, Fekkes M, Sanderman R, Sprangers MA, te Velde A, Verrips E: Translation, validation, and norming of the Dutch language version of the SF-36 Health Survey in community and chronic disease populations. J Clin Epidemiol 1998, 51(11):1055-1068.

35. Beurskens AJ, de Vet HC, Koke AJ, Lindeman E, van der Heijden GJ, Regtop W, Knipschild PG: A patient-specific approach for measuring functional status in low back pain. J Manipulative Physiol Ther 1999, 22(3):144-148.

36. Vercoulen JH, Swanink CM, Fennis JF, Galama JM, van der Meer JW, Bleijenberg G: Prognosis in chronic fatigue syndrome: a prospective study on the natural course. J Neurol Neurosurg Psychiatry 1996, 60(5):489-494.

37. De Vree B, van der Werf SP, Prins J, Bazelmans E, Vercoulen J, Servaes P, de Vries M, Bleijenberg G: Meetinstrumenten bij chronische vermoeidheid. Gedragstherapie 2002, 35(2):157-164. 
38. Schulz KF, Altman DG, Moher D: CONSORT 2010 statement: Updated guidelines for reporting parallel group randomised trials. Int J Surg 2011, 9(8):672-677.

39. Klasnja P, Consolvo S, McDonald DW, Landay JA, Pratt W: Using mobile \& personal sensing technologies to support health behavior change in everyday life: lessons learned. AMIA Annu Symp Proc 2009, 2009:338-342.

40. Nijs J, van Eupen I, Vandecauter J, Augustinus E, Bleyen G, Moorkens G, Meeus M: Can pacing self-management alter physical behavior and symptom severity in chronic fatigue syndrome? A case series. J Rehabil Res Dev 2009, 46(7):985-996.

41. Davenport TE, Stevens SR, VanNess MJ, Snell CR, Little T: Conceptual model for physical therapist management of chronic fatigue syndrome/myalgic encephalomyelitis. Phys Ther 2010, 90(4):602-614.

42. Nijs J, Almond F, De Becker P, Truijen S, Paul L: Can exercise limits prevent post-exertional malaise in chronic fatigue syndrome? An uncontrolled clinical trial. Clin Rehabil 2008, 22(5):426-435.

43. Jason L, Muldowney K, Torres-Harding S: The Energy Envelope Theory and myalgic encephalomyelitis/chronic fatigue syndrome. AAOHN J 2008, 56(5):189-195.

44. Friedberg F, Sohl S: Cognitive-behavior therapy in chronic fatigue syndrome: is improvement related to increased physical activity? J Clin Psychol 2009, 65(4):423-442.

45. Knoop H, Prins JB, Moss-Morris R, Bleijenberg G: The central role of cognitive processes in the perpetuation of chronic fatigue syndrome. J Psychosom Res 2010, 68(5):489-494.

46. Silver A, Haeney M, Vijayadurai P, Wilks D, Pattrick M, Main CJ: The role of fear of physical movement and activity in chronic fatigue syndrome. J Psychosom Res 2002, 52(6):485-493.

47. Nijs J, De Meirleir K, Duquet W: Kinesiophobia in chronic fatigue syndrome: assessment and associations with disability. Arch Phys Med Rehabil 2004, 85(10): 1586-1592. 
48. Petrie K, Moss-Morris R, Weinman J: The impact of catastrophic beliefs on functioning in chronic fatigue syndrome. J Psychosom Res 1995, 39(1):3137.

49. Deale A, Chalder T, Wessely S: Illness beliefs and treatment outcome in chronic fatigue syndrome. J Psychosom Res 1998, 45(1):77-83. 
148 Chapter 5 


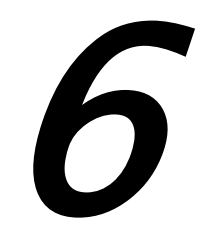

Is there a difference in response to ambulatory activity feedback (AAF) when different goal settings are used? A randomized controlled trial

Evering RMH, Hermens $\mathrm{HJ}$ and Vollenbroek-Hutten MMR. Is there a difference in response to ambulatory activity feedback when different goal settings are used? A randomized controlled trial. Submitted. 


\begin{abstract}
Introduction: A balanced daily physical activity pattern is considered to be important in the treatment of the chronic fatigue syndrome (CFS). The aim of this study is to investigate if ambulatory feedback is more effective when the goal is based on a patient's personal baseline activity pattern than based on the activity pattern of healthy controls.
\end{abstract}

Methods: A randomized controlled trial was performed in which CFS patients received ambulatory feedback at daily physical activities in the home situation. The goal was based on healthy controls or on patient's personal baseline activity pattern. The main outcome parameter was the mean physical activity level per hour. Secondary outcome parameters were number of days with compliance and subjective scores for usefulness and satisfaction.

Results: No significant differences were found between and within groups for changes in daily physical activity patterns during feedback week 1 and 2 as compared to baseline. Significant higher scores were found for perceived usefulness with a personalized goal.

Conclusion: Ambulatory feedback did not result in changed daily physical activity patterns, no matter what goal pattern was used. However, the perceived usefulness of feedback with a personalized goal pattern was more favorable than a goal pattern based on healthy controls. 


\section{Introduction}

Patients with the chronic fatigue syndrome (CFS) show deviating physical activity patterns as compared to healthy controls (1-5). A balanced daily physical activity pattern is therefore considered to be important in the treatment of CFS $(6,7)$. Several studies have shown that using telecommunication technology might have potential for improving physical activity in chronic patients (8-10). Preliminary results showed potential value of an ambulant feedback program as supplement to rehabilitation treatment for CFS patients. Feedback was provided at home with a personal digital assistant during four consecutive feedback periods. The goal of the feedback was balancing daily physical activity patterns and the goal was based on the pattern of healthy controls. Patients were able to change their daily physical activity into the direction of the goal, but the compliance with all four feedback periods was low. Low compliance could be caused by the way the goal was defined, patients were possibly not motivated to change their physical activity pattern into the direction of healthy controls. Following the 'Social Comparison Theory', people have a drive to make a self evaluation based on a comparison with other persons (11). Therefore, ambulatory feedback with a goal pattern based on healthy controls may stimulate CFS patients to change their daily physical activity pattern. However, as large differences in daily physical activity patterns are seen between CFS patients and healthy controls it is questionable whether a goal pattern based on healthy controls is realistic and attainable for CFS patients (1). CFS patients may become de-motivated and stop changing their daily physical activity pattern in the direction of the goal if it turns out to be unattainable. In line with the 'Temporal Comparison Theory' which states a drive to make a self evaluation based on someone's own performances in time (12) it can also be hypothesized that a goal pattern adapted to individual performances may be more stimulating for CFS patients in changing their daily physical activity pattern than a goal pattern based on healthy controls. In this study ambulatory feedback is provided to CFS patients comparing two different goal settings i.e. temporal versus social comparison. The primary objective is to study if ambulatory feedback is more effective in balancing daily physical activity patterns in patients with CFS if the goal pattern is based on personal activity 
patterns (temporal comparison) as compared to a goal pattern based on healthy controls (social comparison). Secondary objectives are compliance in using the feedback system and perceived usefulness of- and satisfaction with the feedback system. 


\section{Methods}

\section{Participants}

Experiments were approved at the accredited Medical Research Ethics Committee of the hospital 'Medisch Spectrum Twente' in Enschede, The Netherlands. Patients with the chronic fatigue syndrome (CFS) were recruited from the Roessingh Rehabilitation Centre in Enschede, The Netherlands, or responded to an article published in a local newspaper and flyers spread around to general practitioners in the eastern part of The Netherlands between January 2010 and April 2011 . In- and exclusion criteria were assessed in an intake procedure. Diagnosis of CFS by a general practitioner or a physician was required for inclusion, following the criteria for CFS of the Centers for Disease Control and Prevention of 1994 (13). Other inclusion/exclusion criteria for CFS patients were: 1) fatigue as primary complaint 2) aged between 18 and 65 years; 3) no structural pathology explaining the fatigue complaints; 4) not yet in treatment with clinical intake; 5) not bounded to a wheelchair; 6) not being pregnant.

\section{Study design}

A randomized controlled trial was performed in which patients with CFS were allocated to group A with a goal based on healthy controls (social comparison) or to group B with a personalized goal (temporal comparison). Demographics and fatigue severity were assessed at baseline and daily physical activities were measured with an accelerometer for seven consecutive days. After baseline measurements CFS patients were allocated to group $A$ or group $B$ and received the intervention existing of two weeks real time ambulatory feedback during the performance of daily physical activities measured with the same accelerometer as in the baseline measurements. The randomization was performed by the executive investigator and patients were informed about the outcome of the randomization after the baseline measurements were performed and before starting the feedback intervention. Group sizes were based on results of other studies in which feedback was provided to stimulate physical activity behavior $(14,15)$. The study was carried out in accordance with the declaration of Helsinki and approved by the accredited 
medical research ethics committee of the hospital 'Medisch Spectrum Twente' in Enschede, The Netherlands.

\section{The monitoring and feedback intervention}

For ambulatory activity monitoring and provision of feedback a system was used that consisted of a tri-axial piezoelectric accelerometer ( $\mathrm{mtx}-\mathrm{w}$ sensor, XSense; The Netherlands) and a personal digital assistant (PDA). Data from the accelerometer was transmitted through Bluetooth connection to the PDA on which data was stored (figure 1a). The feedback was given to the patient at the PDA and this feedback was based on the actual difference between the cumulative physical activity level of the CFS patient and the goal pattern (figure $1 \mathrm{~b}$ and $1 \mathrm{c}$ ). Oral and written instructions were provided regarding proper accelerometer placement, wearing schedule and user instructions. The baseline and feedback measurements took place during daytime when patients were awake at the earliest from 8.00 till the latest at 22.00, excluding time spent bathing or participating in water activities.

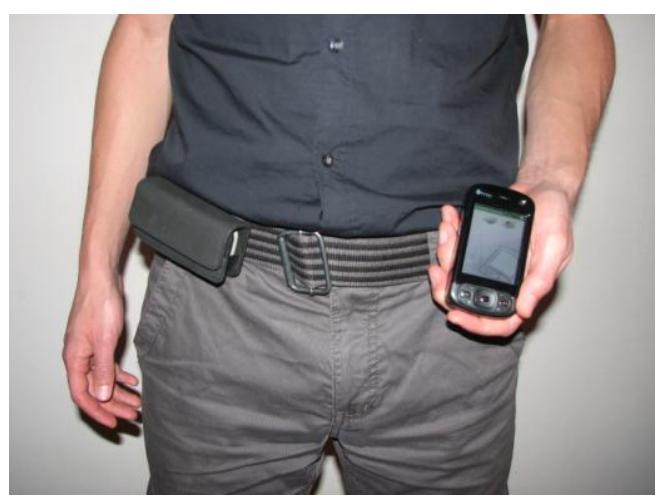

Figure 1 a Wearing of the feedback system

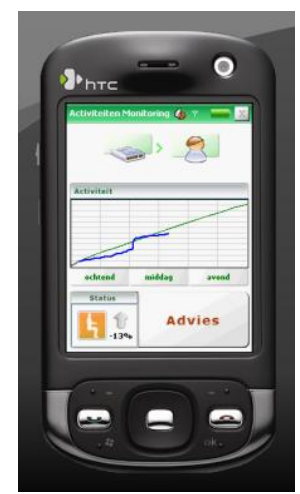

Figure $1 \mathrm{~b}$

Cumulative daily physical activity pattern

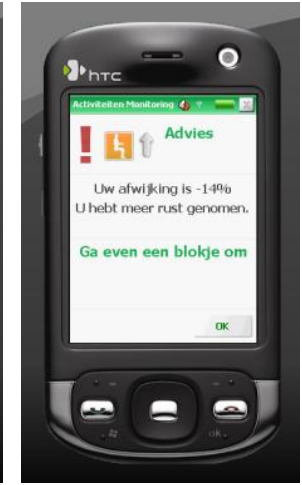

Figure 1c Difference with the goal, activity judgement and advice 


\section{Group A: Goal pattern of healthy control group}

Group A received feedback based on the comparison of the patient's activity pattern with that of the healthy control group. The healthy control group consisted of 57 persons; 32 women and 25 men with a mean age of 41 years (ranging from 19 to 70 years). The pattern of the healthy control group can be categorized as a moderately physical activity pattern (16).

\section{Group B: Goal pattern adapted to the individual baseline pattern}

Group B received feedback based on the comparison of the patient's current activity pattern with that of a personalized goal. The personalized goal was determined by taking the mean of the individual activity pattern at baseline and the pattern of the healthy control group. In this way, the gap of the individual pattern at baseline with the healthy control group was declined with $50 \%$ (figure 2 ).

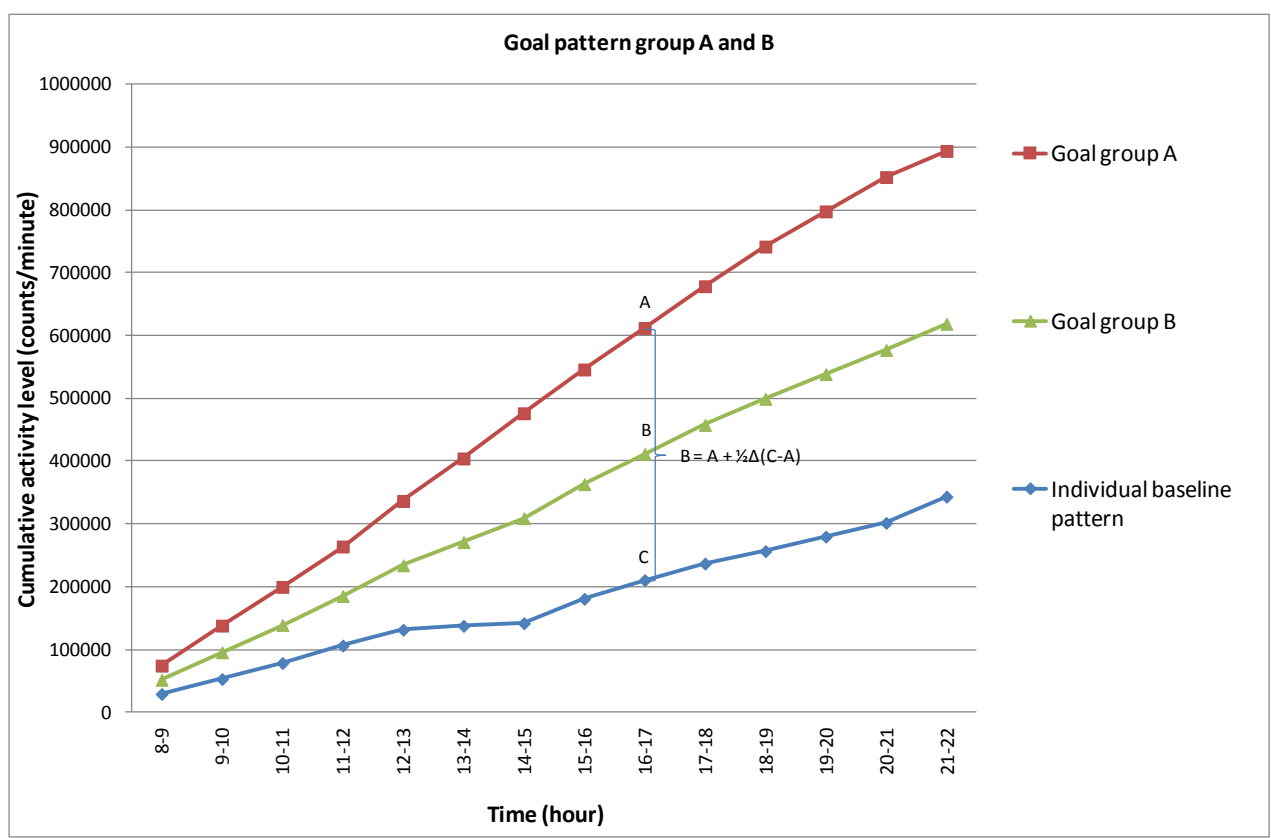

Figure 2 Goal group B derived from goal group A and the individual baseline pattern 


\section{Feedback intervention}

In both groups, feedback was provided in two different ways: [1] The PDA showed continuously a graph (figure $1 \mathrm{~b}$ ) of the cumulative goal pattern for the whole day (8.00 - 22.00) together with the cumulative activity pattern of the CFS patient drawn minute by minute. Also the difference was given between the cumulative activity level of the goal and the CFS patient in percentages. [2] In addition three text lines were presented at the PDA (figure 1c) every 2 hours $(10.00,12.00,14.00$, $16.00,18.00$ and 20.00) representing:

- The difference between the cumulative activity level of the goal and CFS patient at that time.

- A judgment about the performance of the last 2 hours. This judgment gave the patient insight in whether the change in activity level during the last 2 hours was appropriate.

- An activity advice. The activity advice stimulated the patient to perform activities at the right intensity level the next 2 hours in order to decline the difference with the goal. The patient received discouraging activity advices (e.g. Have you already read the newspaper?) when the cumulative activity level was above the goal pattern (>110\%), encouraging activity advices (e.g. Have a nice walk!) if the cumulative activity level was below the goal pattern $(<90 \%)$ and neutral advices (e.g. Keep continuing) if the cumulative activity level was between $90 \%$ and $110 \%$ of the goal pattern.

The difference between the individual cumulative activity level and the goal could become very large if the patient was high or low physically active during a prolonged period of time. Insurmountable differences between the individual cumulative activity level and the goal, build up during the morning and/or afternoon, were prevented by resetting the difference to zero at 13.00 and 17.00 by placing the individual cumulative activity level back to the goal.

\section{Outcome measures}

Demographics were obtained for gender, age, fatigue severity, duration of CFS complaints, work status, educational level and co-morbidity. Fatigue severity was measured with the Checklist Individual Strength (CIS). The CIS consists of 20 items 
with a total score, and scoring on 4 subscales; 'subjective experience of fatigue', 'concentration', 'motivation' and 'physical activity level' (17).

The primary outcome measure was the mean physical activity level per hour in counts per minute measured at baseline and during feedback week 1 and 2 with a tri-axial piezoelectric accelerometer (16). The accelerometer was worn in a slip case at the waist and measured objectively accelerations in the anteroposterior, mediolateral and longitudinal axes of the trunk. The acceleration (sampled with a frequency of $100 \mathrm{~Hz}$ ) was bandpass filtered with a $4^{\text {th }}$ order Butterworth filter with cut-off frequencies at 0.11 and $20 \mathrm{~Hz}$. The absolute value of the acceleration was integrated over time periods of 60 seconds and thereafter summed over the three axes (18).

Secondary outcome measures were compliance in wearing the feedback system and usefulness of- and satisfaction with the feedback system. Compliance with the feedback system was expressed as number of hours the feedback system was worn sufficiently (arbitrary defined as $\geq 30$ minutes per hour) and described for the baseline period, feedback week 1 and feedback week 2 . The usefulness of- and satisfaction with the feedback system was evaluated after the intervention with a standardized questionnaire consisting of nine items with scoring on a five point scale and loading on two subscales designating usefulness and satisfaction (19).

\section{Data analysis}

Data files consisted of activity data per minute and an algorithm was written to allow calculation of the mean physical activity level per hour. Only periods including at least three days with 420 minutes of data between 8.00 and 22.00 were included in the analysis, and the physical activity level was only calculated for hours with at least 30 minutes of data. The mean physical activity level per day and day part was calculated for the baseline period, feedback week 1 and feedback week 2 (three periods of seven days). Day parts were defined as follow: morning (8.00 - 12.00), afternoon (12.00 - 18.00) and evening (18.00 - 22.00) (1). The goal was reached as the mean physical activity level was between $90 \%$ and $110 \%$ of the goal, and was above or beneath the goals if the level was $<90 \%$ or $>110 \%$ of the goal respectively. The number of hours with an activity level below, within or above the range of the 
goal was counted per period within group A and group B.

\section{$\underline{\text { Statistical analysis }}$}

The Statistical Package for the Social Sciences (SPSS18) was used for statistical analysis. The Shapiro-Wilk test was used for testing normality of dependent variables, and the $\alpha$ level of significance was set at 0.05 for all analyses. Independent t-tests were used for testing differences between groups for age, fatigue severity, duration of complaints, and for usefulness and satisfaction with the feedback system. Levene's test was used for testing equality of variances. The Mann-Whitney $U$ test was used instead of the independent $t$-test if the dependent variable was not normally distributed.

Repeated measures general linear model was performed for analyzing differences between groups in compliance with wearing the feedback system. The Mauchly's test of sphericity was used for testing equality of variance between different pairs of the within subject variables, the Greenhouse-Geisser correction if test of sphericity was significant, and the Sidak correction for multiple pairwise comparisons.

Linear mixed model with restricted maximum likelihood was performed for analyzing differences in mean physical activity levels at baseline within and between CFS patients versus healthy controls. Linear mixed model with restricted maximum likelihood was also performed for analyzing differences in mean physical activity levels within and between group A and B. The same analysis was performed without patients having a baseline physical activity level within the range of the goal at all three day parts, as these patients already achieved their goal and are because of this not stimulated to change. In performing linear mixed models the Sidak correction was used for multiple comparisons.

The Pearson chi square test was performed for analyzing differences within groups between periods in distribution of hours with an activity level beneath, within or above the range of the goal. 


\section{Results}

Forty-seven patients were contacted for trial entry; nine patients were not eligible, five patients refused, and five patients were not able to participate in the study because of other reasons. Twenty-eight patients with the chronic fatigue syndrome (CFS) were eligible and able to participate in the study. Seven patients (four in group A and three in group B) had one or more of the following co-morbidities; celiac disease, fibromyalgia, gastroparesis, lactose intolerance, COPD, diabetes, sleep apnea and personality disorder not otherwise specified (PDNOS). These comorbidities could be of influence on the physical activity behavior; however we were not able to check this influence. One patient dropped out the study during the baseline physical activity measurements. Patients were at baseline less physically active as compared to healthy controls, with significantly decreased physical activity levels in the afternoon and evening (figure 3). 


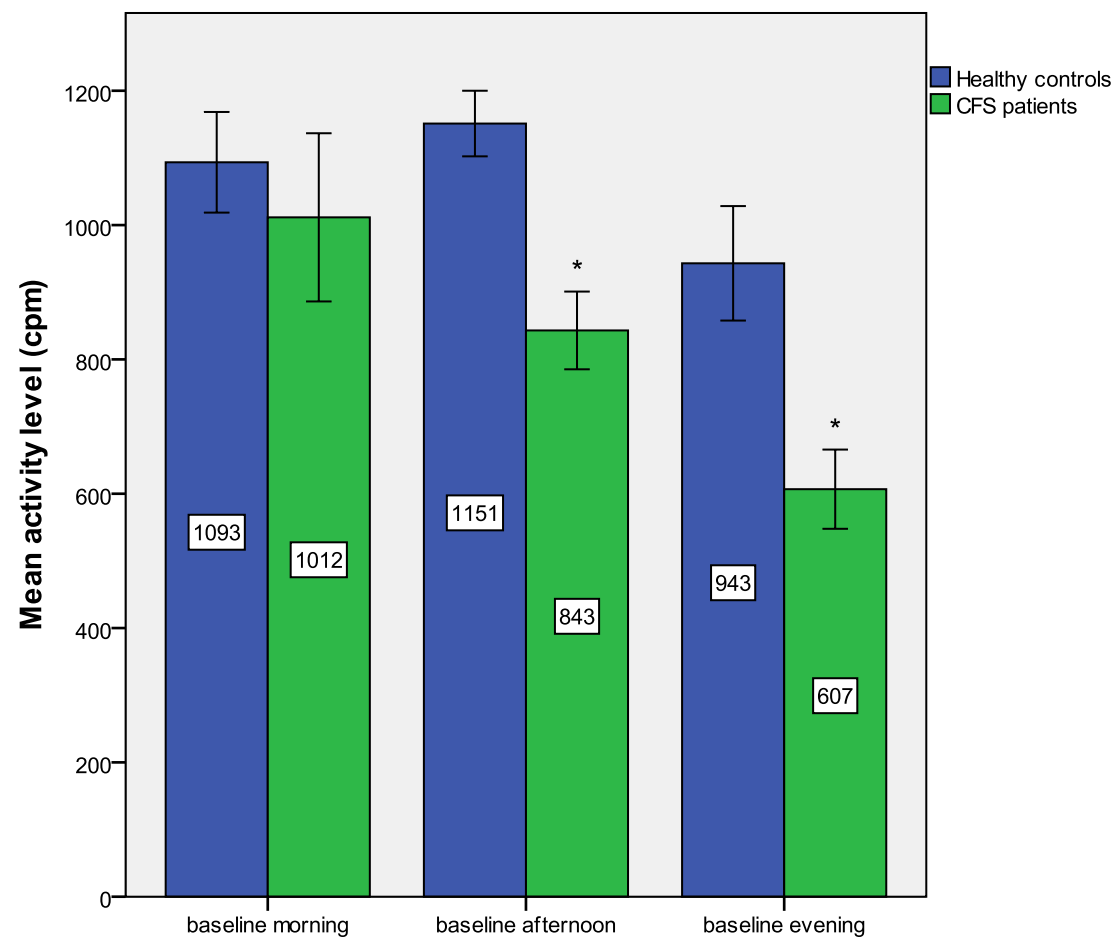

Figure 3 Baseline physical activity pattern per day part in counts per minute "Significant decreased levels in CFS patients as compared to healthy controls

Twenty-seven patients started with the feedback program, thirteen patients were allocated to the group with a goal based on healthy controls (group A) and fourteen patients to the group with a personalized goal (group B). Patient characteristics of both groups are shown in table 1, no significant differences were found between group A and B for age, all 5 CIS scores and duration of CFS complaints. 
Table 1 Patient characteristics group A and B

Group A $(n=13) \quad$ Group B $(n=14)$

Gender

- Male

3

4

- Female

10

10

Age (SD)

$34.2( \pm 13.5)$

$36.1( \pm 13.7)$

CIS-fatigue score

103.6

104.9

- Fatigue

47.7

47.9

- Concentration

27.6

25.8

- Motivation

12.9

16.0

- Physical activity

15.4

15.1

Duration of complaints in months (SD)

$136.0( \pm 92.9)$

$92.0( \pm 104.1)$

Work status

- Working/studying

5

6

- Unemployed/else

8

8

Sick leave/invalidity benefits

- Yes

- No

6

7

Highest level of education

- Secondary education

7

2

- Vocational education

4

8

- Bachelor degree

2

3

- Master degree

0

1 
The physical activity pattern at baseline did not differ between group $A$ and $B$. However, both groups showed significant lower levels during the whole day, in the afternoon and in the evening as compared to healthy controls (table 2).

Table 2 Mean physical activity pattern at baseline in counts per minute (SD)

\begin{tabular}{|c|c|c|c|}
\hline & Group $A(n=13)$ & Group B $(n=14)$ & Healthy controls $(n=57)$ \\
\hline Day mean & $847(412)$ & $800(464)$ & $1087(517)$ \\
\hline - $\quad$ Morning & - $\quad 1004(464)$ & - $1017(695)$ & - $1093(557)$ \\
\hline - Afternoon & - $\quad 897(407)$ & - $\quad 793(333)$ & - $\quad 1151(459)$ \\
\hline - $\quad$ Evening & - $\quad 629(264)$ & - $\quad 586(316)$ & - $943(549)$ \\
\hline
\end{tabular}

\section{Compliance activity measurements}

Thirteen patients started in group $A$ and fourteen in group $B$ resulting in a maximal number of 1274 and 1372 hours per period ( 7 days, 14 hours per day) to which group A and B could comply with, respectively. Three patients dropped out the feedback intervention prematurely; one patient in group $A$ and two patients in group B. Another two patients in group A did not fulfill the criterion of having three days with sufficient data during one of the two feedback weeks; one patient in feedback week 1 and one patient in feedback week 2 .

The overall mean compliance was $60 \%$ in group $A$ and $B$ together during baseline measurements, feedback 1 and 2. The mean compliance in group A was 63\% during the baseline period, 53\% during feedback week 1 and 54\% during feedback week 2 . The mean compliance in group B was $66 \%$ during the baseline period, $64 \%$ during feedback week 1 and $56 \%$ during feedback week 2 . The compliance in group $B$ during the first feedback week was somewhat higher than group $A$, however no statistical differences were found between groups. Also no statistical differences were found within groups between periods (baseline period, feedback week 1 and 2 ), and for the interaction group*period.

\section{Balance in daily physical activity patterns}

No differences were found within and between groups in the daily physical activity level at baseline, feedback week 1 and feedback week 2. Figure 4 shows the mean 
physical activity level as percentage of healthy controls in the morning, afternoon and evening per period. Both groups showed the highest variation between day parts at baseline, and the lowest variation at feedback week 1 . The physical activity level differed significantly between the morning, afternoon and evening $(p<0.001)$. However, the physical activity level per day part was not significant different between groups (group*day part); no changes were found between the baseline period, feedback week 1 and feedback week 2 (period*day part); and no significant interaction was found for group*period*day part. Results did not change when the same analysis was performed without patients having a baseline physical activity level within the range of the goal at all three day parts. However, both groups showed a trend of improved levels in the evening during feedback week 1 and 2 as compared to baseline. Group B also showed an improved trend for activity levels in the afternoon. The trend for improved levels in the afternoon and evening in group B during feedback week 1 seemed to be compensated with decreased levels in the morning. No compensated levels in the morning were shown for feedback week 2 . 

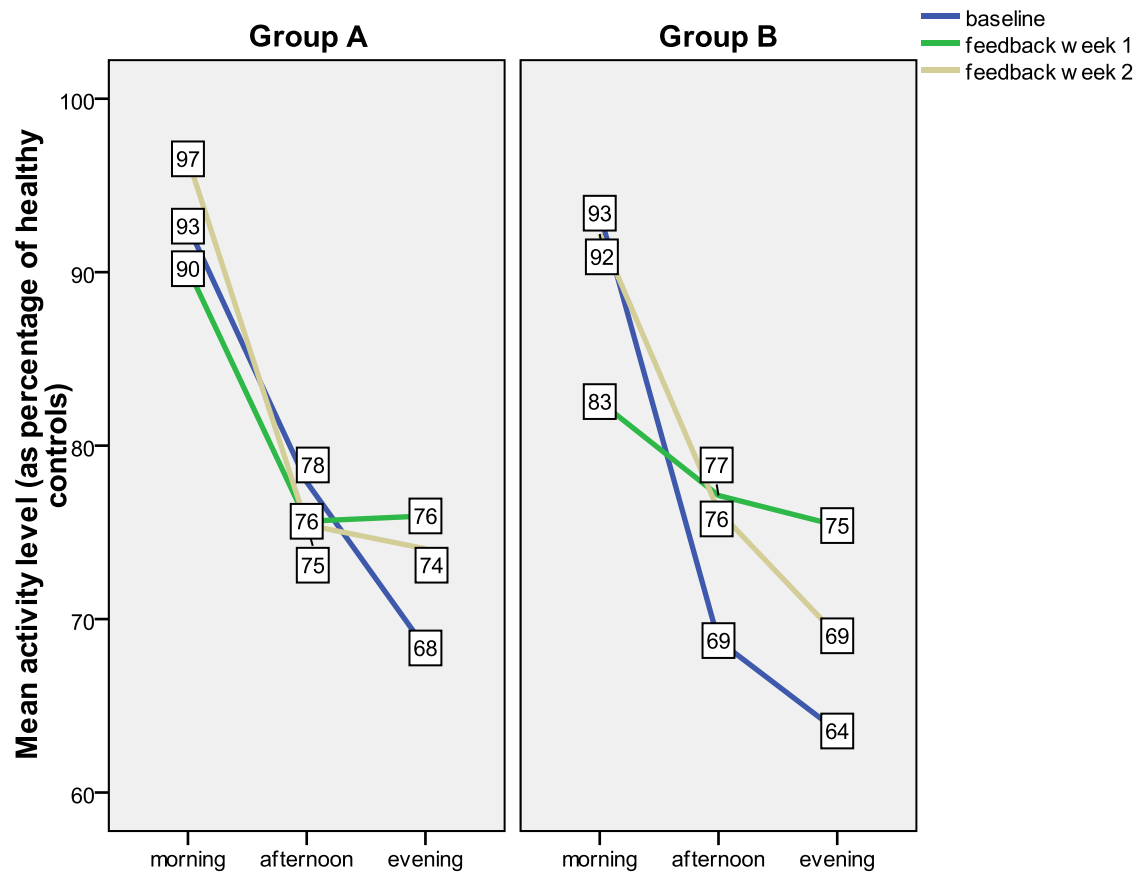

Figure 4 Physical activity level per day part as \% of healthy controls

Table 3 shows the number of hours (maximum of 14 hours per period per CFS patient) in group A and B with a physical activity level below, within or above the range $(90 \%-110 \%)$ of the goal. 
Table 3 Number of hours with an activity level below, within or above the range of the goal

\section{Group A $(n=13)$}

Number of hours at baseline

- Below

- Within

- Above

Number of hours at feedback week 1

- Below

- Within

- Above

Number of hours at feedback week 2

- Below

- Within

- Above
165

- $120(72.7 \%)$

- $\quad 19(11.5 \%)$

- $26(15.8 \%)$

142

- $99(69.7 \%)$

- $21(14.8 \%)$

- $\quad 22(15.5 \%)$

140

- $\quad 91$ (65.0\%)

- $\quad 18(12.9 \%)$

- $\quad 31$ (22.1\%)
Group B $(n=14)$

184

- $117(63.6 \%)$

- 49 (26.6\%)

- $18(9.8 \%)$

166

- $\quad 97(58.4 \%)$

- $\quad 31$ (18.7\%)

- $\quad 38(22.9 \%)$

156

- $90(57.7 \%)$

- $\quad 27(17.3 \%)$

- $\quad 39(25.0 \%)$

Group B showed a significant different distribution between periods of hours with an activity level beneath, within or above the range of the goal. The number of hours beneath and within the range of the goal decreased consistently from baseline to feedback week 1 and to feedback week 2, while the number of hours above the goal increased consistently. Group A did not show a significant different distribution between periods. The number of hours beneath the goal decreased consistently, however the number of hours within and above the goal did not change consistently.

\section{Acceptance of the feedback system}

The acceptance of the feedback system through CFS patients was evaluated with a nine item questionnaire loading on the subscales 'usefulness' (item 1, 3, 5, 7 and 9) and 'satisfaction' (item 2, 4, 6 and 8). Table 4 shows the mean scores on all nine items and the summed scores on the subscales. The summed score for usefulness 
was significantly higher in group $B$ as compared to group $A(p<0.05)$, the score for satisfaction was not statistically different. Only one negative score was found for item 6 in group B reflecting that the feedback system was a little irritating. The most remarkable differences between groups were found for item 7 and 9 both loading for usefulness, with more positive scores in group B.

Table 4 Acceptance of the feedback system

\begin{tabular}{cll} 
Item (score from -2 till +2) & Group A & Group B \\
1. Useless - Useful & 1.00 & 1.64 \\
2. Unpleasant - Pleasant & 0.25 & 0.07 \\
3. Bad - Good & 0.92 & 1.29 \\
4. Annoying - Nice & 0.25 & 0.86 \\
5. Superfluous - Effective & 0.92 & 1.07 \\
6. Irritating - Likeable & 0.08 & -0.14 \\
7. Worthless - Assisting & 0.67 & 1.43 \\
8. Undesirable - Desirable & 1.08 & 1.36 \\
9. Sleep-inducing - Raising alertness & 0.67 & 1.5 \\
Usefulness & 0.83 & 1.39 \\
Satisfaction & 0.42 & 0.54 \\
\hline
\end{tabular}

"Significant different $(\mathrm{p}<0.05)$ 


\section{Discussion}

Although the trends in activity change found in this study were in line with the hypothesis, being a more balanced activity pattern when feedback was based on ones personal baseline activity level as compared to feedback based on healthy controls, this study was not able to show significant improved outcome between both groups. In addition this study did not show overall significant changes in the daily physical activity pattern in patients with CFS into the direction of healthy controls in both groups, despite the fact that the patients had deviating physical activity patterns at baseline as compared to healthy controls (3). The compliance in wearing the feedback system has found to be non-significant higher, and the perceived usefulness of the feedback system significant higher, in the group with a personalized goal. This suggest that patients with CFS have perhaps an higher intention to use the feedback system if the goal is adapted to their personal activity pattern and by such may result in higher compliance rates in the long run. Several reasons could explain the lack of significant changes in daily physical activity patterns. First of all, two weeks of feedback may have been too short. Chronic patients may experience difficulties in changing activity behavior as it likely requires the individual to restructure priorities in daily life and social routines (20, 21). A longer intervention period may be needed in which CFS patients should get the intention or become ready to change activity behavior $(22,23)$. On the other hand, the intervention period may have been too long. Most of the patients needed to increase daily physical activity during the two weekly intervention period, while Black and McCully concluded that CFS patients developed exercise intolerance after 4 to 10 days when activity levels were increased (24). It maybe necessary that CFS patients should maintain appropriate energy expenditures without exhausting available energy reserves, especially with intervention periods of more than 10 days $(25,26)$. A second reason for the lack of finding changes in activity behavior might be that CFS patients needed more explanation about the importance of healthy physical activity patterns, as physical activity has been considered a perpetuating factor in CFS (27). Cognitive behavioral therapy (CBT) and graded exercise therapy (GET) are the most promising treatment modalities for CFS and both underline the 
importance of a regular and balanced daily physical activity pattern $(6,7)$.

Preliminary results have shown significant changes in daily physical activity patterns with use of the same feedback system as used in this study, in which the feedback program was added to an existing rehabilitation program comprising multidisciplinary cognitive behavioral therapy. As such, implementing ambulatory feedback programs in existing treatment programs may enhance treatment outcome in CFS as patients are more aware about the importance of balanced daily physical activity patterns $(25,28,29)$. This awareness maybe improved even more as patients are learned to set their own personal goals in the feedback program ( 30 , 31). A third reason for unchanged physical activity patterns could be the way the feedback has been provided. A recent study investigated the effectiveness of internet weight loss interventions and has found greater weight loss with directive (prescriptive, protocol driven) e-coach support as compared to nondirective (collaborative, flexible) and minimal support conditions (32). More prescriptive and protocol driven feedback may enhance experienced importance and usefulness of the feedback. Accurate timing of the feedback messages may also be important in stimulating patients to change activity behavior (33). Feedback messages were given at fixed time moments of the day. It could have been more accurate to provide messages only when the activity level was not within the range of the goal, or providing messages only when patients are willing to change their activity behavior.

In this study we have found a trend for more improved activity levels in the afternoon with a goal based on a temporal comparison (personalized goal) as compared to a goal based on a social comparison (healthy controls). However, we have not found any significant difference in effectiveness between both goal settings. It could be that differences between the feedback protocols has been too limited for obtaining differences in effectiveness, with only differences in the information provided to patients about the goal pattern before starting the feedback program and the presentation of the cumulative goal pattern at the screen of the PDA. Differences between the two feedback protocols could have been enlarged if more aspects of the feedback intervention were adapted to the theory of temporal comparison and theory of social comparison. 
The usefulness of the feedback system was significantly higher in the group with a personalized goal; the biggest two differences between groups were raising alertness and assisting in changing activity patterns. Theoretically, an increased alertness can increase the awareness of patients into their activity behavior and imperfections therein. Increased experience of assistance will enlarge the feeling of control about someone's behavior. As such, an increased alertness and experience of assistance in changing activity behavior may increase the intention to change (22).

The higher perceived usefulness could explain the non-significant higher compliance in wearing the feedback system in the group with a personalized goal. In accordance to the technology acceptance model, subjects choose to comply when the expected benefits outweigh the perceived barriers (34). Increased flexibility in determining the appropriate intensity of the goal may have improved compliance, as individuals with CFS who experience high levels of disability may be unable to comply at a rigid predefined goal (35). Sufficient compliance with teletreatment applications is important in obtaining optimal clinical benefits (36). Hlavaty, Brown \& Jason (2011) observed more improvement at self reported outcome measures in CFS patients with an higher amount of homework compliance in non-pharmacological interventions (35).

A strength of this study is its design of a randomized controlled trial in allocating the goal pattern diminishing the probability of selection bias. Another strength is the validity of objectively measuring physical activity behavior with an accelerometer. Measurements of physical activity in CFS patients with subjective outcome assessments seem to result more often in significant lower activity levels than objective outcome assessments (3). Subjective outcome assessments maybe biased by cognitions concerning illness and disability $(5,37)$. Weaknesses of this study maybe the limited group sizes for detecting significant differences within and between groups and limited comparability of both groups due to heterogeneity of included patients. 


\section{Conclusion}

CFS patients have shown deviating physical activity patterns in comparison with healthy controls. Ambulatory feedback has not changed these activity patterns in to the direction of healthy controls and no differences has been found between a personalized goal versus a goal based on the pattern of healthy controls. The perceived usefulness of the feedback system with a personalized goal pattern scored significant higher as compared to a goal based on healthy controls. In line with the Temporal Comparison Theory, CFS patients may favor a personalized goal setting. More research is needed in the way the feedback program should be implemented into the treatment of CFS in changing daily physical activity patterns. 


\section{References}

1. Evering RM, Tonis TM, Vollenbroek-Hutten MM. Deviations in daily physical activity patterns in patients with the chronic fatigue syndrome: A case control study. J Psychosom Res. 2011 Sep;71(3):129-35.

2. Burton C, Knoop H, Popovic N, Sharpe M, Bleijenberg G. Reduced complexity of activity patterns in patients with Chronic Fatigue Syndrome: a case control study. Biopsychosoc Med. 2009;3:7.

3. Evering RM, van Weering MG, Groothuis-Oudshoorn KC, VollenbroekHutten MM. Daily physical activity of patients with the chronic fatigue syndrome: a systematic review. Clin Rehabil. 2011 Feb;25(2):112-33.

4. Kop WJ, Lyden A, Berlin AA, Ambrose K, Olsen C, Gracely RH, et al. Ambulatory monitoring of physical activity and symptoms in fibromyalgia and chronic fatigue syndrome. Arthritis Rheum. 2005;52(1):296-303.

5. Van der Werf SP, Prins JB, Vercoulen JH, van der Meer JW, Bleijenberg G. Identifying physical activity patterns in chronic fatigue syndrome using actigraphic assessment. J Psychosom Res. 2000;49(5):373-9.

6. Rimes KA, Chalder T. Treatments for chronic fatigue syndrome. Occup Med (Lond). 2005 Jan;55(1):32-9.

7. Reid SF, Chalder T, Cleare A, Hotopf M, Wessely S. Chronic fatigue syndrome. Clin Evid (Online). 2008;8:1101.

8. Weinstock RS, Brooks G, Palmas W, Morin PC, Teresi JA, Eimicke JP, et al. Lessened decline in physical activity and impairment of older adults with diabetes with telemedicine and pedometer use: results from the IDEATel study. Age Ageing. 2011 Jan;40(1):98-105.

9. King DK, Estabrooks PA, Strycker LA, Toobert DJ, Bull SS, Glasgow RE. Outcomes of a multifaceted physical activity regimen as part of a diabetes self-management intervention. Ann Behav Med. 2006 Apr;31(2):128-37.

10. Christian JG, Bessesen DH, Byers TE, Christian KK, Goldstein MG, Bock BC. Clinic-based support to help overweight patients with type 2 diabetes increase physical activity and lose weight. Arch Intern Med. 2008 Jan 28;168(2):141-6. 
11. Festinger L. a theory of social comparison processes. Human relations : studies towards the integration of the social sciences. 1954;2.

12. Albert S. Temporal Comparison Theory. Psychological Review. 1977;84(6):485-503.

13. Fukuda K, Straus SE, Hickie I, Sharpe MC, Dobbins JG, Komaroff A. The chronic fatigue syndrome: a comprehensive approach to its definition and study. International Chronic Fatigue Syndrome Study Group. Ann Intern Med. 1994 Dec 15;121(12):953-9.

14. Hurling R, Fairley BW, Dias MB. Internet-based exercise intervention systems: Are more interactive designs better? Psychology and Health. 2006;21(6):757-72.

15. Linton SJ, Jannert M, Overmeer T. Whose Goals Should Guide? A Comparison of Two Forms of Goal Formulation on Operant Activity Training. Journal of Occupational Rehabilitation. 1999;9(2):97-105.

16. Bouten CV, Verboeket-van de Venne WP, Westerterp KR, Verduin M, Janssen JD. Daily physical activity assessment: comparison between movement registration and doubly labeled water. J Appl Physiol. 1996 Aug;81(2):1019-26.

17. Vercoulen JH, Swanink CM, Fennis JF, Galama JM, van der Meer JW, Bleijenberg G. Dimensional assessment of chronic fatigue syndrome. J Psychosom Res. 1994 Jul;38(5):383-92.

18. Bouten CV, Westerterp KR, Verduin M, Janssen JD. Assessment of energy expenditure for physical activity using a triaxial accelerometer. Med Sci Sports Exerc. 1994 Dec;26(12):1516-23.

19. Van Der Laan JD, Heino A, De Waard D. A simple procedure for the assessment of acceptance of advanced transport telematics. Transportation Research Part C: Emerging Technologies. 1997;5(1):1-10.

20. Klasnja P, Consolvo S, McDonald DW, Landay JA, Pratt W. Using mobile \& personal sensing technologies to support health behavior change in everyday life: lessons learned. AMIA Annu Symp Proc. 2009:338-42.

21. Surawy C, Hackmann A, Hawton K, Sharpe M. Chronic fatigue syndrome: a cognitive approach. Behav Res Ther. 1995 Jun;33(5):535-44. 
22. Ajzen $\mathrm{H}$. The theory of planned behavior. Organizational behavior and human decision processes. 1991;50:179-211.

23. Prochaska JO, DiClemente CC. Stages and processes of self-change of smoking: toward an integrative model of change. J Consult Clin Psychol. 1983 Jun;51(3):390-5.

24. Black CD, McCully KK. Time course of exercise induced alterations in daily activity in chronic fatigue syndrome. Dyn Med. 2005 Oct 28;4:10.

25. Jason L, Benton M, Torres-Harding S, Muldowney K. The impact of energy modulation on physical functioning and fatigue severity among patients with ME/CFS. Patient Educ Couns. 2009 Nov;77(2):237-41.

26. Jason LA, Roesner N, Porter N, Parenti B, Mortensen J, Till L. Provision of social support to individuals with chronic fatigue syndrome. J Clin Psychol. 2010 Mar;66(3):249-58.

27. Vercoulen JH, Swanink CM, Galama JM, Fennis JF, Jongen PJ, Hommes OR, et al. The persistence of fatigue in chronic fatigue syndrome and multiple sclerosis: development of a model. J Psychosom Res. 1998 Dec;45(6):50717.

28. Larun L, Malterud K. Finding the right balance of physical activity: a focus group study about experiences among patients with chronic fatigue syndrome. Patient Educ Couns. 2011 May;83(2):222-6.

29. Van Houdenhove B, Luyten P. Customizing treatment of chronic fatigue syndrome and fibromyalgia: the role of perpetuating factors. Psychosomatics. 2008 Nov-Dec;49(6):470-7.

30. Deary V. A precarious balance: using a self-regulation model to conceptualize and treat chronic fatigue syndrome. Br J Health Psychol. 2008 May; 13(Pt 2):231-6.

31. Marques M, De Gucht V, Maes S, Leal I. Protocol for the "Four steps to control your fatigue (4-STEPS)" randomised controlled trial: A selfregulation based physical activity intervention for patients with unexplained Chronic Fatigue. BMC Public Health. 2012 Mar 19;12(1):202. 
32. Gabriele JM, Carpenter BD, Tate DF, Fisher EB. Directive and nondirective ecoach support for weight loss in overweight adults. Ann Behav Med. 2011 Apr;41(2):252-63.

33. van Weering MG, Vollenbroek-Hutten MM, Hermens HJ. Do Personalized Feedback Messages about Activity Patterns Stimulate Patients with Chronic Low Back Pain to Change their Activity Behavior on a Short Term Notice? Appl Psychophysiol Biofeedback. 2012 Feb 7.

34. Davis FD. Perceived usefulness, perceived ease of use and user acceptance of information technology. MIS Quarterly. 1989;13:210-15.

35. Hlavaty LE, Brown MM, Jason LA. The effect of homework compliance on treatment outcomes for participants with myalgic encephalomyelitis/chronic fatigue syndrome. Rehabil Psychol. 2011 Aug;56(3):212-8.

36. Huis in 't Veld RM, Kosterink SM, Barbe T, Lindegard A, Marecek T, Vollenbroek-Hutten MM. Relation between patient satisfaction, compliance and the clinical benefit of a teletreatment application for chronic pain. J Telemed Telecare. 2010;16(6):322-8.

37. Vercoulen JH, Bazelmans E, Swanink CM, Fennis JF, Galama JM, Jongen PJ, et al. Physical activity in chronic fatigue syndrome: assessment and its role in fatigue. J Psychiatr Res. 1997 Nov-Dec;31(6):661-73. 


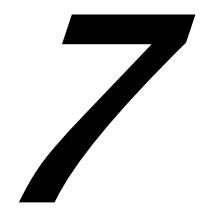

General discussion 
Patients with chronic fatigue syndrome (CFS) are characterized with persistent fatigue which disturbs activities of daily life. Up to now cognitive behavioural therapy (CBT) and graded exercise therapy (GET) have found the most promising treatment results in CFS. Both treatment principles underline the importance of a sufficient daily physical activity level and a balanced daily physical activity pattern (1-7). However, despite the promising results found with CBT and GET, still a significant number of CFS patients do not encounter a reduction of CFS complaints after treatment (7-10). The current way in which programs based on CBT and GET pay attention to a balanced daily physical activity pattern may be optimized, as till now daily physical activity is most often measured by means of subjective outcome measures with which physical activity is only measured at fixed time stamps (6). Individual tailoring of treatment programs in the home environment aimed at a more balanced daily physical activity pattern may enhance treatment outcome in CFS (11-13). The goal of this thesis is to study whether ambulant monitoring of and providing direct feedback on daily physical activities can improve the balance in the daily physical activity pattern and results in improved treatment outcome in patients with CFS.

\section{Daily physical activity in CFS}

Several studies have investigated the physical activity level in CFS patients. It has been postulated that a low level of physical activity is one of the perpetuating factors in CFS (14). A previous review from our research group has shown significant lower physical activity levels in CFS patients as compared to asymptomatic controls (15). However, this review has focussed on a heterogeneous population of patients with chronic pain and fatigue with large heterogeneity between chronic conditions, and included a limited number of studies concerning a comparison between CFS patients and asymptomatic controls (15).

Therefore, in chapter 2 an attempt has been made to present an up to date overview of the physical activity level of CFS patients as compared to healthy controls by performing a systematic review. Most of the studies included in this 
review have shown that CFS patients are less physically active as compared to healthy controls. Several different outcome measures with different quality are found in literature for measuring physical activity. No relation is found between methodological quality of the outcome measure used and outcome of the results. However, subjective outcome measurements show more often lower daily physical activity levels in CFS compared to asymptomatic controls than objective outcome measurements do. This might indicate that CFS patients misperceive their level of physical activity. They seem to judge themselves being less active then they actual are. Misperception in the physical activity level in CFS patients could magnify the feeling of ill health and possibly have a maintaining role in the course of the disorder (16-18). Subjective as well as objective monitoring of physical activity at baseline simultaneously seem to be necessary to get insight in the existence of distorted perceptions. In spite of, the physical activity pattern is often determined only by means of subjective reported data from the patient (6). The addition of objective monitoring will also give the healthcare professional a more adequate insight in the daily physical activity pattern of the CFS patient throughout the day as it will be measured continuously during the day. This information can be used to tailor the treatment program more adequately to individual needs in balancing the daily physical activity pattern (18-20).

It has been theorized that CFS patients avoid physical activities in order to prevent exacerbation of the symptoms, but also that CFS patients have feelings of not accepting low levels of physical activity resulting in bursts of physical activity (21). This might result in large variability in activities over the day as well as in deviating overall patterns. The review performed within this thesis did however not show more variation in the physical activity level between CFS patients as compared to asymptomatic controls.

Concerning the pattern over the day it appeared from the review that there is still very little information about CFS patients. Only a few studies investigated deviations in particular aspects of daily physical activity in CFS patients as compared to healthy controls $(18,22-24)$. One of these studies have registered the 10 largest activity peaks during a 12 day period of monitoring physical activity, and found less intense and shorter physical activity peaks followed by longer rest periods in CFS 
patients (18). Two other studies have analysed physical activity data in more detail and found more abrupt interruptions of voluntary physical activity during diurnal periods and less complexity in the physical activity pattern in CFS patients $(23,24)$. Finally, Kop et al. (2005) have monitored physical activity continuously over a 5 day period and registered the duration in activities at high-, moderate-, low-, and very low intensity levels (22). They found that patients with CFS and/or fibromyalgia spent significant less time in physical activities at high intensity levels compared to healthy controls (0.2\% vs. $1.3 \%)(22)$.

Starting from the lack of knowledge in the physical activity pattern over the day in CFS patients we studied (chapter 3) how CFS patients distribute their daily physical activities throughout the day and investigated the awareness of CFS patients in performing physical activities by measuring daily physical activity with subjective and objective outcome measures. Results show that CFS patients have equal physical activity levels in the morning, but decreased levels in the afternoon and evening. Moreover, CFS patients have spent far more daily hours at low intensity levels and less at high intensity levels. This indicates that CFS patients have decreased physical activity levels in the afternoon and evening as a consequence of performing fewer activities at high intensity levels and more at low intensity levels. CFS patients may perform less frequently activities at high intensity levels as these are expected to result in high fatigue levels, and perform more frequently activities at low intensity levels as these are expected to produce less fatigue (17). The correlation between subjective and objective outcome measures has shown that CFS patients are more aware about their daily physical activity level than healthy controls. However, the level of awareness has shown to be moderate in the CFS group indicating that some CFS patients may still insufficiently aware about their physical activity level.

Knowing now that CFS patients are less active and have deviating patterns during the day the next important question is why? What is the reason that CFS patients have equal levels in the morning and only decreased levels in the afternoon and evening? It could be hypothesized that CFS patients are less fatigued in the morning and as such do a lot, but when the levels of fatigue increases during the day the ability to be active decreases $(17,22,25)$. It could also be that patients do not 
accept their limits in performing daily physical activities and decrease only their physical activity levels when they are exhausted (26). In other words, are CFS patients less tolerant to perform physical activity as a consequence of an early failure in the stress system, or do CFS patients have decreased physical capacity levels causing the inability to generate and maintain sufficient production of energy (26). To investigate this relation between physical activity levels and fatigue severity, more adequate monitoring is needed of fatigue severity and physical activity simultaneously during the day. Investigating the reason why patients with CFS are less physically active will help healthcare professionals to apply a more theoretically driven treatment approach. However, measurements of fatigue severity and physical activity simultaneously are difficult to perform as these measurements will likely influence each others outcome through cognitions CFS patients have about the role of physical activity in fatigue severity $(14,27)$.

\section{Development of an ambulant feedback program}

CFS patients have shown imbalanced daily physical activity patterns (chapter 3) and restoration in this balance may improve their health status $(2,5)$. In chapter 4,5 and 6 we investigated the potential value of ambulant monitoring of and feedback on daily physical activities in the home environment. A state of the art ambulant feedback system was used (28). The feedback provided to the patient was based on a comparison of the daily physical activity pattern of the CFS patient with that of a group of asymptomatic controls. Feedback was provided in two ways: 1) Patients got insight in the goal and their own pattern continuously during the day with the presentation of a figure at the personal digital assistant (PDA). 2) Feedback and advices were provided automatically in the form of text messages at the PDA every hour between 8.00 and 22.00 .

In the first randomized controlled trial (RCT) performed and evaluated in this thesis (chapter 4 and 5), the ambulant feedback program has been supplemented to a current multi-component rehabilitation program in 'Het Roessingh' (Enschede, the 
Netherlands) based on the principles of CBT and GET. In chapter 4 the way CFS patients in the intervention group deal with ambulant feedback at home provided through the feedback system is studied. Following the approach of DeChant et al. (1996), a stage 2 evaluation is performed focusing on accessibility and quality of the feedback system expressed as compliance with the feedback system and changes made in physical activity (29). The results show that physical activity levels improved significantly during all four feedback periods as patients have declined the gap with the goal pattern in the morning and afternoon as compared to the physical activity levels at baseline. Patients have been able to increase their physical activity level in the morning and afternoon. However, the physical activity level in the evening did not increase while the gap between the physical activity pattern at baseline and the goal pattern has found to be the largest in the evening. As such although their average activity level increased, the balance in activities over the day did not. An explanation for this might be the goal pattern based on healthy controls, as the goal pattern was considerably higher than the baseline values of the patient. The goal pattern might have been too high as CFS patients have been unable to sustain the increased physical activity level till the end of the day. It may be more appropriate to adapt the goal pattern to individual capacity levels of daily physical activity as such that CFS patients distribute the amount of physical activity equally throughout the day.

The compliance with the feedback system has found less optimistic. Fifteen patients of the thirty patients who are included into the data analysis did not comply sufficiently with the feedback system. Twelve of these fifteen patients dropped out the feedback program and three of the fifteen patients wore the system less than prescribed. The dropout of twelve CFS patients (40\%) seems high compared to a review published in the Cochrane Library (2004) that showed an overall dropout rate of $14 \%$ in intervention groups with exercise therapy in chronic fatigue syndrome, and compared to the median dropout rate of $26 \%$ reported in a systematic review about novel technologies for the management of chronic illnesses $(30,31)$. Group characteristics could not explain the high dropout rate as these did not differ between compliers and non compliers. However, the non compliers have approached the physical activity level of the goal at baseline more 
closely than the compliers (94\% vs. $84 \%$ ). This suggests that those patients who are more in need for feedback may be more motivated to use the feedback system than other CFS patients $(6,32)$. Changes in physical activity patterns have been observed instantaneously from the first feedback day. Relative active CFS patients may have reached the goal pattern right at the first day of the feedback program and have become unmotivated to use the feedback system any longer. Because of that, an ambulant monitoring and feedback program in the treatment of CFS may be helpful only if it is adequately tailored to individual needs of CFS patients.

Another reason explaining the low compliance rates might be the intensive protocol patients have to follow. During treatment patients were asked to comply four consecutive feedback periods (nine days per period) five days per feedback period from 8.00 till 22.00, while other treatment protocols comprised only 3 to 5 weekly sessions of exercise bouts with duration of 30 minutes per session (31). Yet another reason could be that the feedback gave advises on activities they don't like or that the feedback became boring and more the same after a while. Lastly problems with portability of the feedback system may have impeded the compliance as patients reported several problems for not wearing it. According to the Technology Acceptance Model, the compliance with the feedback system could be influenced by perceived usefulness and perceived ease of use (33). Patients may choose to not comply when the barriers outweigh the expected benefits (34). Barriers in usability related to perceived usefulness and ease of use may be prevented with more involvement in design and testing of telecommunication technologies from patients, important persons in their social environment, and care givers who will be involved in the treatment of the patient $(35,36)$. In the feedback program assumptions have been made by the executive researcher about the correctness of several aspects i.e. 1) designing of the goal, 2) timing-, 3) frequency- and 4) content- of the feedback. These assumptions have been made without advices from other stakeholders i.e. 1) healthcare professionals, 2) CFS patients engaged in the rehabilitation program and 3) other important persons in the social environment of the CFS patient. As such, more involvement of stakeholders in several aspects of the feedback program in the fulfilment of clinical 
needs could improve new developments and clinical use of an ambulant feedback system in the treatment of CFS $(37,38)$.

\section{Additional value of ambulant feedback in treatment of CFS}

In the first RCT performed and evaluated in this thesis, the additional value of the ambulant feedback program to a multi-component rehabilitation program comprising CBT and GET is evaluated in chapter 5. Evaluation of the primary outcome parameters (fatigue severity and physical functioning) and secondary outcome parameters (social functioning, patient specific complaints, self efficacy, somatic attributions and psychological attributions) of the rehabilitation treatment have not supported an additional value of the ambulant feedback program. The intervention group and control group improved significantly after treatment at the primary and secondary outcome parameters, but the improvements found did not differ between both groups.

This result was not expected as in chapter 4 we have found in the intervention group significant improvements in daily physical activity. It could be that the rehabilitation treatment based on CBT and GET provided in the control- and intervention group has contributed to the improved physical activity levels, and not the ambulant feedback intervention as provided in the intervention group alone. However, we were not able to investigate this assumption as the daily physical activity is not measured in the control group during the four feedback periods. Another reason for not finding an additional value may be the result of an inadequate involvement of the stakeholders in the implementation of the ambulant feedback program (39). The feedback program has been implemented by the executive researcher. Stronger involvement of the healthcare professionals from the rehabilitation treatment in the implementation process may have embedded the ambulant feedback program more adequately in the rehabilitation treatment. In the way we currently have implemented the feedback program, the feedback provided by the feedback system did not always fit the rationale of the rehabilitation program. 
A third reason for not finding an additional value of the ambulant feedback program to the rehabilitation treatment could be that changing cognitions about daily physical activity are also or even of more importance than changing the daily physical activity behaviour itself in the treatment of CFS (40). The ambulant feedback system only provided feedback about the amount of physical activity the CFS patient has performed and in what extent the physical activity level of the goal pattern has reached. However, CFS patients who use the ambulant feedback system may still be uncertain if they perform the correct type of physical activity in the right way. Feedback focussing on the type of physical activity which is performed and the accuracy of inserting adequate rest periods may have increased the confidence of CFS patients in performing the correct type of physical activity in the right way. This kind of feedback may increase the sense of control in reducing complaints of fatigue. An increase in the sense of control has been recognized as an important mediator in improving the treatment outcome in CFS $(41,42)$. Finally, another reason for not finding an additional value may be the result of inadequate tailoring of the feedback intervention to individual needs. As mentioned before, the goal pattern based on healthy controls may have been too high as CFS patients have been unable to sustain the increased physical activity level till the end of the day. A more flexible goal pattern in the ambulant feedback program may enhance the attainability of the goal and improve experienced usability and compliance. CFS patients can become unmotivated to use the feedback system as the goal asks for unacceptable high changes in daily physical activity patterns (43, 44). Information about individual physical activity levels at baseline may be used to tailor the goal pattern in the feedback intervention to individual needs (45-47).

\section{Individual tailoring of the goal pattern}

Tailoring the feedback program to individual needs of patients with CFS will likely improve the usability of the feedback system and increasing the effectiveness in changing daily physical activity patterns (48). The predefined goal pattern in the intervention group of the RCT evaluated in chapter 4 and 5 was based on physical 
activity patterns of healthy controls while it could have been more adequate to tailor the goal to physical activity levels of the individual patient (13). This belief is strengthened with the large differences in physical activity patterns recognized between CFS patients $(18,49)$. In chapter 6 is studied if ambulatory feedback is more effective in balancing daily physical activity patterns in CFS patients if the goal pattern is based on individual activity patterns (temporal comparison) as compared to a goal pattern based on healthy controls (social comparison) (50,51). A second RCT is performed in which CFS patients have received the feedback program for two weeks consecutively, without a multi-component rehabilitation program. One group have received feedback with a goal based on the pattern of healthy controls, and one group have received feedback based on a goal adapted to the individual physical activity pattern at baseline. The results have shown a trend of more improved daily physical activity patterns in both groups, and a trend of an increased compliance in favour of the group with a goal based on the individual physical activity pattern at baseline. Moreover, the perceived usefulness of the feedback system has found to be significant higher in this group as well. Increased flexibility in determining the appropriate intensity of the goal by tailoring the goal to the individual physical activity pattern at baseline may have improved the compliance and perceived usefulness. Especially keeping in mind that individuals with CFS who experience high levels of disability may be unable to comply at a rigid predefined goal (52). This seems to be in accordance with the technology acceptance model, as tailoring the goal pattern to the individual CFS patient may have increased the use of the feedback system by an increase in the perceived usefulness of the feedback system (53).

However, improvements found in balancing daily physical activity patterns have not been significant within both groups. These results were not expected and disappointing. In literature only two studies were found which have performed a randomized controlled trial studying the effectiveness of an individual tailored feedback intervention in promoting physical activity $(54,55)$, however feedback provided in both studies was not as continuous as in our study but only received when patients logged in on a web-portal. The first study from De Cocker at al. (2012) did not find an increased effectiveness with such an intervention as 
compared to a standard feedback intervention in subjects disseminated by the general practitioner (54). The second study from Slootmaker et al. (2009) also did not find an increased effectiveness with an individual tailored feedback intervention as compared to the standard condition comprising an information brochure with general physical activity recommendations in healthy inactive office workers. Several factors are recognized to influence the effectiveness of an ambulant feedback intervention such as timing-, duration-, exposure- and intensity of the feedback, and mode of delivery (56). For instance, one can study the timing of providing ambulant feedback in more detail as this can be done at fixed time spans or only at moments when subjects are able- or willing to receive the feedback. In both studies mentioned above, subjects in the intervention group had to log in on a web-portal for receiving personalized tailored feedback $(54,55)$. In this way, subjects only receive feedback when they are able- and willing to receive the feedback, however, some subjects may not receive any individual tailored feedback as it may be inconvenient for them to log in on a web-portal.

The results of the second RCT reported in chapter 6 are in contradiction with the results in the intervention group of the first RCT as reported in chapter 4 in which the feedback program, as supplement to a multi-component rehabilitation program, seem to be effective in changing daily physical activity patterns. A first reason for the contradicting results may be the differences in study design between the two RCTs. In chapter 6 the ambulant feedback program has been implemented autonomously without impedance of a rehabilitation program. Van Weering et al., (2012) has also implemented the ambulant feedback as an autonomous 'stand alone' treatment in patients with chronic low back pain and reported similar results as in chapter 6 , comprising only a trend of improved daily physical activity patterns without significant changes (28). Maybe, the ambulant feedback program is ineffective in changing daily physical activity patterns when it is implemented as a 'stand alone' treatment. However, the trends seen in CFS patients and patients with chronic low back pain are promising. More research in tailoring the ambulant feedback program to individual needs and in larger study samples seem necessary to elucidate if the ambulant feedback program can be implemented as an effective 'stand alone' treatment in patients with chronic diseases. 
Another reason for the contradicting results between the two RCTs may be the inclusion of different samples of CFS patients. However, the intervention group in the first RCT (chapter 4) and CFS patients included in the second RCT (chapter 6) are comparable for group characteristics at baseline for age, gender, fatigue severity and duration of fatigue complaints. Only the mean physical activity level was significant lower at baseline in the CFS group included in chapter 6 . However, it seems unlikely that this is the reason for not finding significant changes in the CFS group of chapter 6 as the compliers in chapter 4 have shown decreased daily physical levels as compared to the non compliers.

\section{Recommendations for future research}

A deviating daily physical activity pattern is found in CFS patients expressed in decreased levels in the afternoon and evening. Promising results are found with an ambulant feedback program in changing the daily physical activity pattern of CFS patients. Results with the ambulant feedback program have been discussed in more detail and have given rise to formulate the recommendations presented in the next three paragraphs.

\section{Individual tailoring of the ambulant feedback program}

In future, the ambulant feedback program may be tailored more adequately to individual patients by improving the timing of the feedback messages in stimulating patients to change activity behavior (57). The ambulant feedback program has provided feedback in a time-contingent strategy as feedback messages are provided at fixed time moments based on the amount of physical activity performed over time. Time-contingent strategies are generally based on rehabilitation programmes designed for chronic pain (58). It could have been more accurate to provide messages only when the activity level was not within the range of the goal, or providing messages only when patients are willing to change their activity behavior. These and other contextual factors influencing the ability to follow the feedback could be taken into account in accurate timing of providing 
feedback $(12,59,60)$. Op den Akker et al. (2010) studied the way to improve the compliance with ambulant feedback by taking into account various contextual factors (61). Tailoring the timing, content and representation of the feedback can improve the effectiveness of the feedback $(62,63)$. Incorporation of a decision component in the ambulant feedback program may enable an adequate selection in timing and content of feedback tailored to the needs of the individual patient (61). The decision component should be able to decide when patients have an inadequate physical activity level and are in need of feedback, and it should be able to decide what kind of feedback is needed to stimulate the patient in the most optimal way to change the physical activity level in the right way.

\section{The implementation of an ambulant feedback program}

The implementation of the ambulant feedback program in the treatment of CFS will be improved with more involvement of the healthcare professional in the implementation process (39). The role of the healthcare professional is important seeing that they may advise CFS patients how to wear the feedback system as many problems have been reported about wearing the feedback system. Healthcare professionals also have more insight in which period within the rehabilitation treatment it is most adequate to use the feedback system, and for which CFS patients it is most helpful to use the feedback system in balancing daily physical activity patterns. Positive feedback from healthcare professionals in the use of the feedback system may also increase the sense of control of the CFS patient in balancing daily physical activity patterns, which is recognized as an important aspect in the treatment of CFS $(14,64)$. Healthcare professionals obtain information from the individual CFS patient about illness beliefs, cognitions and other contextual factors which can be of influence on the perpetuation of CFS before starting treatment (6). This information can be used to tailor the content and timing of the feedback more adequately to individual needs, as mentioned in the previous paragraph. For instance, the content of feedback advices can be focused on reducing catastrophic beliefs about physical activity behaviour, as some CFS patients may feel insecure about the level of physical activity they are able to perform (65-67). A study of Voerman et al. (2007) has indicated that interventions 
focusing on changing activity behaviour can positively influence illness related cognitions as well (68). Finally, regular evaluations of the progression made in balancing the daily physical activity pattern with the healthcare professional may also decrease misleading believes about avoiding physical activity and the focus on symptoms of CFS, which have been found to be associated with a decrease in complaints of fatigue $(27,69)$.

\section{The self management of the CFS patient}

The ambulant feedback program has aimed for increased self management of the CFS patient by remotely monitoring of physical activity and providing ambulant feedback. In traditional treatment programs healthcare professionals use face-toface communication to instruct patients. Modern technologies enable the opportunity to have remotely contact and to share remotely obtained data from the patient with the healthcare professional via a web-portal (70-72). In line of the chronic care model, providing chronic patients more insight in their health status and improvements in remote communication with healthcare professionals will increase the self management of the patient (73). However, the ambulant feedback program did not enable remote assessment of the health status and remote communication between the CFS patient and healthcare professional. The use of a digital diary at the PDA will enable remote assessment of the health status and the use of a web-portal will enable remote communication and sharing of remotely obtained data with the healthcare professional (74). Incorporation of a digital diary and access to a web-portal into the ambulant feedback program may increase the self management of the CFS patient even more. The patient can have insight in his changes in physical activity behaviour and health status at home, and in case severe situations occur the healthcare professional can be alarmed automatically. Remote communication reduces travel and time costs for the patient, and increases the flexibility and efficiency in making appointments for the healthcare professional. 


\section{Conclusion}

CFS patients have decreased daily physical activity levels and deviations in daily physical activity patterns as compared to healthy controls. State of the art technology has been used to provide ambulant feedback in the home environment of the patient with CFS and has shown promising results in changing physical activity behaviour. It is expected that adequate optimization and implementation of the ambulant feedback program can contribute to a more appropriate tailoring of multi-component treatment programs to individual needs and may enhance treatment outcome. 


\section{References}

1. Wessely S, David A, Butler S, Chalder T. Management of chronic (post-viral) fatigue syndrome. J R Coll Gen Pract. 1989;39(318):26-9.

2. Reid SF, Chalder T, Cleare A, Hotopf M, Wessely S. Chronic fatigue syndrome. Clin Evid (Online). 2008;2008.

3. Price JR, Mitchell E, Tidy E, Hunot V. Cognitive behaviour therapy for chronic fatigue syndrome in adults. Cochrane Database Syst Rev. 2008(3):CD001027.

4. Malouff JM, Thorsteinsson EB, Rooke SE, Bhullar N, Schutte NS. Efficacy of cognitive behavioral therapy for chronic fatigue syndrome: a meta-analysis. Clin Psychol Rev. 2008 Jun;28(5):736-45.

5. Rimes KA, Chalder T. Treatments for chronic fatigue syndrome. Occup Med (Lond). 2005 Jan;55(1):32-9.

6. Bazelmans E, Prins J, Bleijenberg G. Cognitive Behavior Therapy for Relatively Active and for Passive Chronic Fatigue Syndrome Patients. Cognitive and Behavioral Practice. 2006;13(2):157-66.

7. Torenbeek M, Mes CA, van Liere MJ, Schreurs KM, ter Meer R, Kortleven GC, et al. [Favourable results of a rehabilitation programme with cognitive behavioural therapy and graded physical activity in patients with the chronic-fatigue syndrome]. Ned Tijdschr Geneeskd. 2006 Sep 23;150(38):2088-94.

8. Bazelmans E, Prins JB, Lulofs R, van der Meer JW, Bleijenberg G. Cognitive behaviour group therapy for chronic fatigue syndrome: a non-randomised waiting list controlled study. Psychother Psychosom. 2005;74(4):218-24.

9. Prins JB, Bleijenberg G, Bazelmans E, Elving LD, de Boo TM, Severens JL, et al. Cognitive behaviour therapy for chronic fatigue syndrome: a multicentre randomised controlled trial. Lancet. 2001 Mar 17;357(9259):841-7.

10. Stulemeijer M, de Jong LW, Fiselier TJ, Hoogveld SW, Bleijenberg G. Cognitive behaviour therapy for adolescents with chronic fatigue syndrome: randomised controlled trial. BMJ. 2005 Jan 1;330(7481):14. 
11. Van Houdenhove B, Luyten P. Customizing treatment of chronic fatigue syndrome and fibromyalgia: the role of perpetuating factors.

Psychosomatics. 2008 Nov-Dec;49(6):470-7.

12. Jason L, Benton M, Torres-Harding S, Muldowney K. The impact of energy modulation on physical functioning and fatigue severity among patients with ME/CFS. Patient Educ Couns. 2009 Nov;77(2):237-41.

13. Larun L, Malterud K. Finding the right balance of physical activity: a focus group study about experiences among patients with chronic fatigue syndrome. Patient Educ Couns. 2011 May;83(2):222-6.

14. Vercoulen JH, Swanink CM, Galama JM, Fennis JF, Jongen PJ, Hommes OR, et al. The persistence of fatigue in chronic fatigue syndrome and multiple sclerosis: development of a model. J Psychosom Res. 1998 Dec;45(6):50717.

15. Van Weering M, Vollenbroek-Hutten MM, Kotte EM, Hermens HJ. Daily physical activities of patients with chronic pain or fatigue versus asymptomatic controls. A systematic review. Clin Rehabil. 2007 Nov;21(11):1007-23.

16. Fry AM, Martin M. Cognitive idiosyncrasies among children with the chronic fatigue syndrome: anomalies in self-reported activity levels. J Psychosom Res. 1996 Sep;41(3):213-23.

17. Vercoulen JH, Bazelmans E, Swanink CM, Fennis JF, Galama JM, Jongen PJ, et al. Physical activity in chronic fatigue syndrome: assessment and its role in fatigue. J Psychiatr Res. 1997 Nov-Dec;31(6):661-73.

18. Van der Werf SP, Prins JB, Vercoulen JH, van der Meer JW, Bleijenberg G. Identifying physical activity patterns in chronic fatigue syndrome using actigraphic assessment. J Psychosom Res. 2000 Nov;49(5):373-9.

19. van Weering MG, Vollenbroek-Hutten MM, Hermens HJ. The relationship between objectively and subjectively measured activity levels in people with chronic low back pain. Clin Rehabil. 2011 Mar;25(3):256-63.

20. Tabak M, Vollenbroek-Hutten MM, van der Valk PD, van der Palen J, Tonis TM, Hermens HJ. Telemonitoring of Daily Activity and Symptom Behavior in Patients with COPD. Int J Telemed Appl. 2012;2012:438736. 
21. Surawy C, Hackmann A, Hawton K, Sharpe M. Chronic fatigue syndrome: a cognitive approach. Behav Res Ther. 1995 Jun;33(5):535-44.

22. Kop WJ, Lyden A, Berlin AA, Ambrose K, Olsen C, Gracely RH, et al. Ambulatory monitoring of physical activity and symptoms in fibromyalgia and chronic fatigue syndrome. Arthritis Rheum. 2005 Jan;52(1):296-303.

23. Ohashi K, Bleijenberg G, van der Werf S, Prins J, Amaral LA, Natelson BH, et al. Decreased fractal correlation in diurnal physical activity in chronic fatigue syndrome. Methods Inf Med. 2004;43(1):26-9.

24. Burton C, Knoop H, Popovic N, Sharpe M, Bleijenberg G. Reduced complexity of activity patterns in patients with chronic fatigue syndrome: a case control study. Biopsychosoc Med. 2009;3:7.

25. Vercoulen JH, Hommes OR, Swanink CM, Jongen PJ, Fennis JF, Galama JM, et al. The measurement of fatigue in patients with multiple sclerosis. A multidimensional comparison with patients with chronic fatigue syndrome and healthy subjects. Arch Neurol. 1996 Jul;53(7):642-9.

26. Van Houdenhove B, Verheyen L, Pardaens K, Luyten P, Van Wambeke P. Rehabilitation of decreased motor performance in patients with chronic fatigue syndrome: should we treat low effort capacity or reduced effort tolerance? Clin Rehabil. 2007 Dec;21(12):1121-42.

27. Deale A, Chalder T, Wessely S. Illness beliefs and treatment outcome in chronic fatigue syndrome. J Psychosom Res. 1998 Jul;45(1):77-83.

28. Van Weering M, Vollenbroek-Hutten MM, Hermens HJ. Chapter 6: Potential value of an activity-based feedback system for treatment of patients with chronic low back pain. In: Van Weering M, editor. Towards a new treatment for chronic low back pain patients, using activity monitoring and personalized feedback. Enschede, The Netherlands: Gildeprint Drukkerijen; 2011 . p. 115-42.

29. DeChant HK, Tohme WG, Mun SK, Hayes WS, Schulman KA. Health systems evaluation of telemedicine: a staged approach. Telemed J. 1996;2(4):30312. 
30. Rosser BA, Vowles KE, Keogh E, Eccleston C, Mountain GA. Technologicallyassisted behaviour change: a systematic review of studies of novel technologies for the management of chronic illness. J Telemed Telecare. 2009;15(7):327-38.

31. Edmonds M, McGuire H, Price J. Exercise therapy for chronic fatigue syndrome. Cochrane Database Syst Rev. 2004(3):CD003200.

32. Friedberg F, Sohl S. Cognitive-behavior therapy in chronic fatigue syndrome: is improvement related to increased physical activity? J Clin Psychol. 2009 Apr;65(4):423-42.

33. Taylor S, Todd PA. Understanding Information Technology Usage: a Test of Competing Models. Information Systems Research. 1995 Jun;6(2):144-76.

34. Huis in 't Veld RM, Kosterink SM, Barbe T, Lindegard A, Marecek T, Vollenbroek-Hutten MM. Relation between patient satisfaction, compliance and the clinical benefit of a teletreatment application for chronic pain. J Telemed Telecare. 2010;16(6):322-8.

35. Arsand E, Tatara N, Ostengen G, Hartvigsen G. Mobile phone-based selfmanagement tools for type 2 diabetes: the few touch application. J Diabetes Sci Technol. 2010 Mar;4(2):328-36.

36. Klasnja P, Consolvo S, McDonald DW, Landay JA, Pratt W, editors. Using mobile \& personal sensing technologies to support health behavior change in everyday life: lessons learned2009 2009.

37. Vollenbroek-Hutten MM, Hermens HJ. Remote care nearby. J Telemed Telecare. 2010;16(6):294-301.

38. Kennedy A, Rogers A, Bower P. Support for self care for patients with chronic disease. BMJ. 2007 Nov 10;335(7627):968-70.

39. Mair FS, May C, O'Donnell C, Finch T, Sullivan F, Murray E. Factors that promote or inhibit the implementation of e-health systems: an explanatory systematic review. Bull World Health Organ. 2012 May 1;90(5):357-64.

40. Wiborg JF, Knoop H, Stulemeijer M, Prins JB, Bleijenberg G. How does cognitive behaviour therapy reduce fatigue in patients with chronic fatigue syndrome? The role of physical activity. Psychol Med. 2010 Aug;40(8): $1281-7$. 
41. Wiborg JF, Knoop H, Frank LE, Bleijenberg G. Towards an evidence-based treatment model for cognitive behavioral interventions focusing on chronic fatigue syndrome. J Psychosom Res. 2012 May;72(5):399-404.

42. Schreurs KM, Veehof MM, Passade L, Vollenbroek-Hutten MM. Cognitive behavioural treatment for chronic fatigue syndrome in a rehabilitation setting: effectiveness and predictors of outcome. Behav Res Ther. 2011 Dec;49(12):908-13.

43. Shepherd C. Pacing and Exercise in Chronic Fatigue Syndrome. Physiotherapy. $2001 ; 87(8): 395-6$.

44. Nijs J, Paul L, Wallman K. Chronic fatigue syndrome: an approach combining self-management with graded exercise to avoid exacerbations. J Rehabil Med. 2008 Apr;40(4):241-7.

45. Nijs J, Almond F, De Becker P, Truijen S, Paul L. Can exercise limits prevent post-exertional malaise in chronic fatigue syndrome? An uncontrolled clinical trial. Clin Rehabil. 2008 May;22(5):426-35.

46. Goudsmit EM, Nijs J, Jason LA, Wallman KE. Pacing as a strategy to improve energy management in myalgic encephalomyelitis/chronic fatigue syndrome: a consensus document. Disabil Rehabil. 2012;34(13):1140-7.

47. Davenport TE, Stevens SR, VanNess MJ, Snell CR, Little T. Conceptual model for physical therapist management of chronic fatigue syndrome/myalgic encephalomyelitis. Phys Ther. 2010 Apr;90(4):602-14.

48. Scobbie L, Dixon D, Wyke S. Goal setting and action planning in the rehabilitation setting: development of a theoretically informed practice framework. Clin Rehabil. 2011 May;25(5):468-82.

49. Vanness JM, Snell CR, Strayer DR, Dempsey Lt, Stevens SR. Subclassifying chronic fatigue syndrome through exercise testing. Med Sci Sports Exerc. 2003 Jun;35(6):908-13.

50. Albert S. Temporal Comparison Theory. Psychological Review. $1977 ; 84(6): 485-503$.

51. Festinger L. a theory of social comparison processes. Human relations : studies towards the integration of the social sciences. 1954;2. 
52. Hlavaty LE, Brown MM, Jason LA. The effect of homework compliance on treatment outcomes for participants with myalgic encephalomyelitis/chronic fatigue syndrome. Rehabil Psychol. 2011 Aug;56(3):212-8.

53. Davis FD. Perceived usefulness, perceived ease of use and user acceptance of information technology. MIS Quarterly. 1989;13:210-15.

54. De Cocker K, Spittaels H, Cardon G, De Bourdeaudhuij I, Vandelanotte C. Web-based, computer-tailored, pedometer-based physical activity advice: development, dissemination through general practice, acceptability, and preliminary efficacy in a randomized controlled trial. J Med Internet Res. 2012;14(2):e53.

55. Slootmaker SM, Chinapaw MJ, Schuit AJ, Seidell JC, Van Mechelen W. Feasibility and effectiveness of online physical activity advice based on a personal activity monitor: randomized controlled trial. J Med Internet Res. 2009;11(3):e27.

56. Neville LM, O'Hara B, Milat A. Computer-tailored physical activity behavior change interventions targeting adults: a systematic review. Int J Behav Nutr Phys Act. 2009;6:30.

57. van Weering MG, Vollenbroek-Hutten MM, Hermens HJ. Do Personalized Feedback Messages about Activity Patterns Stimulate Patients with Chronic Low Back Pain to Change their Activity Behavior on a Short Term Notice? Appl Psychophysiol Biofeedback. 2012 Feb 7.

58. Gill JR, Brown CA. A structured review of the evidence for pacing as a chronic pain intervention. Eur J Pain. 2009 Feb;13(2):214-6.

59. Brown M, Khorana N, Jason LA. The role of changes in activity as a function of perceived available and expended energy in nonpharmacological treatment outcomes for ME/CFS. J Clin Psychol. 2011 Mar;67(3):253-60.

60. Jason L, Muldowney K, Torres-Harding S. The Energy Envelope Theory and myalgic encephalomyelitis/chronic fatigue syndrome. AAOHN J. 2008 May;56(5):189-95. 
61. Akker op den H, Jones VM, Hermens HJ. Predicting Feedback Compliance in a Teletreatment Application. 3rd International Symposium on Applied Sciences in Biomedical and Communication Technologies, ISABEL November; Rome, Italy2010.

62. Akker op den H, Moualed LS, Jones VM, Hermens HJ. A self-learning personalized feedback agent for motivating physical activiy. 4th International Symposium on Applied Sciences in Biomedical and Communication Technologies, ISABEL; October; Barcelona, Spain2011.

63. Noar SM, Benac CN, Harris MS. Does tailoring matter? Meta-analytic review of tailored print health behavior change interventions. Psychol Bull. 2007 Jul;133(4):673-93.

64. Marques M, De Gucht V, Maes S, Leal I. Protocol for the "Four steps to control your fatigue (4-STEPS)" randomised controlled trial: A selfregulation based physical activity intervention for patients with unexplained Chronic Fatigue. BMC Public Health. 2012 Mar 19;12(1):202.

65. Silver A, Haeney M, Vijayadurai P, Wilks D, Pattrick M, Main CJ. The role of fear of physical movement and activity in chronic fatigue syndrome. J Psychosom Res. 2002 Jun;52(6):485-93.

66. Petrie K, Moss-Morris R, Weinman J. The impact of catastrophic beliefs on functioning in chronic fatigue syndrome. J Psychosom Res. 1995 Jan;39(1):31-7.

67. Nijs J, De Meirleir K, Duquet W. Kinesiophobia in chronic fatigue syndrome: assessment and associations with disability. Arch Phys Med Rehabil. 2004 Oct;85(10):1586-92.

68. Voerman GE, Sandsjo L, Vollenbroek-Hutten MM, Larsman P, Kadefors R, Hermens $\mathrm{HJ}$. Changes in cognitive-behavioral factors and muscle activation patterns after interventions for work-related neck-shoulder complaints: relations with discomfort and disability. J Occup Rehabil. 2007 Dec; 17(4):593-609.

69. Moss-Morris R, Sharon C, Tobin R, Baldi JC. A randomized controlled graded exercise trial for chronic fatigue syndrome: outcomes and mechanisms of change. J Health Psychol. 2005 Mar;10(2):245-59. 
70. Czabke A, Loeschke J, Lueth TC. Concept and modular telemedicine platform for measuring of vital signs, ADL and behavioral patterns of elderly in home settings. Conf Proc IEEE Eng Med Biol Soc. $2011 ; 2011: 3164-7$.

71. Hermens HJ, Vollenbroek-Hutten MM. Towards remote monitoring and remotely supervised training. J Electromyogr Kinesiol. 2008 Dec;18(6):90819.

72. Van Hoof J, Wouters EJM. Zorgdomotica. Houten: Bohn Stafleu van Loghum; 2012.

73. Wagner EH. Chronic disease management: what will it take to improve care for chronic illness? Eff Clin Pract. 1998 Aug-Sep;1 (1):2-4.

74. Burke LE, Styn MA, Glanz K, Ewing LJ, Elci OU, Conroy MB, et al. SMART trial: A randomized clinical trial of self-monitoring in behavioral weight management-design and baseline findings. Contemp Clin Trials. 2009 Nov;30(6):540-51. 
198 Chapter 7 


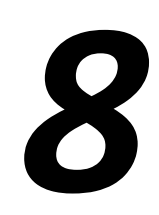

Summary 
Patients with chronic fatigue syndrome (CFS) are characterized with persistent fatigue which disturbs activities of daily life. CFS is a symptom-based diagnosis that is made without findings of distinguished physical examination or laboratory tests. CFS can be diagnosed if the fatigue last for at least six months, is of new onset, is not the result of persistent physical exertion, does not improve considerably by taking rest, and has resulted in substantial loss in professional, social or personal functioning. Furthermore, patients must report four out of eight symptoms i.e. unrefreshing sleep, post-exertional malaise, headache, muscle pain, multi-joint pain, sore throat, tender lymph nodes, and concentration and memory impairment. The prevalence of CFS in the Netherlands is estimated to be between 30,000 to 40,000 patients and the prognosis without treatment is not favourable. The most promising treatment results in CFS are found with cognitive behavioural therapy (CBT) and graded exercise therapy (GET). Both treatment strategies underline the importance of regular physical activity. However, still a significant number of CFS patients do not encounter a reduction of CFS complaints after CBT and GET. The goal of this thesis is to study whether ambulant monitoring of and providing direct feedback on daily physical activities can improve the balance in the daily physical activity pattern and result in improved treatment outcome in patients with CFS. To achieve this goal the daily physical activity pattern is studied in patients with CFS. Subsequently, a 'state of the art' feedback system is used to investigate the potential value of ambulant feedback at the daily physical activity pattern in the treatment of CFS.

In the scientific literature it is hypothesized that CFS starts with an acute illness accompanied by a period of inactivity. This is followed by experiencing fatigue after exertion resulting in further avoidance of activity. At the same time there is a loss of tolerance to everyday activity owing to a decreased fitness level. In the end, symptoms develop at increasingly lower levels of exercise and activities previously undertaken become more difficult. As such, this hypothesis reflects a negative vicious circle explaining the avoidance of physical activities. In several studies the physical activity level in CFS patients has been investigated. In chapter 2 a systematic review was performed for exploring the existing knowledge in the 
scientific literature about daily physical activity in CFS patients as compared to healthy controls. Seventeen studies were included with 22 different comparisons between CFS patients and healthy controls. Eighteen of these comparisons showed a decreased daily physical activity level in CFS patients as compared to healthy controls, while four comparisons did not show a difference between both groups. A meta-analysis of seven studies showed a daily physical activity level in CFS patients of only $68 \%$ of the daily physical activity level observed in healthy controls. Several different outcome measures were found in literature for measuring physical activity but no relation was found between methodological quality of the outcome measure used and the level of physical activity. Subjective outcome measurements showed more often decreased daily physical activity levels in CFS than objective outcome measurements. This indicated that CFS patients may misperceive their level of physical activity. However, little information was found about how the physical activity pattern of CFS patients over the day looks like.

In chapter 3 the daily physical activity pattern was studied in CFS patients and compared with healthy controls. The daily physical activity pattern was monitored in 35 patients with CFS and in 35 age- and gender-matched healthy controls. The awareness in performing physical activity was evaluated by comparing objectively measured physical activity levels with subjective ratings of self-reported physical activity levels assessed at a visual analogue scale. The results showed that CFS patients have equal physical activity levels in the morning, but decreased levels in the afternoon and evening. Moreover, CFS patients spent far more daily hours at low intensity levels and less at high intensity levels. Finally, CFS patients seem to be more aware about their daily physical activity level than healthy controls.

In chapter 4 and 5 the results were presented of a randomized controlled trial (RCT) which was performed for studying the additional value of an ambulant feedback program as supplement to a multi-component rehabilitation treatment based on the principles of CBT and GET. Eighty-one CFS patients were found to be eligible for treatment in rehabilitation centre 'Het Roessingh' and were included in the RCT. Forty-two patients were allocated to the intervention group receiving the ambulant 
feedback program as supplement to the standard rehabilitation treatment and 39 patients to the control group receiving standard rehabilitation treatment alone. CFS patients received ambulant feedback in their home environment with a personal digital assistant (PDA) during four consecutive feedback periods. The ambulant feedback was based on the difference between the cumulative daily physical activity pattern of the patient and a predefined goal pattern based on healthy controls. Patients got insight in these patterns continuously during the day with the presentation of a figure at the PDA. In addition, text messages were provided at the PDA every two hours between 8.00 and 22.00. These messages contained feedback about the difference between the physical activity pattern of the patient and the goal pattern, and contained an activity advice.

The goal of chapter 4 was exploring the compliance of CFS patients in wearing of the feedback system at home and changes made in the daily physical activity pattern towards the predefined goal pattern. Thirty of the 42 CFS patients in the intervention group completed the physical activity measurements at baseline sufficiently and were included for further analysis, while twelve CFS patients did not complete the baseline measurements sufficiently and were excluded from further analysis. Compliance in wearing the feedback system was around $90 \%$ during each of the four feedback periods. However, only fifteen patients $(50 \%)$ wore the feedback system adequately during all four feedback periods. Changes were found especially in the morning and afternoon, were made in the direction of the goal and were seen instantaneously meaning from the first feedback day on. The low compliance rate might be caused by inadequacies in the goal setting, study protocol, and problems in portability of the feedback system.

The goal of chapter 5 was exploring the additional value of the ambulant feedback program in addition to the multi-component rehabilitation treatment based on the principles of CBT and GET. The intervention group and the control group showed statistically significant improvements in fatigue severity, physical functioning, social functioning, patient specific complaints and self-efficacy directly after treatment and at follow up as compared to baseline. However, the extent in which the 
improvements were found at the outcome measures did not differ between the intervention group and control group. The results did not support an additional value of the ambulant feedback program as supplement to a multi-component rehabilitation treatment comprising CBT and GET.

The goal of chapter 6 was exploring if the ambulant feedback program would support CFS patients more adequately if the goal was adapted to the individual physical activity pattern as measured at baseline. A second RCT was performed in which CFS patients received the feedback program for two weeks consecutively, without the multi-component rehabilitation treatment. Twenty-seven patients started with the feedback program, of which 13 patients were allocated to the group with a goal based on the activity pattern of healthy controls and 14 patients to the group with a personalized goal adapted to individual activity patterns at baseline. The results showed a trend of improved daily physical activity patterns, and an increased compliance in favour of the group with a goal tailored to individual physical activity levels at baseline. Moreover, the perceived usefulness of the feedback system scored significant higher in the group with a personalized goal. However, improvements seen in physical activity patterns were not significant and more research is needed to elucidate the effectiveness of the ambulant feedback program.

In chapter 7 scientific and clinical implications were discussed in more detail. Ambulant feedback in the home environment of the CFS patient showed promising results in changing the physical activity pattern. It is expected that adequate adaptations in, and implementation of, the ambulant feedback program can contribute to improvements in the treatment of CFS. 
204 Chapter 8 


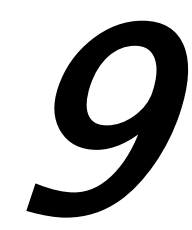

Samenvatting 
Patiënten met het chronische vermoeidheidssyndroom (CVS) worden gekenmerkt door aanhoudende vermoeidheid welke activiteiten in het dagelijks leven verstoren. CVS is een op symptomen gebaseerde diagnose welke wordt gemaakt zonder dat een lichamelijke verklaring gegeven kan worden voor de aanwezige klachten. CVS kan worden gediagnosticeerd als de vermoeidheid ten minste zes maanden aanhoudt, een duidelijk aanwijsbaar begin heeft, niet het resultaat is van voortdurende inspanning, niet aanzienlijk verbeterd door rust, en heeft geleid tot een forse afname in beroepsmatig, sociaal of persoonlijk functioneren. Tevens dienen patiënten ten minste vier uit de volgende acht symptomen te rapporteren, te weten: vermoeid ontwaken; toename van de klachten gedurende meer dan 24 uur na inspanning; hoofdpijn; spierpijn; verspringende gewrichtspijn zonder roodheid of zwelling; pijnlijke keel; pijnlijke lymfeklieren in hals of oksels; ernstige vermindering van het korte termijn geheugen en concentratie problemen. De prevalentie van CVS in Nederland wordt geschat op 30.000 tot 40.000 patiënten en zonder behandeling is de prognose ongunstig. De meest belovende behandelresultaten in CVS zijn gevonden met cognitieve gedragstherapie (CGT) en 'graded exercise training (GET)'. Beide behandelstrategieën zijn gefocust op het behandelen van persisterende factoren in CVS en onderstrepen het belang van regelmatige fysieke activiteit. Echter, een significant aandeel van patiënten met CVS ondervindt geen vermindering in CVS klachten na CGT en GET. Het doel van dit proefschrift is bestuderen of ambulant monitoren van, en feedback geven op, dagelijkse lichamelijke activiteiten de balans in het dagelijks activiteitenpatroon kan verbeteren en kan resulteren in verbeterde behandeluitkomsten in patiënten met CVS. Om dit doel te bereiken is onderzoek gedaan naar het dagelijks lichamelijk activiteitenpatroon van CVS patiënten. Vervolgens is met een 'state of the art' ambulant feedback systeem onderzoek gedaan naar de potentiële waarde van ambulante feedback op het dagelijks lichamelijk activiteitenpatroon in de behandeling van CVS.

In de wetenschappelijke literatuur is gehypothetiseerd dat CVS begint met een acute ziekte die gepaard gaat met een periode van inactiviteit. Dit wordt gevolgd door het ervaren van vermoeidheid na inspanning resulterend in een verdere 
vermijding van activiteit. Op het zelfde moment ontstaat een verminderde tolerantie voor alledaagse activiteiten als gevolg van een verlaagde lichamelijke conditie. Uiteindelijk ontstaan sneller klachten bij inspanning, en activiteiten die eerder wel werden ondernomen worden moeilijker om nog uit te voeren. De beschreven hypothese geeft een negatieve vicieuze cirkel weer welke een verklaring geeft voor het vermijden van lichamelijke activiteiten. In verschillende studies is onderzoek gedaan naar het lichamelijk activiteiten niveau van CVS patiënten. In hoofdstuk 2 is een systematische review uitgevoerd voor het bestuderen van bestaande kennis in de wetenschappelijke literatuur over het dagelijks lichamelijk activiteitenniveau van patiënten met CVS ten op zichtte van gezonde controle personen. Zeventien verschillende studies werden geïncludeerd met 22 verschillende vergelijkingen tussen CVS patiënten en gezonde controle personen. Achttien van deze vergelijkingen lieten zien dat CVS patiënten een lager dagelijks lichamelijk activiteitenniveau hebben dan gezonde controle personen, terwijl vier vergelijkingen geen verschillen lieten zien tussen beide groepen. Een meta-analyse van zeven studies liet een lichamelijk activiteiten niveau zien in CVS patiënten van slechts $68 \%$ ten op zichtte van gezonde controle personen. Verschillende uitkomstmaten werden gevonden in de literatuur voor het meten van lichamelijke activiteit maar geen relatie was gevonden tussen de methodologische kwaliteit van de uitkomstmaat en het lichamelijk activiteiten niveau. Subjectieve uitkomstmaten lieten vaker verlaagde lichamelijke activiteiten niveaus zien in patiënten met CVS dan objectieve uitkomstmaten. Dit geeft aan dat CVS patiënten mogelijk het eigen lichamelijk activiteiten niveau niet goed kunnen inschatten. Echter, weinig informatie was gevonden over hoe het fysieke activiteiten patroon van CVS patiënten er over de dag uit ziet.

In hoofdstuk 3 is het dagelijkse lichamelijke activiteiten patroon onderzocht in CVS patiënten en vergeleken met gezonde controle personen. Het dagelijks activiteitenpatroon was gemeten in 35 CVS patiënten en 35 in leeftijd en geslacht overeenkomstige gezonde controle personen. Het bewustzijn in het uitvoeren van lichamelijke activiteiten was geëvalueerd door het vergelijken van objectief gemeten activiteitenniveaus met subjectief gescoorde activiteitenniveaus gemeten met een 
visuele analoge schaal. De resultaten lieten zien dat CVS patiënten een gelijk activiteitenniveau hebben in de ochtend en een lager activiteitenniveau in de middag en avond ten op zichtte van gezonde controle personen. Bovendien spendeerden CVS patiënten meer uren per dag aan activiteiten op een laag intensiteitniveau en minder op een hoog intensiteitniveau. Ten slotte leken CVS patiënten zich meer bewust te zijn van het eigen lichamelijk activiteiten niveau dan gezonde controle personen.

In hoofdstuk 4 en 5 zijn de resultaten gepresenteerd van een 'randomized controlled trial (RCT)' welke was uitgevoerd om de toegevoegde waarde te onderzoeken van een ambulant feedback programma als aanvulling op een interdisciplinair revalidatieprogramma gebaseerd op de principes van CGT en GET. Eenentachtig CVS patiënten waren geschikt bevonden voor de behandeling in revalidatiecentrum 'Het Roessingh' en werden geïncludeerd in de RCT. Tweeënveertig patiënten werden toegewezen tot de interventie groep en ontvingen het ambulante feedback programma als aanvulling op het revalidatieprogramma, 39 patiënten werden toegewezen tot de controle groep en ontvingen alleen het revalidatieprogramma. CVS patiënten in de interventie groep ontvingen ambulante feedback in de thuisomgeving met een persoonlijke digitale assistent (PDA) tijdens vier achtereenvolgende feedback perioden. De ambulante feedback was gebaseerd op het verschil tussen het cumulatief dagelijks activiteitenniveau van de patiënt en een vooraf gedefinieerd doelpatroon gebaseerd op gezonde controle personen. Patiënten kregen gedurende de dag continu inzicht in deze activiteitenpatronen door middel van een figuur afgebeeld op de PDA. In aanvulling daarop werden tussen 8.00 uur en 22.00 uur elke 2 uur tekstberichten weergegeven op de PDA. De berichten bevatten feedback over het verschil tussen het lichamelijk activiteitenpatroon van de patiënt en het doelpatroon, en bevatten een beweegadvies.

Het doel van hoofdstuk 4 was het uitzoeken van de volgzaamheid van CVS patiënten in het dragen van het feedback systeem in de thuis situatie, en het bestuderen van veranderingen die gemaakt zijn in het dagelijks lichamelijk 
activiteitenpatroon in de richting van het vooraf gedefinieerde doelpatroon. Dertig van de 42 CVS patiënten in de interventiegroep hadden de baseline metingen in voldoende mate afgerond en werden geïncludeerd voor nadere analyse, terwijl twaalf CFS patiënten de baseline metingen niet in voldoende mate hadden afgerond en werden geëxcludeerd voor verdere analyse. De volgzaamheid in het dragen van het feedback systeem was rond de $90 \%$ tijdens elk van de vier feedback perioden. Vijftien patiënten (50\%) hadden het feedback systeem adequaat gedragen tijdens alle vier de feedback perioden. Veranderingen werden met name waargenomen in de ochtend en middag, werden gedaan in de richting van het doel, en werden waargenomen vanaf dag één dat het feedback systeem werd gedragen. De volgzaamheid met het feedback systeem was laag en was mogelijk veroorzaakt door beperkingen in het afstemmen van het doel op individuele behoeften, door bepaalde aspecten van het studieprotocol, en problemen in het dragen van het feedback systeem.

Het doel van hoofdstuk 5 was het onderzoeken van de toegevoegde waarde van het geven van ambulante feedback als aanvulling op de behandeling voor CVS gebaseerd op de principes van CGT en GET. De toegevoegde waarde was onderzocht met de primaire en secundaire uitkomstmaten van de revalidatiebehandeling. De interventiegroep en de controle groep lieten een significante verbetering zien in ernst van de vermoeidheid, fysiek functioneren, sociaal functioneren, patiënt specifieke klachten en zelf effectiviteit. Echter, de mate waarin de verbeteringen werden gevonden verschilden niet tussen de interventie- en de controle groep. De resultaten lieten geen toegevoegde waarde zien van het ambulante feedback programma als aanvulling op een multidisciplinair revalidatie behandeling gestoeld op de principes van CGT en GET.

Het doel van hoofdstuk 6 was om te onderzoeken of het ambulante feedback programma CVS patiënten beter ondersteunt als het doel is aangepast op het individuele activiteitenpatroon gemeten voorafgaand aan de behandeling. Een tweede RCT was uitgevoerd waarin CVS patiënten gedurende een periode van 2 weken ambulante feedback ontvingen, zonder daarbij het multidisciplinaire 
revalidatieprogramma te betrekken. Zevenentwintig CVS patiënten startten met het feedback programma, waarvan 13 patiënten werden toegewezen aan de groep met een doel gebaseerd op het activiteitenpatroon van gezonde controle personen en 14 CVS patiënten aan de groep met een verpersoonlijkt doel aangepast op het individuele activiteitenpatroon gemeten op baseline. De resultaten lieten een trend zien van verbeteringen in het dagelijkse fysieke activiteiten patroon in beide groepen en een hogere volgzaamheid in de groep met een verpersoonlijkt doel. Bovendien was in de groep met een verpersoonlijkt doel de ervaren bruikbaarheid van het feedback systeem significant hoger.

In hoofdstuk 7 zijn wetenschappelijke en klinische implicaties nader bediscussieerd. Ambulante feedback in de thuisomgeving van de CVS patiënt liet belovende resultaten zien in veranderingen in het fysieke activiteiten patroon. Naar verwachting kunnen adequate aanpassingen in, en implementatie van, het feedback programma bijdragen aan verbeteringen in de behandeling van CVS. 


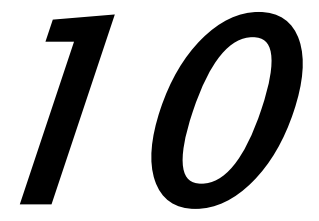

Dankwoord 


\section{Dankwoord}

Het is fijn om na een intensieve periode van onderzoek doen deze periode af te ronden met de tot standkoming van dit proefschrift. Ik ben trots op het resultaat en wil graag even stil staan bij de mensen die mij de afgelopen jaren hebben ondersteund en het mede mogelijk hebben gemaakt dat ik dit proefschrift heb kunnen schrijven.

Ik wil graag beginnen de mensen te bedanken die hebben deelgenomen aan het onderzoek. In totaal hebben 109 personen met het chronische vermoeidheidssyndroom deelgenomen aan één van de studies opgenomen in dit proefschrift. Zonder de bereidwillige deeIname van deze personen was het niet mogelijk geweest om het onderzoek uit te voeren. Ik hoop van harte dat de onderzoeksresultaten mogen bijdragen aan verbeteringen in de behandeling van het chronische vermoeidheidssyndroom.

Ook ben ik zeer dankbaar voor de medewerking die ik heb ontvangen vanuit het revalidatiecentrum het Roessingh. Ik heb vanuit het multidisciplinaire behandelteam de mogelijkheid gekregen om inzicht te verkrijgen in de bestaande behandeling voor het chronische vermoeidheidssyndroom. Dit heeft mij goed geholpen in de uitvoering van het onderzoek. Ook ben ik vanuit het secretariaat van de pijnrevalidatie ontzettend goed ondersteund in het vinden van deelnemers voor het onderzoek. Zonder hen was het me niet gelukt om zoveel deelnemers mee te krijgen in het onderzoek. Ten slotte ben ik zeer dankbaar voor de wijze waarop ik ondersteund ben in de mogelijkheid om inzicht te verkrijgen in de behandelresultaten.

Het was niet mogelijk geweest om het onderzoek uit te voeren zonder de ondersteuning van mijn promotor. Miriam, ik ben jou zeer dankbaar voor de wijze waarop je me hebt begeleidt. Je stond altijd open voor mijn mening, gaf advies waar gevraagd en kritiek waar nodig. Je hebt me geholpen structuur aan te brengen in de artikelen, en je hebt veel schrijfmateriaal in 'no time' gereviewed. Ondanks dat ik RRD had verlaten, ruimde je nog steeds tijd voor me 
in om me door de laatste loodjes heen te loodsen. Je was altijd super gedreven in het werk maar ook belangstellend op het persoonlijke vlak. Het was erg fijn om met jou te mogen samenwerken.

Ook wil ik mijn oud-collega's bij RRD bedanken voor de prettige werksfeer. De bereidwilligheid om elkaar voort te helpen in het werk, en de prettige wijze waarop pauzes werden ingevuld tussen het werken door, maakten het werken bij RRD erg prettig. Thijs, bedankt dat je me altijd hielp met het verwerken van activiteitendata in Matlab. Leendert, bedankt voor de hulp in het beheer van de feedback systemen. Jasper, bedankt voor de leuke hardloopclinics, waar mogelijk zal ik ze zeker blijven volgen. Borrelcommissie, bedankt voor de ontspannende 'laatste donderdag van de maand borrel'. Jos, bedankt voor de laatste puntjes op de 'i' van dit proefschrift. Birgit, bedankt dat je als kamergenoot altijd een luisterend oor had voor datgene wat er bij mij speelde, zowel op het werk als op persoonlijk vlak.

Tevens wil ik mijn ouders, broers, vrienden en overige familie bedanken voor de belangstelling in mijn onderzoek, en voor de nodige afleiding om te kunnen ontspannen.

Ten slotte wil ik dit dankwoord eindigen met de persoon die mij altijd met raad en daad heeft bijgestaan. Miranda, jij bent mijn grootste bron van inspiratie. Jij weet als geen ander wat het is om voor een PhD graad te moeten werken. Bedankt dat je er altijd voor me bent! 
214 Chapter 10 


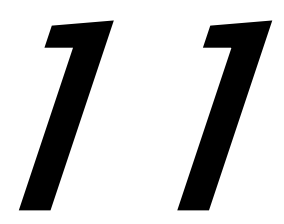

Over de Auteur 


\section{Over de Auteur}

Richard Evering is geboren op 2 september 1983 te Losser. Hij heeft het voorbereidend wetenschappelijk onderwijs (VWO) gevolgd op het Twents Carmel College te Oldenzaal en in $\mathbf{2 0 0 2}$ het diploma behaald. Aansluitend is hij begonnen aan de Universiteit van Maastricht met de opleiding Algemene Gezondheidswetenschappen.

Tijdens de bacheloropleiding heeft hij stage gelopen in Denemarken aan het Copenhagen Muscle Research Centre. Tijdens deze stage heeft hij onderzoekservaring opgedaan op het gebied van de regulatie van de energiestofwisseling bij lichamelijke inspanning. $\mathrm{Na}$ het behalen van de graad Bachelor of Science in 2005 heeft hij aansluitend de Master Physical Activiy and Health doorlopen aan de Universiteit van Maastricht. Hij heeft hierin onderzoek gedaan naar de effectiviteit van een geperiodiseerd spinningstrainingsprogramma op de fysieke gesteldheid. In 2006 is hij afgestudeerd als Master of Science. Na het afronden van deze Master heeft hij in Groningen een jaar lang aan de Rijksuniversiteit Groningen een tweede onderzoeksmaster gevolgd, te weten 'Behavioral and Cognitive Neurosciences'. In 2007 is hij in dienst gekomen bij Roessingh Research and Development op het ZonMw project 'Optimalization of Cognitive Behavioral Therapy (CBT) for CFS patients in rehabilitation by means of ambulatory activity-based feedback (ABF)'. Dit proefschrift is het resultaat van een vierjarig promotie traject dat is uitgevoerd binnen het ZonMw project.

In november 2011 is hij in dienst gekomen van Saxion in Enschede alwaar hij bij het ter perse gaan van dit proefschrift nog steeds in dienst is. Bij het Saxion is hij werkzaam als onderzoeker bij het Kenniscentrum Gezondheid Welzijn en Technologie binnen het lectoraat Technologie in Zorg en Welzijn. Daarnaast is hij als docent werkzaam bij de Academie Gezondheidszorg en nauw betrokken bij de studieroute Gezondheid en Technologie. 


\section{Peer-reviewed journal articles}

Evering RMH, van Weering MGH, Groothuis-Oudshoorn KCGM, Vollenbroek-Hutten MMR. Daily physical activity of patients with the chronic fatigue syndrome: a systematic review. Clin Rehabil. 2011 Feb;25(2):112-33.

Evering RMH, Tonis TM, Vollenbroek-Hutten MMR. Deviations in daily physical activity patterns in patients with the chronic fatigue syndrome: A case control study. J Psychosom Res. 2011 Sep;71(3):129-35.

\section{International conference contributions}

Vollenbroek-Hutten MMR, Hermens HJ, Evering RMH, Dekker-van Weering MGH, Jansen-Kosterink S, Huis in 't Veld R. The potential of telemedicine for patients with chronic disorders experiencing problems with their physical functioning. eTELEMED 2012 : The Fourth International Conference on eHealth, Telemedicine, and Social Medicine; Valencia, Spain2012. p. 30-5.

Evering RMH, Tonis TM, Vollenbroek-Hutten MMR. Deviations in daily physical activity patterns in patients with the chronic fatigue syndrome: A case control study. 2nd International Conference for Ambulatory Monitoring of Physical Activity and Movement (ICAMPAM); 2011 24-27 Mai 2011; Glasgow, Scotland.

Evering RMH, Tonis TM, Vollenbroek-Hutten MMR. Daily physical activity patterns of patients with chronic fatigue syndrome compared to asymptomatic controls. 3rd Dutch Conference on Bio-Medical Engineering (BME2011); 2011 20-21 January 2011; Egmond aan Zee, The Netherlands. 
Evering RMH. Effecten van feedback op het activiteitenniveau. Chronisch Vermoeidheidssyndroom: met kennis behandelen Nieuwe

onderzoeksresultaten en implicaties voor praktijk en implementatie; 201114 April 2011 ; Nijmegen, The Netherlands.

Evering RMH, Vollenbroek-Hutten MMR. Ambulatory activity-based feedback for improving daily physical activity patterns in patients with the chronic fatigue syndrome: a longitudinal study. 28e Medisch Informatica Congres (MIC2011); 2011 10-11 November 2011; Veldhoven, The Netherlands. 


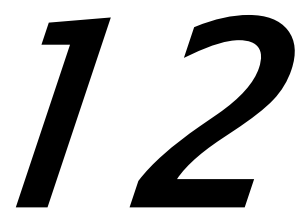

Progress Range 


\section{Progress Range}

The following publications have also been published in the Progress Range by Roessingh Research and Development, Enschede, the Netherlands. Copies can be ordered, when available, via info@rrd.nl.

Progress 1: Pot JWGA, Boer H, Van Harten WH, Hermens HJ and Seydel ER. Comprehensive Need-Assessment. Ontwikkeling van een meetinstrument voor zorgbehoeften en kwaliteitsbeoordeling door patiënten, Roessingh Research \& Development, the Netherlands, September 1994, ISBN 90-25452-01-2.

Progress 2: Van Leerdam NGA and Hermens HJ. Revalidatietechnologie in Euregio, Roessingh Research \& Development, the Netherlands, July 1995, ISBN 90-75452-02-0.

Progress 3: Duda L. Van Noort LO, Röseler S, Greitemann BOL, Van Harten WH and Klazinga NS. Rehabilitation in Germany and the Netherlands, A comparison of two rehabilitation-systems, Roessingh Research \& Development, the Netherlands, August 1995, ISBN 90-75452-03-9.

Progress 4: Hermens HJ, Nene AV and Zilvold G. Electrophysiological Kinesiology, Proceedings of the 11 th congress of the International Society of Electrophysiologie and Kinesiology in Enschede, TheNetherlands 1996, Roessingh Research \& Development, the Netherlands, October 1996, ISBN 90-75452-04-7.

Progress 5: Van Harten WH,.Bouwen aan een kwaliteitssysteem in de revalidatiezorg. Een poging tot constructieve technology assessment van een kwaliteitssysteem in een gezondheids-zorginstelling, Roessingh Research \& Development, the Netherlands, December 1997, ISBN 90-75452-07-1.

Progress 6: Baardman G and IJzerman MJ. Design and evaluation of a hybrid orthosis for people with paraplegia, Roessingh Research \& Development, the Netherlands, November 1997, ISBN 90-75452-08-X.

Progress 7: Hutten MM. Lumbar Dynamometry: A useful method for assessment of patients with chronic low back pain?, Roessingh Research \& Development, the Netherlands, November 1999, ISBN 90-75452-13-6. 
Progress 8: Van der Salm A, Van Harten WH and Maathuis CGB. Ketenkwaliteit Cerebrale Parese Zorg. Een beschrijving van de cerebrale parese zorg en mogelijke verbeteringen hierin, Roessingh Research \& Development, the Netherlands, April 2001, ISBN 90-75452$19-5$.

Progress 9: Nederhand MJ. Muscle activation patterns in post traumatic neck pain, Roessingh Research \& Development, the Netherlands, March 2003, ISBN 90-75452-27-6.

Progress 10: Jannink MJA. Usabillity of custom-made orthopaedic shoes in patients with degenerative disorders of the foot, Roessingh Research \& Development, the Netherlands, September 2004, ISBN 90-75452-28-4.

Progress 11: Blokhorst MG. State-dependent factors and attention in whiplash associated disorder, Roessingh Research \& Development, the Netherlands, January 2005, ISBN 90365-2111-4.

Progress 12: Buurke JH. Walking after stroke co-ordination patterns \& functional recovery, Roessingh Research \& Development, the Netherlands, February 2005, ISBN 90-365-21408.

Progress 13: Van der Salm A. Spasticity reduction using electrical stimulation in the lower limb of spinal cord injury patients, Roessingh Research \& Development, the Netherlands, October 2005, ISBN 90-365-2253-6.

Progress 14: Snoek GJ. Patient preferences for reconstructive interventions of the upper limb in tetraplegia, Roessingh Research \& Development, the Netherlands, December 2005, ISBN 90-365-2255-2.

Progress 15: De Kroon JR. Therapeutic electrical stimulation of the upper extremity in stroke, Roessingh Research \& Development, the Netherlands, December 2005, ISBN 90365-2269-2.

Progress 16: Van Dijk H. Motor skill learning, age and augmented feedback. Roessingh Research and Development, the Netherlands, March 2006, ISBN 90-365-2302-9.

Progress 17: Mes CAJ. Improving non-optimal results in chronic pain treatment. Roessingh Research and Development, the Netherlands, January 2007, ISBN 90-365-2435-0. 
Progress 18: Voerman GE. Musculoskeletal neck-shoulder pain: a new ambulant myofeedback intervention approach. Roessingh Research and Development, the Netherlands, March 2007, ISBN 90-365-2460-1.

Progress 19: Kallenberg LAC. Multi-channel array EMG in chronic neck-shoulder pain. Roessingh Research and Development, the Netherlands, March 2007, ISBN 90-365-24598.

Progress 20: Huis in 't Veld MHA. Work-related neck-shoulder pain: The role of cognitivebehavioural factors and remotely supervised treatment. Roessingh Research and Development, the Netherlands, December 2007, ISBN 978-90-365-2584-8.

Progress 21: Fleuren JFM. Assessment of Spasticity: From EMG to patients' perception. Roessingh Research and Development, the Netherlands, October 2009, ISBN 978-90-3652869-6.

Progress 22: Reenalda J. Dynamic sitting to prevent pressure ulcers in spinal cord injured. Roessingh Research and Development, the Netherlands, October 2009, ISBN 978-90-3652884-9.

Progress 23: Prange GB. Rehabilitation Robotics: Stimulating restoration of arm function after stroke. Roessingh Research and Development, the Netherlands, October 2009, ISBN 978-90-365-2901-3.

Progress 24: Vos-van der Hulst. M Prognostic factors and underlying mechanisms in chronic low back pain. Roessingh Research and Development, the Netherlands, November 2009, ISBN 978-90-365-2881-8.

Progress 25: Kottink-Hutten AIR. Assessment of a two-channel implantable peroneal nerve stimulator post-stroke. Roessingh Research and Development, the Netherlands, February 2010, ISBN: 978-90-365-2959-4.

Progress 26: Van Weering MGH. Towards a new treatment for chronic low back pain patients. Roessingh Research and Development, the Netherlands, May 2011, ISBN: 97890-365-3180-1. 
Progress 27: Gulmans J. Crossing Boundaries: Improving Communication in cerebral palsy care. Roessingh Research and Development, the Netherlands, February 2012, ISBN: 97890-365-3305-8.

Progress 28: Molier BI. Influence of augmented feedback on learning upper extremity tasks after stroke. Roessingh Research and Development, the Netherlands, March 2012, ISBN: 978-90-365-3296-9.

Progress 29: Dubbeldam R. Towards a better understanding of foot and ankle kinematics in rheumatoid arthritis - The effects of walking speed and structural impairments. Roessingh Research and Development, the Netherlands, September 2012, ISBN: 978-90365-3407-9.

Progress 30: Evering RMH. Ambulatory feedback at daily physical activity patterns - A treatment for the chronic fatigue syndrome in the home environment? Roessingh Research and Development, the Netherlands, April 2013, ISBN: 978-90-365-3512-0. 